\title{
Trends in diagnostic confirmation and treatment of pre-malignant abnormalities at screening mammography
}

Citation for published version (APA):

Luiten, J. D. (2020). Trends in diagnostic confirmation and treatment of pre-malignant abnormalities at screening mammography. [Doctoral Thesis, Maastricht University]. Maastricht University. https://doi.org/10.26481/dis.20201218jl

Document status and date:

Published: 01/01/2020

DOI:

10.26481/dis.20201218jl

Document Version:

Publisher's PDF, also known as Version of record

\section{Please check the document version of this publication:}

- A submitted manuscript is the version of the article upon submission and before peer-review. There can be important differences between the submitted version and the official published version of record.

People interested in the research are advised to contact the author for the final version of the publication, or visit the DOI to the publisher's website.

- The final author version and the galley proof are versions of the publication after peer review.

- The final published version features the final layout of the paper including the volume, issue and page numbers.

Link to publication

\footnotetext{
General rights rights.

- You may freely distribute the URL identifying the publication in the public portal. please follow below link for the End User Agreement:

www.umlib.nl/taverne-license

Take down policy

If you believe that this document breaches copyright please contact us at:

repository@maastrichtuniversity.nl

providing details and we will investigate your claim.
}

Copyright and moral rights for the publications made accessible in the public portal are retained by the authors and/or other copyright owners and it is a condition of accessing publications that users recognise and abide by the legal requirements associated with these

- Users may download and print one copy of any publication from the public portal for the purpose of private study or research.

- You may not further distribute the material or use it for any profit-making activity or commercial gain

If the publication is distributed under the terms of Article $25 \mathrm{fa}$ of the Dutch Copyright Act, indicated by the "Taverne" license above, 


\section{Trends in diagnostic confirmation and treatment of pre-malignant abnormalities at screening mammography}


(C) Copyright Jacky Denise Luiten, Maastricht 2020

All rights reserved. No part of this book may be reproduced or transmitted in any form or by any means, without prior permission in writing by the author, or when appropriate, by the publishers of the publications.

ISBN: 978-94-6416-283-7

Cover photograph: Henri Senders | www.henrisenders.nl

Cover design: Anne van Bergen

Layout: Tiny Wouters

Title pages photograph: David Cantu | www.infinitenoon.com

Production: Ridderprint | www.ridderprint.nl 


\title{
Trends in diagnostic confirmation and treatment of pre-malignant abnormalities at screening mammography
}

\author{
PROEFSCHRIFT \\ ter verkrijging van de graad van doctor aan de Universiteit Maastricht, \\ op gezag van de Rector Magnificus, Prof.dr. Rianne M. Letschert \\ volgens het besluit van het College van Decanen, \\ in het openbaar te verdedigen \\ op vrijdag 18 december 2020 om 16.00 uur
}

door

Jacky Denise Luiten 


\section{Promotor}

Prof. dr. V.C.G Tjan-Heijnen

\section{Co-promotores}

Dr. L.E.M. Duijm, Canisius Wilhelmina Ziekenhuis Nijmegen

Dr. A.C. Voogd

\section{Beoordelingscommissie}

Prof. dr. A.P. de Bruïne (voorzitter)

Prof. dr. G.J. Dinant

Prof. dr. R.M. Pijnappel, UMC Utrecht

Prof. dr. M.L. Smidt

Prof. dr. H.M. Verkooijen, UMC Utrecht 


\section{Contents}

$\begin{array}{lll}\text { Chapter } 1 & \text { Introduction and outline } & 7\end{array}$

Chapter 2 Trends in incidence and tumor grade in screen-detected 15 ductal carcinoma in situ and invasive breast cancer

Chapter 3 Utility of diagnostic breast excision biopsies during two decades of screening mammography

Chapter 4 Trends in frequency and outcome of high-risk breast lesions at core needle biopsy in women recalled at biennial screening mammography, a multiinstitutional study

Chapter 5 Recall and outcome of screen-detected microcalcifications 65 during two decades of mammography screening in the Netherlands national breast screening program

Chapter 6 Iodine seeds versus wire guided localization in breast conserving surgery for non-palpable ductal carcinoma in situ

Chapter 7 Patterns of treatment and outcome of ductal carcinoma in situ 95 in the Netherlands

Chapter 8 Summary and summary in Dutch - Nederlandse samenvatting

Chapter 9 General discussion and future perspectives

Valorisation

List of publications

Curriculum Vitae 


$$
\text { yo }
$$




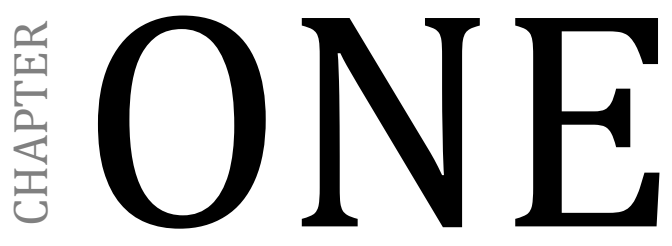

Introduction and outline 


\section{Introduction}

In 1968 the principles of screening for diseases were defined by the World Health Organization. ${ }^{1}$ The aim of screening is to detect and subsequently treat disease in an early stage to decrease related morbidity and mortality.2,3 In 1971 the Health Insurance Plan of New York published the first randomized trial of breast cancer screening, which compared mammography and clinical breast examination. ${ }^{4}$ The favorable outcome of this trial and subsequent studies, together with the results of cost-benefit analysis led to the start of the first population-based breast cancer screening program in the UK in $1988 .{ }^{5}$

In the Netherlands a mammography screening program was gradually implemented between 1989 and 1996 by the National Institute for Public Health and Environment (RIVM, Rijksinstituut voor Volksgezondheid en Milieu). This nation-wide program involves a free of charge biennial screening mammography for women aged 50-70 years. In 1998-1999, the upper age limit was extended from 70 to 75 years.6,7 Yearly, approximately 1.3 million women are invited to the screening program, of whom almost 1 million participate. Ever since the introduction of the screening program the attendance rate is approximately $80 \%{ }^{8}$ In recent years the recall rate was around 23 per 1000 screens, with a cancer detection rate of 6.8 per 1000 screens. $^{8}$

Mammography was originally carried out using general-purpose X-ray imaging systems. In the late 1970s screen-film mammography (SFM) was introduced, resulting in high spatial resolution allowing better discrimination of fine microcalcifications and morphological features of soft tissue structures, such as masses. ${ }^{9}$ The introduction of full field digital mammography (FFDM) around 2000 provided a marked improvement in imaging, especially of dense breasts, resulting in a higher specificity and sensitivity for small lesions. ${ }^{10}$ In the Netherlands the introduction of FFDM at screening was completed in 2010.11-14 Recently, for women with extremely dense breast tissue and normal results on mammography the added value of a supplemental MRI screening was tested in a randomized clinical trial. The MRI resulted in an increased cancer detection rate resulting in the diagnosis of significantly fewer interval cancers, but also led to an increased false positive rate. ${ }^{15}$ To this end, the use of MRI is still debated and longer follow-up is needed to assess the effect on advanced cancers and mortality.

The principal benefit of screening is the early detection of breast cancer leading to fewer advanced stage cancers, a lower breast cancer mortality rate and less morbidity. ${ }^{16-18}$ 
In an effort to detect breast cancer in its earliest phase, any breast abnormality found at screening mammography is examined in detail which results in an increased detection rate of DCIS and other pre-malignant diseases. In the absence of screening, a substantial part of these pre-malignant abnormalities would have remained subclinical without proceeding to invasive breast cancer during a woman's lifetime. ${ }^{19,20}$ As a consequence, screening results in overdiagnosis and subsequent overtreatment, which is one of its primary harms. Another downside are the false positives recalls, of which not only the costs and psychological stress, but also the potential burden of subsequent unnecessary invasive biopsies must not be overlooked.21 A careful consideration of the harm-benefit balance associated with breast cancer screening continues to be a matter of debate.

\section{Outline of thesis}

This thesis describes the trends in confirmation and treatment of pre-malignant abnormalities at screening mammography. Pre-malignant breast lesions were defined as DCIS and high-risk lesions. High-risk lesions were defined as lesions that do not have reached the phase of invasive disease but on the other hand do not show full similarity with normal breast tissue. Examples are flat epithelial atypia, atypical ductal hyperplasia, lobular carcinoma in-situ, papillary lesions.

Chapter 2 analyzes the trends in incidence of screen-detected DCIS and invasive carcinoma prior, during and after the transition from SFM to FFDM. Considering the possibility that low grade DCIS may preferably develop into low grade invasive carcinoma and high grade DCIS to high grade invasive carcinoma, the correlation between screen-detected DCIS and invasive breast cancer classified by grade was investigated.

A representative biopsy of a suspicious abnormality detected at screening mammography is required to obtain a definitive histopathology result. Surgical excision biopsy, which is an invasive technique, used to be the most reliable method to obtain a conclusive diagnosis. ${ }^{22}$ However, a decline in the use of surgical excision biopsies has been described until 2010, caused by the introduction and widespread use of stereotactic core biopsy (SCNB) and it has been postulated that surgical excision biopsies would become an obsolete procedure in the years thereafter. ${ }^{23}$ The aim of chapter 3 was to investigate the more recent trends in the use and 
added value of excision biopsies in screen-detected breast abnormalities and how these trends compare to those observed until 2010.

The histopathology diagnosis obtained through biopsy sometimes reveals premalignant lesions of unknown clinical significance. These so called 'high-risk lesions' are not identical to normal breast tissue, but neither fulfill the criteria of either invasive breast cancer or precursor stadia, also referred to as DCIS. They may carry an increased risk to proceed towards malignancy. ${ }^{24}$ Chapter 4 determines the trends in frequency, management and pathology outcome of highrisk breast lesions found at CNB. The rate of 'upgrade' to DCIS or invasive carcinoma was also determined to support an evidence-based approach for the management of high-risk lesions. Upgrade was defined as a change of diagnosis into DCIS or invasive carcinoma at final pathology following diagnostic surgical excision for lesions, which originally were only classified as high risk lesions at SCNB.

Most DCIS lesions are detected at screening mammography by the presence of microcalcifications. However, not all microcalcifications found at screening are related to underlying DCIS. Chapter 5 focuses on the trends in the detection of microcalcifications at screening mammography and the yield of these findings after recall.

If DCIS is diagnosed and surgical treatment is required, accurate pre-operative localization of the lesion is of utmost importance in order to facilitate adequate resection. In chapter 6 two methods for the localization of non-palpable DCIS were retrospectively compared; wire-guided localization (WGL), the current gold standard, and iodine-125 seed guided localization (I-125 GL).

Chapter 7 describes the patterns in treatment and outcome of DCIS in the Netherlands during a period of three decades. The risk of invasive local relapse following breast-conserving surgery with and without adjuvant radiotherapy was also evaluated.

Chapter 8 provides the summary of this thesis and also provides a summary in Dutch language. The general discussion of this thesis, the future perspectives and several new initiatives and suggestions for additional clinical studies are described in chapter 9. 


\section{Methods}

The data for the studies described in the chapters $2,3,4$ and 5 originate from the southern breast cancer screening region in the Netherlands (BOBZ region, Bevolkings Onderzoek Borstkanker Zuid).

During a two-year follow-up period (up to the next biennial screen), the radiology reports, type of biopsy methods with their outcome, breast surgery reports and final histopathology results of all recalled women were collected. The screening organization routinely received the follow-up data from the hospitals where the women were examined following a recall. To complete 2-year follow-up one of the radiologists (LD) and several radiology residents collected additional reports, which had not been received by the screening organization, through visits at these departments. All data were entered into a database, created for quality control of the screening program and scientific purposes, by the radiologist (LD).

For Chapter 6, a cohort of women with non-palpable DCIS in a single center between March 2006 and June 2013 were retrospectively analyzed.

Chapter 7 was based on data from the Netherlands Cancer Registry (NCR), which is managed by the Netherlands Comprehensive Cancer Organization (IKNL, Integraal Kankercentrum Nederland). The NCR contains all new cases of in situ and invasive malignancies and data on patient, tumor and initial treatment characteristics 25 . Data are available on a national level from 1989 onwards. The NCRs main source of information is the nationwide network and registry of histo- and cytopathology in the Netherlands (PALGA, Pathologisch Anatomisch Landelijk Geautomatiseerd Archief) ${ }^{26}$. 


\section{References}

1. Wilson JMG, G. J. Principles and Practice of Screening for Disease 1968. Available from: http://whqlibdoc.who.int/php/who_php_34.pdf.

2. Dowling EC, Klabunde C, Patnick J, Ballard-Barbash R. Breast and cervical cancer screening programme implementation in 16 countries. J Med Screen. 2010;17(3):139-146.

3. Sankatsing VDV, van Ravesteyn NT, Heijnsdijk EAM, Looman CWN, van Luijt PA, Fracheboud J, et al. The effect of population-based mammography screening in Dutch municipalities on breast cancer mortality: 20 years of follow-up. Int J Cancer. 2017;141(4):671-677.

4. Shapiro S, Strax P, Venet L. Periodic breast cancer screening in reducing mortality from breast cancer. JAMA. 1971;215(11):1777-1785.

5. Advisory Committee on Breast Cancer S. Screening for breast cancer in England: past and future. J Med Screen. 2006;13(2):59-61.

6. Fracheboud J, de Koning HJ, Boer R, Groenewoud JH, Verbeek AL, Broeders MJ, et al. Nationwide breast cancer screening programme fully implemented in The Netherlands. Breast (Edinburgh, Scotland). 2001;10(1):6-11.

7. den Heeten GJ, Broeders MJ. Nationwide breast cancer screening in the Netherlands. Medica Mudi. 2009;53(1):4.

8. IKNL. Monitor bevolkingsonderzoek [cited 2020 Jan]. Available from: https://www.iknl.nl/ getmedia/ 15bd0ea1-eb30-4647-82b8-12e11c3dbe9c/Monitor-bevolkingsonderzoek-borstkanker017-2018_IKNL.pdf.

9. Haus AG. Recent advances in screen-film mammography. Radiol Clin North Am. 1987;25(5):913928.

10. Yaffe M, Boyd N. Mammographic breast density and cancer risk: the radiological view. Gynecol Endocrinol. 2005;21 Suppl 1:6-11.

11. Jing H. YY, Wernick M.N., Yarusso L.M., Nishikawa R.M. A comparison study of image features between FFDM and film mammogram images. Med Phys. 2012;39(7):4386-4394.

12. van Luijt PA, Fracheboud J, Heijnsdijk EA, den Heeten GJ, de Koning HJ, National Evaluation Team for Breast Cancer Screening in Netherlands Study G. Nation-wide data on screening performance during the transition to digital mammography: observations in 6 million screens. Eur J Cancer. 2013;49(16):3517-3525.

13. Nederend J, Duijm LE, Voogd AC, Groenewoud JH, Jansen FH, Louwman MW. Trends in incidence and detection of advanced breast cancer at biennial screening mammography in The Netherlands: a population based study. Breast Cancer Res. 2012;14(1):R10.

14. van Steenbergen LN, Voogd AC, Roukema JA, Louwman WJ, Duijm LE, Coebergh JW, et al. Screening caused rising incidence rates of ductal carcinoma in situ of the breast. Breast Cancer Res Treat. 2009;115(1):181-183.

15. Bakker MF, de Lange SV, Pijnappel RM, Mann RM, Peeters PHM, Monninkhof EM, et al. Supplemental MRI Screening for Women with Extremely Dense Breast Tissue. N Engl J Med. 2019;381(22):2091-2102.

16. Jacklyn G, McGeechan K, Irwig L, Houssami N, Morrell S, Bell K, et al. Trends in stage-specific breast cancer incidence in New South Wales, Australia: insights into the effects of 25 years of screening mammography. Breast Cancer Res Treat. 2017;166(3):843-854.

17. Katalinic A, Eisemann N, Kraywinkel K, Noftz MR, Hubner J. Breast cancer incidence and mortality before and after implementation of the German mammography screening program2019 Nov 1; Int J Cancer. Epub ahead of print.

18. de Munck L, Fracheboud J, de Bock GH, den Heeten GJ, Siesling S, Broeders MJM. Is the incidence of advanced-stage breast cancer affected by whether women attend a steady-state screening program? Int J Cancer. 2018;143(4):842-850.

19. Thomas ET, Del Mar C, Glasziou P, Wright G, Barratt A, Bell KJL. Prevalence of incidental breast cancer and precursor lesions in autopsy studies: a systematic review and meta-analysis. BMC Cancer. 2017;17(1):808. 
20. Jorgensen KJ, Gotzsche PC, Kalager M, Zahl PH. Breast Cancer Screening in Denmark: A Cohort Study of Tumor Size and Overdiagnosis. Ann Intern Med. 2017;166(5):313-323.

21. Honig EL, Mullen LA, Amir T, Alvin MD, Jones MK, Ambinder EB, et al. Factors Impacting False Positive Recall in Screening Mammography. Acad Radiol. 2019;26(11):1505-1512.

22. Rougraff BT, Aboulafia A, Biermann JS, Healey J. Biopsy of soft tissue masses: evidence-based medicine for the musculoskeletal tumor society. Clin Orthop Relat Res. 2009;467(11):2783-2791.

23. van Breest Smallenburg V, Nederend J, Voogd AC, Coebergh JW, van Beek M, Jansen FH, et al. Trends in breast biopsies for abnormalities detected at screening mammography: a population-based study in the Netherlands. Br J Cancer. 2013;109(1):242-248.

24. St-Armant M, Weerakkody Y. High risk breast lesion: Radiopaedia; 2017. Available from: https://radiopaedia.org/articles/high-risk-breast-lesion?lang=us.

25. IKNL. Netherlands Cancer Registry Available from: https://www.iknl.nl/en/ncr. 


$$
\text { yo }
$$




\section{TWO}

Trends in incidence and tumor grade in screen-detected ductal carcinoma in situ and invasive breast cancer

Jacky D. Luiten

Adri C. Voogd

Ernest J.T. Luiten

Lucien E.M. Duijm 


\section{Abstract}

\section{Purpose}

In a biennial screening mammography program, we analyzed the trends in incidence of screen-detected ductal carcinoma in situ (DCIS) and invasive breast cancers in the era of screen-film mammography (SFM) screening, the period of the transition to full-field digital mammography (FFDM) screening and the period of FFDM screening. We also investigated a possible association between the incidence and grading of screen-detected DCIS and invasive breast cancer.

\section{Methods}

In the southern part of the Netherlands, FFDM screening gradually replaced SFM screening between May 2009 and April 2010. We included a consecutive series of 484,422 screens obtained between July 2005 and July 2015 and divided these screens into three groups; SFM-only cohort, transition cohort and FFDM-only cohort.

\section{Results}

A total of 3059 recalled women were diagnosed with DCIS $(n=623)$ or invasive breast cancer $(n=2436)$. The majority of DCIS were high grade $(48.2 \%)$, whereas the majority of the invasive breast cancers were low grade $(45.4 \%)$ or intermediate grade $(41.6 \%)$. The cancer detection rate (CDR) per 1000 screened women showed the same distribution by grade in both groups. The transition to FFDM was characterized by an increased overall detection rate of invasive cancers.

\section{Conclusion}

Screening mammography detects mostly high grade DCIS and low or intermediate grade invasive cancers. The grade distribution as well as the CDR in the years after the introduction of FFDM remained stable compared to the era of SFM screening. By diagnosing and treating high grade DCIS, which otherwise may develop into high grade invasive carcinoma, our findings provide new evidence for the beneficial value of screening mammography programs. 


\section{Introduction}

In the Netherlands, a nation-wide biennial screening mammography program for women aged 50-70 years has been gradually implemented between 1989 and 1996. In 1999, the upper age limit was extended to 75 years. In the southern part of the Netherlands, screen-film mammography (SFM) was replaced by full-field digital mammography (FFDM) in the period from May 2009 to April 2010.1-3

Over the last decades the incidence of breast abnormalities has increased rapidly. The lifetime incidence of invasive breast cancer and ductal carcinoma in situ (DCIS) increased from 1 out of 12 in the early nineties to 1 out of 7 nowadays. ${ }^{4}$

In contrast to invasive breast cancer, DCIS may often be asymptomatic and the increased detection of DCIS is mostly attributed to the use of screening mammography. 5

All women with suspicious abnormalities at screening mammography are recalled to an out-patient breast unit at hospitals for further analysis. According to current Dutch breast cancer guidelines, all cases of DCIS detected at screening mammography are treated surgically, followed by adjuvant radiotherapy in case of breast conserving surgery. ${ }^{4}$ However, autopsy series have shown that a significant part of DCIS stays subclinical during a woman's lifetime. ${ }^{6}$ Therefore overtreatment, caused by the increased detection of DCIS through screening and its subsequent treatment, has become a matter of debate. ${ }^{7-9}$ Moreover, it has been documented that the incidence of screen-detected DCIS increases more rapidly compared to the incidence of screen-detected invasive carcinoma. Taking these observations into account one may argue whether the early detection and treatment of DCIS really reflects overtreatment or may lead to a reduction of the development of subsequent invasive breast cancer.

The aim of the current study was to analyze the trends in incidence of screendetected DCIS and invasive breast cancers depending on the mammographic techniques and to investigate a possible association between screen-detected DCIS and screen-detected invasive breast cancer in large consecutive cohorts over a 10-year period.

Considering the possibility that low grade DCIS may preferably develop into low grade carcinoma and high grade DCIS to high grade carcinoma we investigated the correlation between screen-detected DCIS and invasive breast cancer classified by grade. 


\section{Materials and methods}

\section{Study population}

All women who attended the breast cancer screening program between July 2005 and July 2015 at four specialized screening units in a southern part of the Netherlands, were included in the study. A total of 484, 422 screens were obtained during this 10-year inclusion period.

All women included in this study gave written informed consent with the permission to use their screening and follow-up data for evaluation purposes. Three women who refused to give this permission were excluded from the study. Seventeen patients were excluded due to incomplete or missing tumor characteristics (four initial screens and thirteen subsequent screens). An initial screen was defined as the first time a woman attended the breast cancer screening program. This group consisted of women aged approximately 50 years. The abnormalities detected at initial screening mammography reflect the prevalence of asymptomatic DCIS or invasive carcinoma. The women with suspicious mammographic findings detected at subsequent screening were aged 51-75, with a median age of 62 years.

According to the Dutch Central Committee on Research involving Human Subjects (CCMO) ethical approval was not required for the current study.

We separated all included women in three groups; two SFM-only cohorts (July 2005-June 2007 and July 2007-June 2009), the transition cohort (July 2009-June 2011) and two FFDM-only cohorts (July 2011-June 2013 and July 2013-June 2015).

\section{Screening procedure}

The Dutch nation-wide breast cancer screening program offers biennial screening mammography for all women aged 50-75 years. The details of the screening program have been described previously. $2,10,11$

In summary, all mammograms were obtained by certified screening mammography radiographers and all screens were double read by a team of 16 certified screening radiologists, each of them evaluating at least 3000 screens per year. In case of a subsequent screen, the previous screens were available for comparison. Each screening mammography was classified according to the breast imaging reporting and data system (BI-RADS). ${ }^{12,13}$

Women with a screening BI-RADS 0,4 or 5 were recalled to a dedicated breast unit. At screening, mammographic abnormalities were classified according to the following categories: suspicious mass, suspicious calcifications, suspicious mass in 
combination with calcifications, architectural distortion, asymmetry or other abnormality.

In our screening region, screen-film mammography screening was gradually replaced by digital mammography screening between May 2009 and April 2010.

\section{Follow-up procedure}

All women with suspicious mammographic findings at screening were recalled to their general practitioner and subsequently to a breast unit of a regional hospital for further analysis which consisted of physical examination by a surgical oncologist and additional radiological breast examinations. Subsequent biopsy procedures (including fine needle aspiration cytology, core needle biopsy, vacuum assisted biopsy and/or surgical biopsy) were performed at the discretion of the clinical radiologist and/or surgical oncologist.

During 1-year follow-up, one of the screening radiologists collected patient characteristics, breast imaging reports, pathology findings, tumor grade [DCIS; low, intermediate, high and invasive carcinoma; B\&R grade 1 (low), B\&R grade 2 (intermediate) and B\&R grade 3 (high)] and surgical reports of all women who were recalled for further analysis of an abnormality detected at screening mammography.

\section{Statistical analysis}

Screened women were grouped into separate cohorts consisting of two years, based on the biennial screening program. The main outcome of this study was the incidence of DCIS and invasive breast cancer which were analyzed separately in each consecutive cohort. Both for DCIS and invasive breast cancer the tumor grade at initial screening and subsequent screening was determined, as well as the proportions and tumor grading of DCIS and invasive breast cancer over time. Statistical analyses were performed using SPSS, version 22.0 (SPSS, Inc., Chicago, USA). The mean differences with standard deviation (SD) were calculated for continuous variables. Trends over time and variations between subgroups were expressed using proportions. Chi-square analyses were performed to compare proportional differences between categorical groups. $P$-values less than 0.05 were considered statistically significant. 


\section{Results}

\section{Trends in overall screening outcome}

This study comprised a total of 484,422 screening mammography examinations $(52,613$ initial screens and 431,809 subsequent screens), obtained between July 2005 and July 2015 (Table 2.1). During this 10-year period the biennial number of screening examinations gradually increased from 66,750 (2005-2007) to 131,224 (2013-2015). In the same period, the recall rate increased from 1.3\% (2005-2007) to $3.3 \%$ (2013-2015). A total of 12,965 women were recalled for further analysis of a screen-detected abnormality (average recall rate $2.7 \%$ ). Out of 3059 true positive recalls 623 patients were diagnosed with DCIS and 2436 patients with invasive carcinoma.

The cancer detection rate (CDR) for the total period was 6.3 per 1000 women screened and gradually increased from 4.9 per 1000 (2005-2007) to 7.0 per 1000 (2013-2015, Table 2.1). The positive predictive value of recall was $23.6 \%$ for the total period and decreased from $36.9 \%$ (2005-2007) to $21.3 \%$ (2013-2015) during the 10 -year screening period.

Table 2.1 Overall screening outcome at bi-annual screening mammography.

\begin{tabular}{|c|c|c|c|c|c|c|}
\hline Year of screening & $05 / 07$ & $07 / 09$ & $09 / 11$ & $11 / 13$ & $13 / 15$ & Total \\
\hline Screens & 66,750 & 66,558 & 101,249 & 118,641 & 131,224 & 484,422 \\
\hline Recalls (\%) & $895(1.3)$ & $1020(1.5)$ & 2945 (2.9) & $3737(3.1)$ & $4368(3.3)$ & 12,965 (2.7) \\
\hline $\begin{array}{l}\text { Screen-film } \\
\text { mammography (\%) }\end{array}$ & $895(100)$ & $979(96.0)$ & $204(6.9)$ & - & - & $2078(16.0)$ \\
\hline Full-field digital (\%) & - & $41(4.0)$ & $2741(93.1)$ & 3737 (100) & $4368(100)$ & $10,887(84.0)$ \\
\hline True positive recalls & 327 & 332 & 676 & 799 & 925 & 3059 \\
\hline DCIS (\%) & 65 (19.9) & $56(16.9)$ & $157(23.2)$ & $181(22.7)$ & $164(17.7)$ & $623(20.4)$ \\
\hline $\begin{array}{l}\text { Invasive carcinoma } \\
(\%)\end{array}$ & $262(80.1)$ & $276(83.2)$ & $519(76.8)$ & $618(77.3)$ & $761(82.3)$ & $2436(79.6)$ \\
\hline $\begin{array}{l}\text { Positive predictive } \\
\text { value of recall, } \%\end{array}$ & 36.5 & 32.5 & 23.0 & 21.4 & 21.2 & 23.6 \\
\hline $\begin{array}{l}\text { Cancer detection rate } \\
\text { per } 1000 \text { screens }\end{array}$ & 4.9 & 5.0 & 6.7 & 6.7 & 7.0 & 6.3 \\
\hline
\end{tabular}

\section{Initial versus subsequent screens}

At initial screening, 397 women (13.0\% of all cancers diagnosed following recall) were diagnosed with either DCIS or invasive breast cancer (DCIS: 113 women, invasive carcinomas: 284 women) compared to 2662 women (87.0\%) at subsequent screening (DCIS; 510 patients, invasive carcinomas; 2152 patients). 


\section{DCIS}

DCIS was diagnosed in 623 patients out of 3059 true positive recalls $(20.4 \%$, Table 2.2). The majority of the DCIS lesions (80.7\%) presented as suspicious microcalcifications at screening mammography. Almost half of the screen-detected cases of DCIS were high grade lesions (48.2\%; 300 women)

Table 2.2 Characteristics of DCIS and invasive breast cancers detected at bi-annual screening mammography.

\begin{tabular}{|c|c|c|c|}
\hline True positive recall (\%) & $623(20.4)$ & $2436(79.6)$ & $<0.001^{*}$ \\
\hline Initial screens (\%) & $113(18.1)$ & $284(11.7)$ & \\
\hline Subsequent screens (\%) & $510(81.9)$ & $2152(88.3)$ & \\
\hline Positive predictive value of recall (\%) & 4.8 & 18.8 & \\
\hline Cancer detection rate per 1000 screens & 1.3 & 5.0 & \\
\hline Screening method & & & $0.039 *$ \\
\hline Screen-film mammography (\%) & $126(20.2)$ & $588(24.1)$ & \\
\hline Full-field digital mammography (\%) & $497(79.8)$ & $1848(75.9)$ & \\
\hline Mammographic abnormalities (\%) & & & $<0.001^{*}$ \\
\hline Suspicious mass & $52(8.3)$ & $1736(71.3)$ & \\
\hline Suspicious microcalcifications & $503(80.7)$ & $229(9.4)$ & \\
\hline Suspicious mass with microcalcifications & $63(10.1)$ & $244(10.0)$ & \\
\hline Asymmetry & $2(0.3)$ & $37(1.5)$ & \\
\hline Architectural distortion & $3(0.5)$ & $188(7.7)$ & \\
\hline Other mammographic abnormality & - & $2(0.1)$ & \\
\hline Tumor grade $(\%)$ & & & $<0.001^{*}$ \\
\hline Low & $124(19.9)$ & $1106(45.4)$ & \\
\hline Intermediate & $199(31.9)$ & $1013(41.6)$ & \\
\hline High & $300(48.2)$ & 275 (11.3) & \\
\hline Unknown & - & $42(1.7)$ & \\
\hline
\end{tabular}

Table 2.3 shows the distribution of histological grade of screen-detected DCIS. In both SFM-only cohorts (2005-2007 vs. 2007-2009), the proportional distribution of DCIS by histological grade was largely comparable; low grade $12.3 \%$ vs. $16.1 \%$, intermediate grade $16.9 \%$ vs. $30.4 \%$ and high grade $70.8 \%$ vs. $53.8 \%$ ( $p=0.131$; Table 2.3). No significant differences were found regarding the DCIS rate per 1000 women screened, analyzed by grade; low grade 0.1 vs. 0.1 per 1000 screens ( $p=0.803)$, intermediate grade 0.2 vs. 0.3 per 1000 screens $(p=0.254)$ and high grade 0.7 vs. 0.5 per 1000 screens ( $p=0.07$; Figure 2.1).

Similarly, in both FFDM-only cohorts (2011-2013 vs. 2013-2015) the proportions of low, intermediate and high grade DCIS were also comparable; low grade $18.2 \%$ versus $15.8 \%$, intermediate grade $33.1 \%$ vs. $35.7 \%$ and high grade $48.6 \%$ vs. $48.8 \%$ $(p=0.815)$. Moreover, when analyzed according to grade, no differences were observed between the rate per 1000 women screened; low grade 0.3 vs. 0.2 per 1000 screens ( $p=0.194)$, intermediate grade 0.5 vs. 0.4 per 1000 screens $(p=0.464)$ and high grade 0.7 vs. 0.6 per 1000 screens ( $p=0.203$; Figure 2.1). 


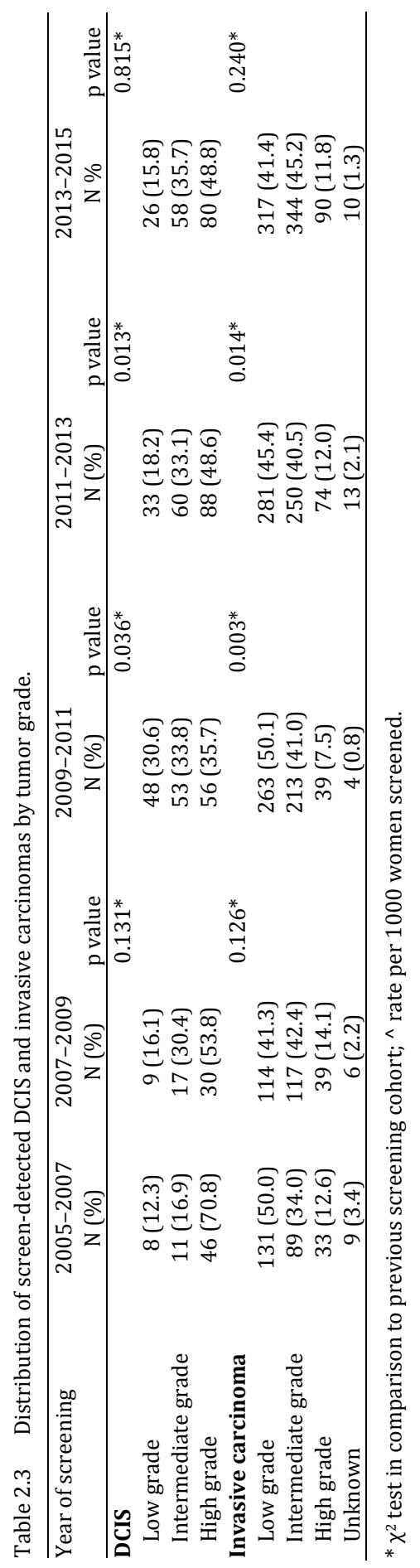




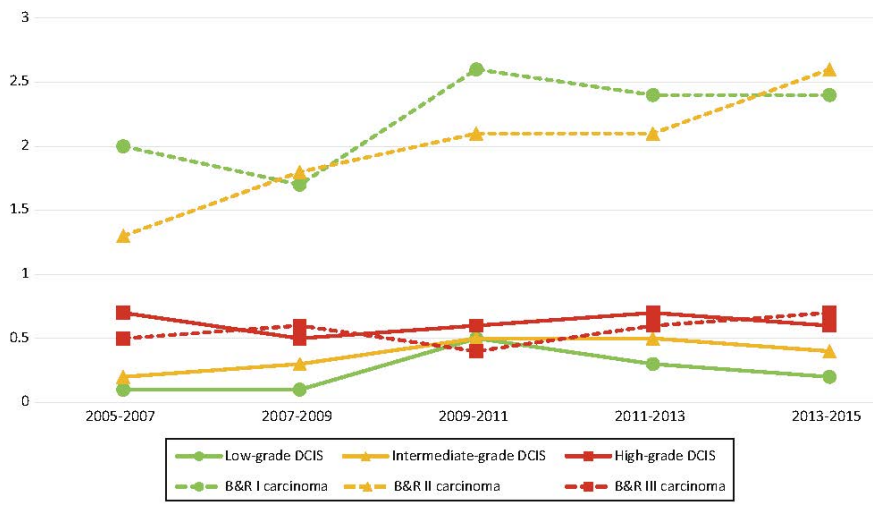

Figure 2.1 Rate per 1000 screened women.

In the period 2009-2011, during which SFM was gradually replaced by FFDM, the distribution in DCIS proportions differed from previous and subsequent cohorts. Compared to the last SFM-only period, a shift from high to low grade DCIS was found, leaving the proportion of intermediate DCIS virtually unchanged; (low grade DCIS: $30.6 \%$ vs. $16.1 \%$, high grade DCIS: $35.7 \%$ vs. $53.8 \%, p=0.036)$. The distribution rate by DCIS grade per 1000 screens for both low grade as well as intermediate grade significantly increased during the transition period (low 0.1 vs. 0.5 per 1000 screens $(p \leq 0.001)$; intermediate 0.3 vs. 0.5 per 1000 screens $(p=0.009)$ whereas the rate of high grade DCIS remained unchanged ( 0.5 per vs. 0.6 per 1000 screens; $p=0.365$; Figure 2.1).

The transition was characterized by an increased overall CDR of DCIS per 1000 women screened ( 0.8 vs. 1.6 per 1000 screens; $p \leq 0.001$ ). In the transitional cohort, when compared to the first FFDM-only period, a significantly higher proportion of low grade DCIS and lower proportion of high grade DCIS (low grade; $30.6 \%$ vs. $18.2 \%$ and high grade; $35.7 \%$ vs. $48.6 \%, p=0.013$; Table 2.3 ) were found leaving the proportion of intermediate grade DCIS rather unchanged. The distribution rate by grade per 1000 screened women changed correspondingly; low grade 0.5 vs. 0.3 per 1000 screens $(p=0.017)$, intermediate grade 0.5 vs. 0.5 per 1000 screens $(p=0.856)$ and high grade 0.7 vs. 0.6 per 1000 screens ( $p=0.084$; Figure 2.1).

Overall, the two FFDM periods together (2011-2015) revealed a significantly lower proportion of high grade DCIS as compared to the two SFM periods (2005-2009) $48.7 \%(168 / 345)$ vs. $62.8 \%(76 / 121)$, resulting in a lower proportion of low grade $(17.1 \%$ vs. $14.0 \%)$ and intermediate grade DCIS (34.2\% vs. $23.1 \%, p=0.029)$. The distribution rate by grade per 1000 women screened increased for low grade 0.1 
vs. 0.2 per 1000 screens; $p<0.001$ ) and intermediate grade (0.2 vs. 0.5 per 1000 screens; $p<0.001$ ), in contrast to high grade DCIS (0.6 vs. 0.7 per 1000 screens; $p=0.232$ ).

\section{DCIS: initial versus subsequent screens}

Table 2.4 shows the DCIS proportions, according to histological grade, at initial and subsequent screening mammography. A total of 623 DCIS lesions were detected (113 initial screen, 510 subsequent screens). The combined proportions of intermediate and high grade DCIS were significantly higher at subsequent screening than at initial screening; $70.7 \%(80 / 113)$ vs. $80.2 \%(419 / 510 ; p=0.023)$.

\section{Invasive carcinoma}

Invasive carcinoma was diagnosed in 2436 recalls $(79.6 \%$ of all screen-detected cancers; Table 2.1). The abnormality most frequently presented itself as a suspicious mass at screening mammography (71.3\%, Table 2.2). The majority of these breast cancers were low grade (45.4\%; 1106 women) or intermediate grade (41.6\%; 1013 women).

The proportional distribution by grade was comparable for both SFM-only cohorts ( $p=0.126$; Table 2.3). The invasive carcinoma rate per 1000 women screened was comparable when analyzed according to grade; low grade 2.0 vs. 1.7 per 1000 screens $(p=0.287)$, intermediate grade 1.3 versus 1.8 per 1000 screens $(p=0.050)$ and high grade 0.5 versus 0.6 per 1000 screens ( $p=0.473$; Figure 2.1).

In the two consecutive FFDM-only cohorts (2011-2013 vs. 2013-2015), the proportional distribution by grade was also comparable ( $p=0.240$; Table 2.3$)$. The rate per 1000 women screened according to grade was comparable for low grade 2.4 vs. 2.4 per 1000 screens ( $p=0.810$ ) and high grade 0.7 vs. 0.5 per 1000 screens $(p=0.545)$. However, the difference with regard to intermediate grade invasive carcinomas was significantly different; 2.1 vs. 2.6 per 1000 screens ( $p=0.008$; Figure 2.1).

The proportion of low grade invasive carcinoma was higher in the transition cohort (2009-2011) as compared to the last SFM cohort (2007-2009) (50.1\% vs. 41.3\%, $p=0.003$ ). This resulted into a lower proportion of high grade invasive carcinoma (14.1\% vs. $7.5 \%, \mathrm{p}=0.003)$. The transition was also characterized by an increased overall CDR of invasive carcinoma per 1000 women screened (5.1 vs. $4.1 ; p=0.003$ ) mainly due to an increased detection rate of low grade invasive carcinoma per 1000 women screened (2.6 vs. 1.7 per 1000 screens; $p \leq 0.001$ ). 
The first FFDM-only period (2011-2013) yielded a higher proportion of high grade invasive carcinoma in contrast to the transition cohort $(12.0 \%$ vs. $7.5 \%, p=0.014)$, as was the rate of high grade carcinomas per 1000 women screened ( 0.6 vs. 0.4 per 1000 screens; $p=0.014$ ) However, the overall CDR per 1000 screens was comparable (5.1 vs. 4.6 per 1000 screens; $p=0.126$ ).

Overall, the SFM-only periods (2005-2009) and the FFDM-only periods (2011-2015) showed a comparable proportional distribution of B\&R grade for invasive carcinoma $(p=0.128)$. However, the detection rate per 1000 women screened increased for low grade (1.8 vs. 2.4 per 1000 screens) and intermediate grade (1.5 vs. 2.4 per 1000 screens) invasive carcinomas (both $p \leq 0.001$ ) and remained stable for high grade invasive carcinomas ( 0.5 vs. 0.7 per 1000 screens; $p=0.167)$.

\section{Invasive carcinoma: initial versus subsequent screens}

Table 2.4 shows the invasive carcinoma proportions, according to B\&R grade, at initial and subsequent screening mammography. A total of 2436 invasive carcinomas were diagnosed; 284 (11.7\%) at initial screening and 2152 (88.3\%) at subsequent screening.

The distribution by grade showed no statistically significant difference between initial and subsequent screens $(p=0.063)$.

Table 2.4 DCIS and invasive carcinoma proportions, according to histological grade, at initial and subsequent screening mammography.

\begin{tabular}{lccc}
\hline & Initial screens & Subsequent screens & pvalue \\
\hline DCIS & $\mathrm{N}(\%)$ & $\mathrm{N}(\%)$ & $0.023^{*}$ \\
Low grade & $113(18.1)$ & $510(81.9)$ & \\
Intermediate grade & $33(29.2)$ & $168(32.9)$ & \\
High grade & $31(27.4)$ & $251(49.2)$ & \\
Invasive carcinoma & $49(43.3)$ & $2152(88.3)$ & \\
Low grade & $284(11.7)$ & $957(44.5)$ & \\
Intermediate grade & $149(52.5)$ & $910(42.3)$ & \\
High grade & $103(36.2)$ & $249(11.6)$ & \\
Unknown & $26(9.2)$ & $36(1.6)$ &
\end{tabular}

* $\chi^{2}$ test; in comparison to previous screening cohort; DCIS ductal carcinoma in situ, B\&R Bloom \& Richardson. 


\section{Discussion}

This population-based study describes the trends in incidence of both screendetected DCIS and invasive breast cancer in the southern part of the Netherlands from July 2005 to July 2015. When comparing high versus low or intermediate grade, our study shows that screen-detected DCIS was mainly high grade in contrast to invasive carcinomas which were mainly found to be low or intermediate grade. This observation suggests that treatment of poorly differentiated DCIS detected through mammographic screening could play a role in the relative reduction of the incidence of poorly differentiated invasive carcinoma, assuming that high grade DCIS was removed before it could develop into high grade invasive cancer. ${ }^{14,15}$ Taken into account that high grade DCIS may preferably develop into high grade invasive carcinoma, increased screen-detected DCIS and the subsequent treatment of high grade DCIS may not purely lead to overtreatment, but prevention of the development into high grade carcinomas. However, high grade invasive cancers, on the other hand, may be more frequently presenting as interval cancers.

Recently, Duffy et al. investigated the association between detection of DCIS at screening and invasive interval cancers subsequent to the relevant screen. ${ }^{16}$ They concluded that a higher rate of screen-detected DCIS is associated with a lower rate of invasive interval cancers, suggesting that detection and treatment of DCIS is worthwhile in prevention of future invasive disease. Our study, however, was directed to screen-detected malignancies in consecutive screening cohorts and therefore we disregarded the interval carcinomas.

Our study not only provides an overview of the impact of the transition of SFM to FFDM on screening outcome, but it also compares the periods before and after the intervention. In the SFM period as well as in the FFDM period the aforementioned ratio in the distribution of DCIS grade and invasive tumor grade was compared with regard to the type of screening technique. During the transition period from SFM to FDDM a significantly increase in the number of low grade DCIS was observed. This finding may be attributed to the better detection of small abnormalities, especially grouped microcalcifications, at FFDM. ${ }^{17,18}$ The clinical value of this increased detection of low grade DCIS and subsequent treatment is currently a matter of debate as the majority of these lesions may remain subclinical.6,9

The total CDR of DCIS per 1000 screened women increased during the transition period and then decreased to a lower level in the FFDM-only periods. In the FFDM period (2011-2015), the total CDR of DCIS per 1000 screened women is almost comparable to this rate in the SFM period (2005-2009). The rate of low or 
intermediate grade invasive carcinomas increased considerably, whereas the rate of high grade disease remained stable.

Comparing initial and subsequent screens a significant part of the breast abnormalities was found at initial screening, which can be seen as the incidence of breast abnormalities in the normal population of asymptomatic woman under 50 years of age. At every subsequent screening round new abnormalities are detected. This finding suggests that new and clinically relevant abnormalities keep on developing and repeated screening therefore remains necessary.

A decreasing, positive predictive value of recall was found during our 10-year inclusion period. This decreased, positive predictive value may partly be explained by an increasing recall rate through the years. A Dutch optimization study stimulated screening radiologists to lower their threshold for recall, in order to increase CDR. ${ }^{19}$ Also, the replacement of independent double reading by blinded double reading at the moment of the introduction of FFDM screening resulted in higher recall rate.20,21 Finally, other possible explanations for the increased recall rates may be the routine use of two-view screening mammography after the introduction of FFDM screening ${ }^{22}$, as well as a better and consistent image quality of digital mammography compared to screen-film mammography. ${ }^{17,18}$ Along with the increased recall rate, the overall CDR per 1000 screens increased gradually over the years.

Our study has several strengths and limitations. A unique aspect of our study is that, to our knowledge, we are the first to investigate the correlation between screen-detected DCIS and screen-detected invasive breast cancer with complete information on tumor grade. Furthermore, our population-based study design and our large sample size makes extrapolation of our results to other screening, comparable program possible.

On the other hand, we only focused on women who attended the mammographic screening program, therefore we disregarded the women who did not attend and the abnormalities found in between two screening rounds (interval cancers). Moreover, extrapolation to the UK and US program may be limited, because in contrast to our biennial screening, women in the UK are screened every 3 years and in the US annual screening is offered. ${ }^{23,24}$

In conclusion, at screening mammography mostly high grade DCIS and low or intermediate grade invasive carcinomas are detected. Except for the sharp increase of low grade DCIS and low grade invasive carcinomas following the introduction of FFDM screening, the grade distribution of DCIS and invasive carcinomas as well as the proportion of patients detected in the years after the introduction of FFDM remained rather stable compared to the era of SFM screening. By detecting high 
grade DCIS, which otherwise may preferably develop into high grade invasive carcinoma if not removed, our findings possibly shed a new light on the clinical value of screening mammography program. 


\section{References}

1. Jing HYY, Wernick MN, Yarusso LM, Nishikawa RM. A comparison study of image features between FFDM and film mammogram images. Med Phys 2012;39(7):8.

2. Nederend J, Duijm LE, Voogd AC, Groenewoud JH, Jansen FH, Louwman MW. Trends in incidence and detection of advanced breast cancer at biennial screening mammography in The Netherlands: a population based study. Breast Cancer Res 2012;14(1):R10.

3. van Steenbergen LN, Voogd AC, Roukema JA, Louwman WJ, Duijm LE, Coebergh JW, van de PollFranse LV. Screening caused rising incidence rates of ductal carcinoma in situ of the breast. Breast Cancer Res Treat 2009;115(1):181-183.

4. Richtlijn mammacarinoom [Internet] Dutch breast cancer guideline. NABON. http://www.oncoline.nl/mammacarcinoom

5. Ernster VL, Ballard-Barbash R, Barlow WE, Zheng Y, Weaver DL, Cutter G, Yankaskas BC, Rosenberg R, Carney PA, Kerlikowske K et al. Detection of ductal carcinoma in situ in women undergoing screening mammography. J Natl Cancer Inst 2002;94(20):1546-1554.

6. Hollingsworth A. Overestimating overdiagnosis in breast cancer screening. Cureus 2017;9(1):e966.

7. Yen MFTL, Vitak B, Smith RA, Chen HH, Duffy SW. Quantifying the potential problem of overdiagnosis of ductal carcinoma in situ in breast cancer screening. Eur J Cancer 2003;39(12):8.

8. Duffy SW, Agbaje O, Tabar L, Vitak B, Bjurstam N, Bjorneld L, Myles JP, Warwick J. Overdiagnosis and overtreatment of breast cancer: estimates of overdiagnosis from two trials of mammographic screening for breast cancer. Breast Cancer Res 2005;7(6):258-265.

9. Seigneurin A, Labarere J, Francois O, Exbrayat C, Dupouy M, Filippi M, Colonna M. Overdiagnosis and overtreatment associated with breast cancer mammography screening: a simulation study with calibration to population-based data. Breast 2016;28:60-66.

10. Duijm LE, Groenewoud JH, Jansen FH, Fracheboud J, van Beek M, de Koning HJ. Mammography screening in the Netherlands: delay in the diagnosis of breast cancer after breast cancer screening. Br J Cancer 2004;91(10):1795-1799.

11. Setz-Pels W, Duijm LE, Coebergh JW, Rutten M, Nederend J, Voogd AC. Re-attendance after falsepositive screening mammography: a population-based study in the Netherlands. Br J Cancer 2013;109(8):2044-2050.

12. Radiology AC: Breast Imaging Reporting and Data System (BIRADS), 4th edn. American College of Radiology 2003. https://www.acr.org/Quality-Safety/Resources/BIRADS.

13. Sickles E, D’Orsi CJ, Bassett LW: ACR BI-RADS" Mammography. ACR BI-RADS" Atlas, Breast Imaging Reporting and Data System. American College of Radiology 2013. https://www.acr.org/Quality-Safety/Resources/BIRADS.

14. Cuzick J, Sestak I, Pinder SE, Ellis IO, Forsyth S, Bundred NJ, Forbes JF, Bishop H, Fentiman IS, George WD. Effect of tamoxifen and radiotherapy in women with locally excised ductal carcinoma in situ: long-term results from the UK/ANZ DCIS trial. Lancet Oncol 2011;12(1):21-29.

15. Ellis IO. Intraductal proliferative lesions of the breast: morphology, associated risk and molecular biology. Mod Pathol 2010;23(Suppl 2):S1-S7.

16. Duffy SW, Dibden A, Michalopoulos D, Offman J, Parmar D, Jenkins J, Collins B, Robson T, Scorfield $\mathrm{S}$, Green $\mathrm{K}$ et al. Screen detection of ductal carcinoma in situ and subsequent incidence of invasive interval breast cancers: a retrospective population-based study. Lancet Oncol 2016;17(1): 109-114.

17. Del Turco MR, Mantellini P, Ciatto S, Bonardi R, Martinelli F, Lazzari B, Houssami N. Full-field digital versus screenfilm mammography: comparative accuracy in concurrent screening cohorts. Am J Roentgenol 2007;189(4):860-866.

18. Karssemeijer N, Bluekens AM, Beijerinck D, Deurenberg JJ, Beekman M, Visser R, van Engen R, Bartels-Kortland A, Broeders MJ. Breast cancer screening results 5 years after introduction of digital mammography in a population-based screening program. Radiology 2009;253(2):353-358. 
19. Otten JD, Karssemeijer N, Hendriks JH, Groenewoud JH, Fracheboud J, Verbeek AL, de Koning HJ, Holland R. Effect of recall rate on earlier screen detection of breast cancers based on the Dutch performance indicators. J Natl Cancer Inst 2005;97(10):748-754.

20. Klompenhouwer EG, Voogd AC, den Heeten GJ, Strobbe LJ, de Haan AF, Wauters CA, Broeders MJ, Duijm LE. Blinded double reading yields a higher programme sensitivity than nonblinded double reading at digital screening mammography: a prospected population based study in the south of The Netherlands. Eur J Cancer 2015;51(3):391-399.

21. Klompenhouwer EG, Voogd AC, den Heeten GJ, Strobbe LJ, Tjan-Heijnen VC, Broeders MJ, Duijm LE. Discrepant screening mammography assessments at blinded and non-blinded double reading: impact of arbitration by a third reader on screening outcome. Eur Radiol 2015;25(10):2821-2829.

22. van Breest Smallenburg V, Duijm LE, den Heeten GJ, Groenewoud JH, Jansen FH, Fracheboud J, Plaisier ML, van Doorne-Nagtegaal HJ, Broeders MJ. Two-view versus single-view mammography at subsequent screening in a region of the Dutch breast screening programme. Eur J Radiol 2012;81(9):2189-2194.

23. Dowling EC, Klabunde C, Patnick J, Ballard-Barbash R. Breast and cervical cancer screening programme implementation in 16 countries. J Med Screen 2010;17(3):139-146.

24. Smith-Bindman R, Chu PW, Miglioretti DL, Sickles EA, Blanks R, Ballard-Barbash R, Bobo JK, Lee NC, Wallis MG, Patnick J et al. Comparison of screening mammography in the United States and the United kingdom. JAMA 2003;290(16):2129-2137. 


$$
\text { yo }
$$




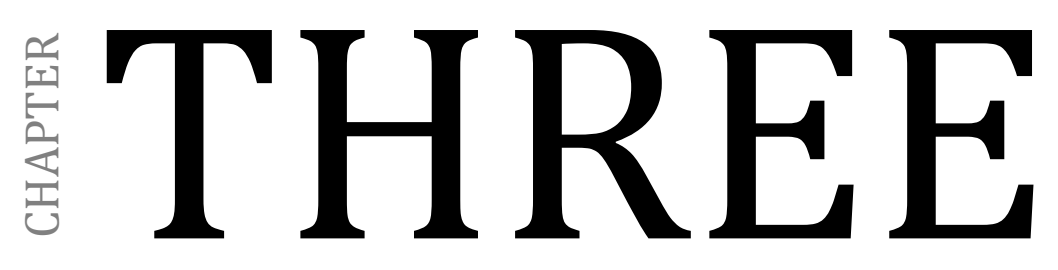

Utility of diagnostic breast excision biopsies during two decades of screening mammography

Jacky D. Luiten

Adri C. Voogd

Vivianne C.G. Tjan-Heijnen

Jelle Wesseling

Ernest J.T. Luiten

Lucien E.M. Duijm 


\section{Abstract}

Introduction

We evaluated the use and value of breast surgical excision biopsies for diagnostic purposes over the last decades in women undergoing mammographic screening, either as a primary procedure or following an inconclusive percutaneous biopsy.

\section{Methods}

All women who underwent an excision biopsy among 817,656 screens, obtained from January 1997 to January 2017, were included.

\section{Results}

Of 18,593 recalled women (recall rate, $2.3 \%$ ) with screen-detected abnormalities, 908 (4.9\%) underwent an excision biopsy. Of these, 411 (45.3\%) were performed as first diagnostic intervention, decreasing from 4.3 per 1000 screens in 1997-1998 to 0 per 1000 screens in 2015-2016 and onwards. The remaining 497 (54.7\%) excision biopsies were performed secondary to pathologic findings at percutaneous biopsy. During 1997-1998, 1.0 secondary biopsies per 1000 screens were performed, decreasing to 0.3 per 1000 in 2005-2006 and afterwards increased to 0.6 per 1000 in 2015-2016 ( $p=0.003$ ). Of all 487 secondary biopsies, $303(61.0 \%)$ had a benign pathology outcome, increasing from $40.4 \%$ in $1997-1998$ to $70.2 \%$ in 2015-2016. Of all 211 biopsies in the three most recent cohorts (2011-2016) the overall upgrade rate was $26.5 \%$, consisting of 39 (18.5\%) DCIS (27 low grade) and $17(8.1 \%)$ invasive carcinomas.

\section{Conclusion}

Although the use of excision biopsy significantly decreased over the past two decades, we observed a significant increase in more recent years. Since the vast majority of currently performed excision biopsies reveals a benign diagnosis or shows low grade DCIS, a secondary excision biopsy should only be considered if radiologic surveillance and repeated percutaneous biopsy continues to yield indeterminate results. 


\section{Introduction}

In the Netherlands, all women aged 50-75 years are invited to attend the nationwide biennial screening mammography program, which was implemented between 1989 and 1996. In 1998 the upper age limit of the program was extended to 75 years of age and during 2009-2010 screen-film mammography was replaced by full-field digital mammography. ${ }^{1-3}$

Adequate biopsy of a suspicious abnormality detected at screening mammography is required to obtain a definitive pathology result. A simple biopsy technique that can be used is fine needle aspiration (FNA). FNA was first described in 1847 for head and neck cancers. ${ }^{4}$ During the 1960s FNA became more widely used and was considered as the gold standard for the pre-operative diagnosis of breast cancer. ${ }^{5}$ However, due the fact that FNA only collects cells, core biopsy evolved as an alternative to harvest tissue. Core biopsy enabled pathologists to make a more reliable diagnosis as it delivers full tissue structure instead of separate cells only. In addition, more reliable testing of hormone receptor and HER2 status is hereby feasible. 6,7 Considering the fact that nowadays most breast lesions are non-palpable at the time of initial diagnosis, biopsies are usually performed under guidance of ultrasound or mammography. The core biopsy technique was first described in 1977 and in the 1990s large core biopsies gradually replaced FNA. ${ }^{8}$ Core biopsy was also an adequate alternative for surgical excision biopsy.

Surgical excision biopsy is an invasive technique and used to be the most reliable method to obtain a conclusive diagnosis of a potentially malignant breast lesion, with a diagnostic accuracy of 94\%-99\%. ${ }^{9}$ However, surgical excision biopsies are maximal invasive procedures, are usually performed under general anesthesia and have been found to hamper the assessment of future screening mammography. ${ }^{10,11}$ Therefore, the use of excision biopsy, next to fine needle aspiration and core biopsy, has become a matter of debate. In a systematic review, published in 2002, Crowe et al. already reported a decline in the use of excisional biopsies between 1995 and 2002.12 Later, a population-based study by van Breest Smallenburg et al., in 2013 reported a decline in the use of excision biopsy between 1997 and 2010 and showed that it was gradually replaced by large percutaneous core biopsy. ${ }^{13}$ However, percutaneous core biopsies do not always provide a definite histopathological diagnosis, especially in the current era of digital mammography, which is characterized by the detection of many small lesions. This persistent uncertainty may cause physicians at the multidisciplinary board meetings to opt for an excision biopsy. Furthermore, we distinguished between excision biopsies performed as first biopsy method (primary excision biopsies) and excision biopsies 
performed secondary to a preceding percutaneous biopsy with no classifying diagnosis (secondary excision biopsies).

The aim of this study was to analyze the more recent trends in the use and added value of excision biopsies in screen-detected breast abnormalities and how these trends compare to those observed until 2010.

\section{Methods}

\section{Study population}

All women who attended the breast cancer screening program at four specialized screening units in the southern part of the Netherlands between January 1997 to January 2017 were asked to give written informed consent to use their screening and follow-up data for evaluation purpose. Three recalled women refused to give permission. Subsequently, a total of 817,656 screens were included in this study. According to the Dutch Central Committee on Research involving Human Subjects (CCMO) ethical approval was not required for the current study.

\section{Screening procedure}

In the Dutch national screening program screening mammograms are taken biennially by dedicated screening mammography radiographers. Certified screening radiologists double read all mammograms and classify the results according to the Breast Imaging Reporting and Data System (BI-RADS). ${ }^{14,15}$ Women with a BI-RADS 0,4 or 5 screening result are recalled to a dedicated breast unit. The Dutch breast cancer screening program has been described in detail in previous studies. $^{2,16,17}$

\section{Follow up}

All women with a suspicious abnormality on screening mammograms (BIRADS 4-5, classified as; suspicious mass, suspicious calcifications, suspicious mass in combination with calcifications, architectural distortion, asymmetry, or other abnormality) are recalled to specialized breast cancer units for further analysis via their general practitioner. Additional breast radiology examinations will be performed, with or without biopsy. Women are recalled directly to the radiology department in case of an uncertain finding at screening mammography (BIRADS 0). If additional analysis does not reveal a suspicious lesion, women are discharged and the general practitioner is informed. 
The available diagnostic biopsy procedures include fine needle aspiration (FNA) cytology, or histologic analysis, carried out by either core needle biopsy (14-18 Gauge), vacuum assisted needle biopsy (9-11 Gauge) or excision biopsy. In this study we focused on excision biopsies. Excision biopsies - primary biopsy method or secondary to percutaneous core needle biopsies, in case of persistent uncertainty (secondary excision biopsies) - were analyzed separately, assuming that the trends in use could differ. Screening and follow up data of all recalled women were collected in a database kept up to date by one of the screening radiologists (LD).

\section{Statistical analysis}

The main outcome of this study was the incidence of the use of excision biopsies, where we especially focused on the difference between primary and secondary excision biopsies and the proportion of benign and malignant excision biopsy outcomes. Statistical analyses were performed using SPSS, version 24.0 (SPSS, Inc., Chicago, USA). The mean differences with standard deviation (SD) were calculated for continuous variables. Trends over time and variations between subgroups were expressed using proportions and percentiles. 95\% confidence intervals $(95 \% \mathrm{CI})$ and chi-square analyses were performed to compare proportional differences between categorical groups and Fischer Exact Test was employed when sample sizes were small, causing the expected values to be smaller than ten. $P$-values less than 0.05 were considered statistically significant.

\section{Results}

\section{Excision biopsy over time}

An excision biopsy was carried out in 908 recalled women (4.9\% of recalls), which decreased from 214 (39.9\%; 1997-1998) to 84 (2.3\%; 2015-2016; $p<0.001)$.

The overall excision biopsy rate was 1.1 per 1000 screened women. This rate initially decreased from 4.4 in 1997-1998 to 0.4 per 1000 screens in 2005-2006 $(p<0.001)$ and subsequently increased again to 0.6 per 1000 screens in $2015-2016$ $(p=0.04$, Figure 3.1). 


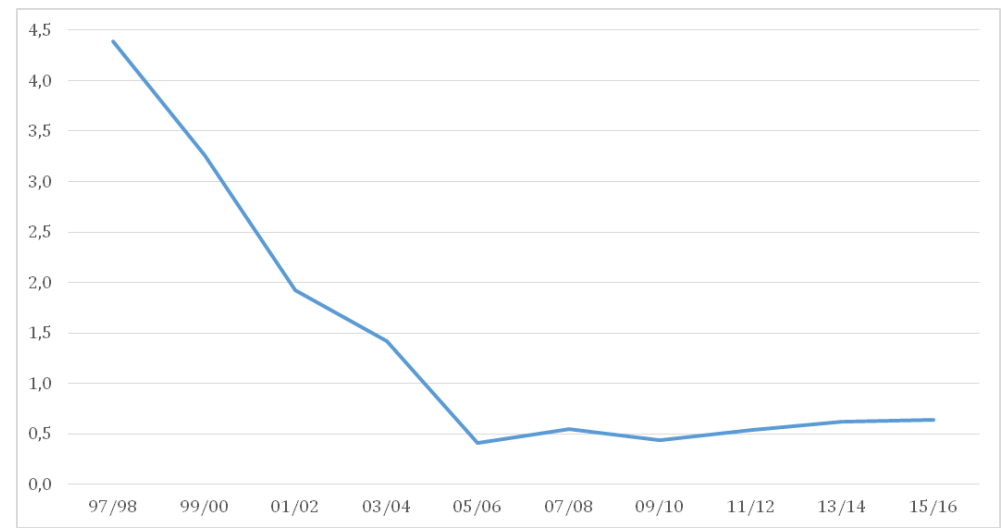

Figure 3.1 Number of women undergoing a surgical excision biopsy per 1000 screens.

\section{Trends in primary and secondary excision biopsies}

During the past two decades, 411 (45.3\%) excision biopsies were performed as first diagnostic intervention (primary excision biopsy), compared to $497(54.7 \%)$ performed following previous percutaneous biopsies (secondary excision biopsy). During the first screening period 1997-1998, a primary excision biopsy was performed in $167(78.0 \%)$ of all 214 patients who underwent excision biopsy, which decreased to 0 out of 84 in the last cohort $(p<0.001)$. In the last decade, only 24 recalled women underwent a surgical excision biopsy as the first diagnostic intervention, mostly due to inability to perform a stereotactic core needle biopsy (SCNB).

The use of secondary excision biopsies among the patients undergoing an excision biopsy increased from $22.0 \%$ ( 47 out of 214 ) in 1997-1998, to $100 \%$ (84 out of 84 ) in 2015-2016. The majority $(286,57.8 \%)$ of the 495 secondary excision biopsies were performed because of pathologic findings at percutaneous biopsy for which pathologists were unable to guarantee a benign disorder. Discordance between radiologic findings and the result of percutaneous biopsy was the reason to perform an excision biopsy secondary to percutaneous biopsy in 109 patients (22.0\%); other indications for a secondary excision biopsy are specified in Table 3.1. The observed increase in secondary excision biopsies was mostly due to an increase in suspicious findings at percutaneous biopsy, while the other reasons for secondary excision showed no increase or other trend during this period (Table 3.1). 


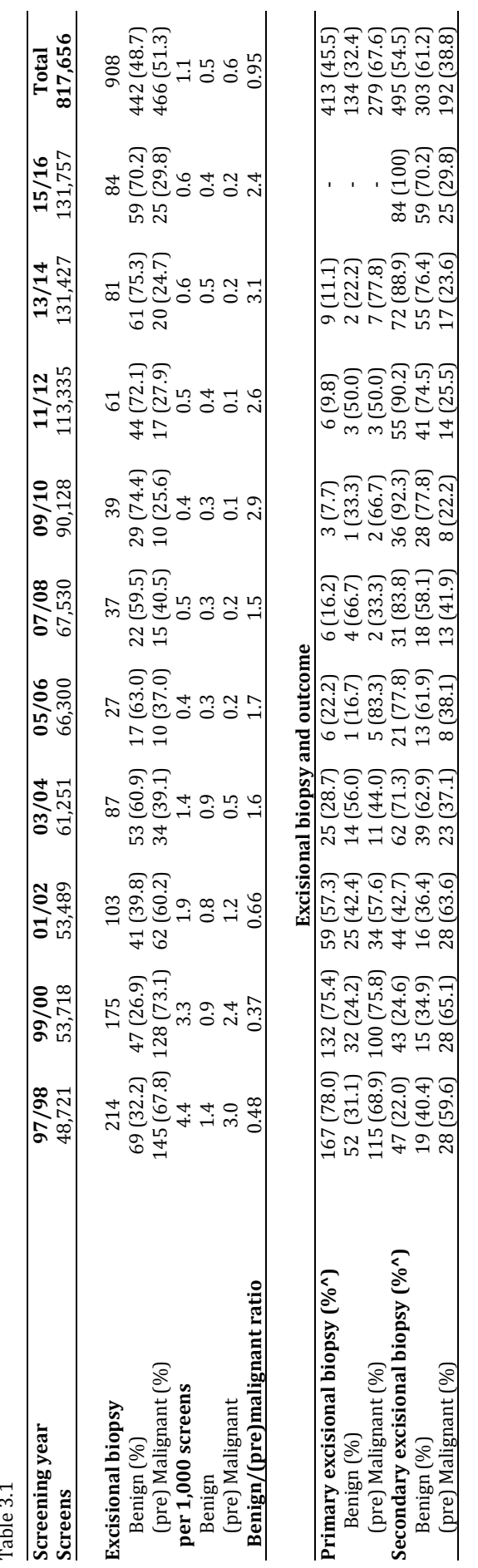

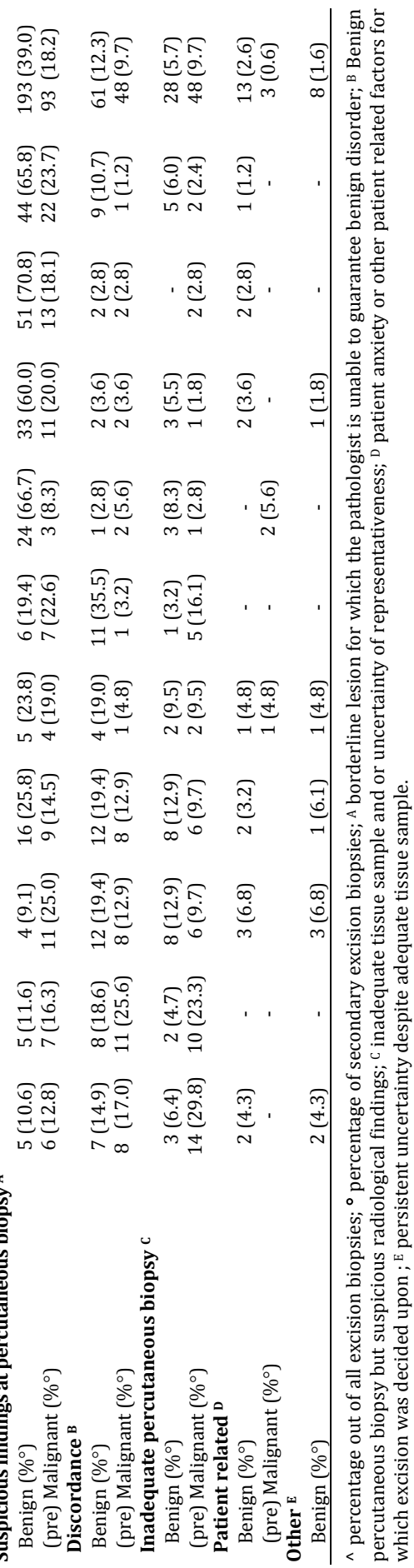


The rate of primary excision biopsies per 1000 screens decreased over the years from 3.4 in 1997-1998 to 0 per 1000 screens in 2015-2016 ( $p<0.001$, Figure 3.3). The rate of secondary excision biopsies per 1000 screens decreased initially from 1.0 performed in 1997-1998 to 0.3 per 1000 screens in 2005-2006 ( $p<0.001)$. After that period a significant increase to 0.6 per 1000 screens was observed in 2015-2016 ( $p=0.003$, Figure 3.3).

\section{Histological diagnosis of excision biopsies}

The final histopathological diagnosis was benign in 442 (48.7\%) of the 908 women who underwent an excision biopsy. The percentage of benign excision biopsy results increased from $32.2 \%$ (69/214 patients), in 1997-1998, to 70.2\% (59/84 patients) in 2015-2016 ( $p<0.001)$. Figure 3.2 shows the benign versus (pre-) malignant ratio in excision biopsies per 1000 screens. The benign versus (pre-) malignant biopsy ratio increased from 0.5 (1997-1998) to 2.4 in (2015-2016; $p<0.001$, Table 3.1).

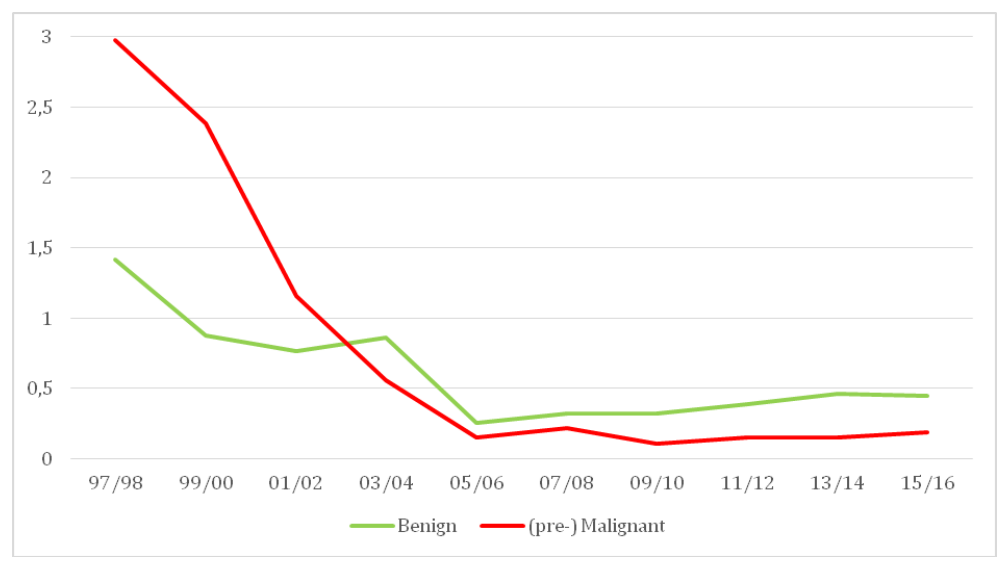

Figure 3.2 Benign versus (pre-)malignant excisional biopsies per 1000 screens.

Of all 411 primary excision biopsies, 134 (32.6\%) were benign. Of all 497 secondary biopsies, 303 (61.0\%) showed a benign histopathological diagnosis. This percentage increased from $40.4 \%$ (19 out of 47) in 1997-1998 to $70.2 \%$ (59 out of 84 ) in 2015-2016 (Table 3.1). The (pre-)malignant histopathological results of secondary excision biopsies in the three most recent cohorts (2011-2012, 2013-2014 and 2015-2016) were further analyzed. Of all 211 biopsies, only 56 showed a (pre-)malignant histopathological result, resulting in an overall upgrade rate of $26.5 \%$. Of all secondary biopsies $18.5 \%$ showed DCIS (27 low grade, 
12.8\%; 10 intermediate grade, 4.7\%; 2 high grade, $0.9 \%$ ) and $8.1 \%$ invasive carcinomas (11 low grade, 5.2\%; 4 intermediate grade, 1.9\%; 2 high grade, $0.9 \%$; Figure 3.4).

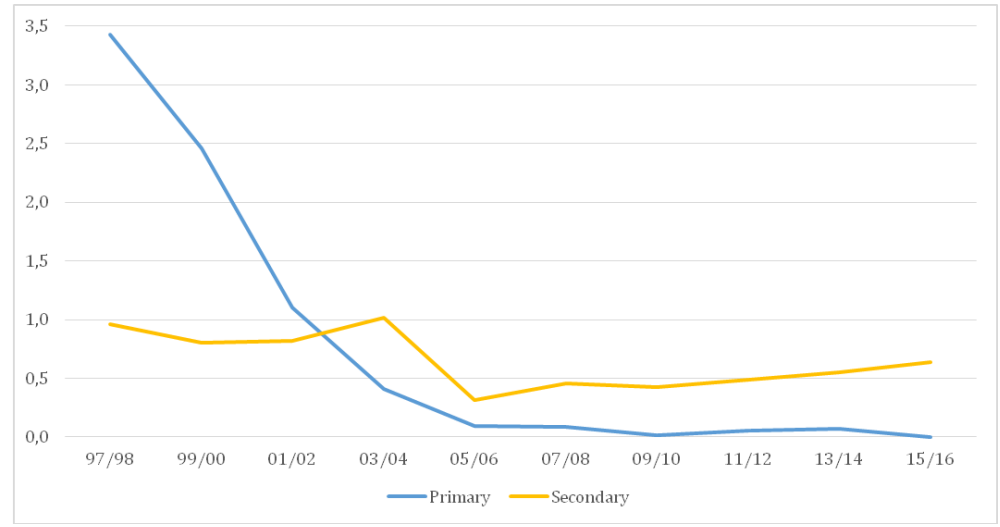

Figure 3.3 Primary versus secondary excisional biopsies per 1000 screens.

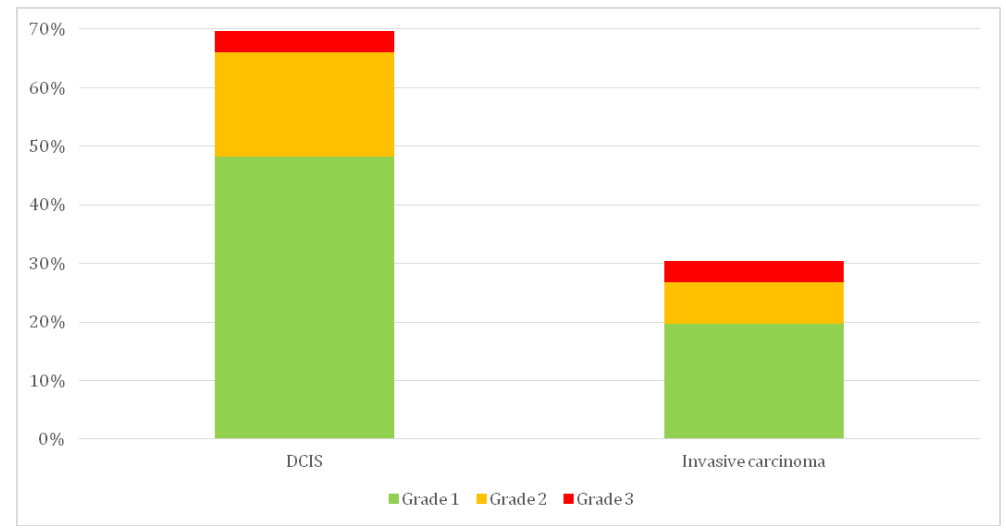

Figure 3.4 (Pre-)malignant pathology outcome of secondary excision biopsies divided per grade from 2011 to 2016.

\section{Discussion}

This population-based study describes the changes in use and evaluates the added value of excision biopsies of screen-detected mammographic suspicious breast lesions in the southern part of the Netherlands from January 1997 to January 2017. 
A sharp decline in the use of primary excision biopsy was observed over the past two decades. Currently, primary excision biopsy has been replaced by percutaneous core biopsy in almost all patients, which was also demonstrated in this study. ${ }^{15-17}$

Although it has been postulated that, with the introduction and widespread use of (S)CNB, an excisional biopsy would become an obsolete procedure, an ongoing significant increase was observed over the last few years, comprising mainly secondary excisional biopsies due to an increase in the number of suspicious findings at percutaneous biopsy. In daily practice, most secondary biopsies are performed if percutaneous biopsy yields an inconclusive histopathologic diagnosis, implying malignancy cannot be ruled out completely or when a discordance between radiologic and histopathologic findings persists after (repeated) percutaneous biopsy. This discordance is known to be related to an increased likelihood of upgrading to carcinoma. ${ }^{18}$

The recent increase in secondary excision biopsies is probably related to the introduction of full-field digital mammography, revealing smaller breast lesions due to the higher sensitivity of digital mammography compared to screen-film mammography. ${ }^{19,20}$ These changes in imaging techniques and diagnosis revealing lesions of unknown significance have had an impact on the types of specimens in which radiologists and pathologists encounter high-risk lesions. ${ }^{21}$ This poses clinicians for therapeutic dilemmas for which either subsequent need for additional secondary excision biopsy or mammographic surveillance is imposed depending on the level of agreement in multidisciplinary tumor boards. ${ }^{22,23}$ These lesions include, for example, atypical ductal hyperplasia (with the differential diagnosis of ductal carcinoma in-situ), papillary lesions, atypical lobular hyperplasia and flat epithelial atypia. ${ }^{24}$ Since surgical excision is still regarded as the gold standard to obtain a definitive histopathologic diagnosis, surgical excision of the these lesions may be considered in order to minimize the risk of missing out malignant disease. ${ }^{22}$ However, Mercado et al., in 2006 demonstrated that approximately 80\% of all papillary lesions consist of benign pathology at secondary surgical excision. ${ }^{25}$ Another study, by Sen et al., in 2016, also demonstrated that $97.6 \%$ of all atypical lobular hyperplasia was benign at secondary surgical excision. ${ }^{26}$ Consequently, mammographic surveillance can be performed safely for some subtypes of highrisk lesions, without the risk of a significant underdiagnoses and -treatment. ${ }^{13,26}$ In the Netherlands and many other countries, pathology results of diagnostic core biopsies are discussed in a multidisciplinary tumor board. Secondary excision biopsy, preceded by percutaneous biopsy in almost all cases, appears to be the necessary following step in case of persistent uncertainty. Still, it can be questioned 
if the increase in the use of these excision biopsies can be considered as an improvement in the diagnostic process. Proponents might prefer to proceed to an excision biopsy to gain a definitive pathology result claiming that over $25 \%$ of the high-risk lesions show a (pre-) malignant pathology result after surgical excision. Others might state that these lesions may be safely managed by active radiographic surveillance, knowing that the majority of these lesions are low grade DCIS. Actually, this issue is currently subject of several ongoing studies. ${ }^{27,28}$

One may question whether our current approach of high-risk mammographic lesions may be too defensive and results in too many unnecessary surgical excisions. In a recent survey amongst breast pathologists in the United States, almost 90\% reported using one or more assurance behaviors, manifesting itself in ordering additional services with marginal or no additional medical value to avoid adverse patient outcomes. ${ }^{29}$ This phenomenon is understandable, since a delay in diagnosis of breast cancer is a leading cause of malpractice suits filed in the United States. ${ }^{30}$

The rate of excision biopsy procedures is much higher in the United States compared to European countries, including the Netherlands and the United Kingdom. This higher excision biopsy rate may be due to differences in legislation, with a higher rate of malpractice claims for delayed cancer diagnoses in the US than in Europe. ${ }^{11,31}$ Unfortunately, we were not able to reliably retrieve the detailed considerations to proceed to a secondary excision biopsy as these were frequently not specified in the multidisciplinary tumor board reports.

In conclusion, following a sharp decline of the overall excision biopsies rate, a significant increase of secondary excision biopsies was noted the last few years.

Since the vast majority of all excision biopsies performed nowadays is benign, secondary excision biopsy should only be considered for women in whom radiologic surveillance and repeated percutaneous biopsy continues to yield indeterminate result. 


\section{References}

1. Jing HYY, Wernick MN, Yarusso LM, Nishikawa RM. A comparison study of image features between FFDM and film mammogram images. Med Phys 2012;39(7):8.

2. Nederend J, Duijm LE, Voogd AC, et al. Trends in incidence and detection of advanced breast cancer at biennial screening mammography in The Netherlands: a population based study. Breast Cancer Res 2012;14(1):R10.

3. van Steenbergen LN, Voogd AC, Roukema JA, et al. Screening caused rising incidence rates of ductal carcinoma in situ of the breast. Breast Canc Res Treat 2009;115(1):181e3.

4. Lloyd RV. Endocrine Pathology, differential diagnosis and molecular advances. New York: Springer Science p Business Media; 2004.

5. Sennerstam RB, Franzen BSH, Wiksell HOT, et al. Core-needle biopsy of breast cancer is associated with a higher rate of distant metastases 5 to 15 years after diagnosis than FNA biopsy. Cancer Cytopathol. 2017;125(10):748-756.

6. Badoual C, Maruani A, Ghorra C, et al. Pathological prognostic factors of invasive breast carcinoma in ultrasound-guided large core biopsiescorrelation with subsequent surgical excisions. Breast 2005;14(1):22-27.

7. Usami S, Moriya T, Kasajima A, et al. Pathological aspects of core needle biopsy for non-palpable breast lesions. Breast Canc 2005;12(4):272-278.

8. Rakha EA, Ellis IO. An overview of assessment of prognostic and predictive factors in breast cancer needle core biopsy specimens. J Clin Pathol 2007;60(12):1300-1306.

9. Rougraff BT, Aboulafia A, Biermann JS, et al. Biopsy of soft tissue masses: evidence-based medicine for the musculoskeletal tumor society. Clin Orthop Relat Res 2009;467(11):2783-2791.

10. Taplin SH, Abraham L, Geller BM, et al. Effect of previous benign breast biopsy on the interpretive .performance of subsequent screening mammography. J Natl Cancer Inst 2010;102(14): 1040-1051.

11. van Breest Smallenburg V, Duijm LE, Voogd AC, et al. Lower sensitivity of screening mammography after previous benign breast surgery. Int J Cancer 2012;130(1):122-128.

12. Crowe Jr JP, Rim A, Patrick R, et al. A prospective review of the decline of excisional breast biopsy. Am J Surg 2002;184(4):353-355.

13. van Breest Smallenburg V, Nederend J, Voogd AC, et al. Trends in breast biopsies for abnormalities detected at screening mammography: a populationbased study in The Netherlands. Br J Canc 2013;109(1):242-248.

14. American College Radiology o. Breast imaging reporting and datesystem (BIRADS). fourth ed. American College of Radiology; 2003.

15. Sickles E, D'Orsi CJ, Bassett LW. ACR BI-RADS® mammography. ACR BI-RADS® atlas, breast imaging Reporting and data System American College of radiology. 2013.

16. Duijm LE, Groenewoud JH, Jansen FH, et al. Mammography screening in The Netherlands: delay in the diagnosis of breast cancer after breast cancer screening. Br J Canc 2004;91(10):1795-1799.

17. Setz-Pels W, Duijm LE, Coebergh JW, et al. Re-attendance after false-positive screening mammography: a population-based study in The Netherlands. Br J Canc 2013;109(8):2044-2050.

18. Calhoun BC, Collie AM, Lott-Limbach AA, et al. Lobular neoplasia diagnosed on breast Core biopsy: frequency of carcinoma on excision and implications for management. Ann Diagn Pathol 2016;25:20-25.

19. K€os, üs, NK€os, üs, A, Duran M, et al. Comparison of standard mammography with digital mammography and digital infrared thermal imaging for breast cancer screening. J Turk Ger Gynecol Assoc 2010;11(3):152-157.

20. Nederend J, Duijm LE, Louwman MW, et al. Impact of transition from analog screening mammography to digital screening mammography on screening outcome in The Netherlands: a population-based study. Ann Oncol 2012;23(12):3098-3103.

21. Calhoun BC. Core needle biopsy of the breast: an evaluation of contemporary data. Surg Pathol Clin 2018;11(1):1-16. 
22. Rudin AV, Hoskin TL, Fahy A, et al. Flat epithelial atypia on core biopsy and upgrade to cancer: a systematic review and meta-analysis. Ann Surg Oncol 2017;24(12):3549-3558.

23. Sydnor MK, Wilson JD, Hijaz TA, et al. Underestimation of the presence of breast carcinoma in papillary lesions initially diagnosed at core-needle biopsy. Radiology 2007;242(1):58-62.

24. Margenthaler JA, Duke D, Monsees BS, et al. Correlation between core biopsy and excisional biopsy in breast high-risk lesions. Am J Surg 2006;192(4):534-537.

25. Mercado CL, Hamele-Bena D, Oken SM, et al. Papillary lesions of the breast at percutaneous coreneedle biopsy. Radiology 2006;238(3):801-808.

26. Sen LQ, Berg WA, Hooley RJ, et al. Core breast biopsies showing lobular carcinoma in situ should Be excised and surveillance is reasonable for atypical lobular hyperplasia. AJR Am J Roentgenol 2016;207(5):1132-1145.

27. Elshof LE, Tryfonidis K, Slaets L, et al. Feasibility of a prospective, randomised, open-label, international multicentre, phase III, non-inferiority trial to assess the safety of active surveillance for low risk ductal carcinoma in situ - the LORD study. Eur J Cancer 2015;51(12):1497-1510.

28. Francis A, Thomas J, Fallowfield L, et al. Addressing overtreatment of screendetected DCIS; the LORIS trial. Eur J Cancer 2015;51(16):2296-303.

29. Reisch LM, Carney PA, Oster NV, et al. Medical malpractice concerns and defensive medicine: a nationwide survey of breast pathologists. Am J Clin Pathol 2015;144(6):916-922.

30. Kern KA. The delayed diagnosis of breast cancer: medicolegal implications and risk prevention for surgeons. Breast Dis 2001;12:145-158.

31. Smith-Bindman R, Chu PW, Miglioretti DL, et al. Comparison of screening mammography in the United States and the United Kingdom. J Am Med Assoc 2003;290(16):2129-2137. 


$$
\text { yo }
$$




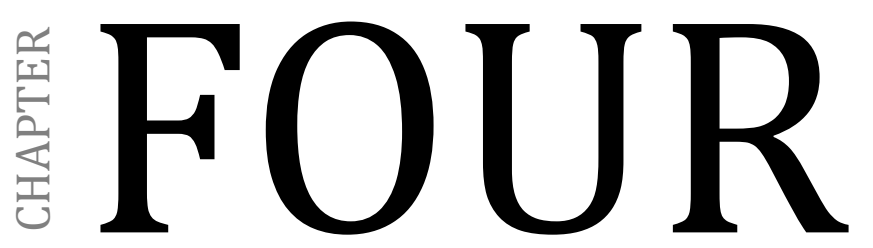

Trends in frequency and outcome of high-risk breast lesions at core needle biopsy in women recalled at biennial screening mammography, a multiinstitutional study

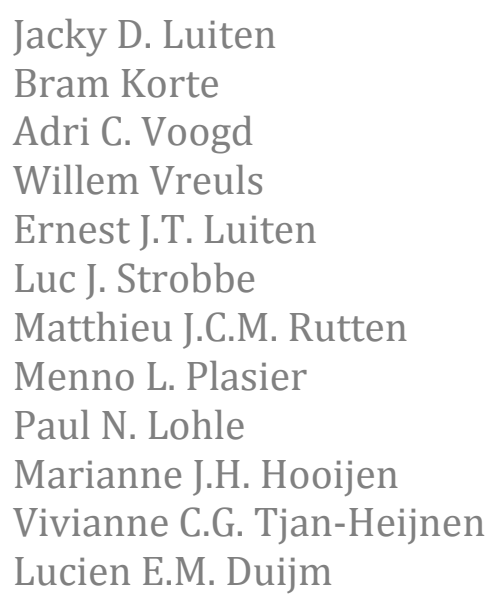




\section{Abstract}

Between January 1, 2011, and December 31, 2016, we studied the incidence, management and outcome of high-risk breast lesions in a consecutive series of 376,519 screens of women who received biennial screening mammography. During the 6-year period covered by the study, the proportion of women who underwent core needle biopsy (CNB) after recall remained fairly stable, ranging from $39.2 \%$ to $48.1 \%$ (mean: 44.2\%, 5,212/11,783), whereas the proportion of high-risk lesions at CNB (i.e., flat epithelial atypia, atypical ductal hyperplasia, lobular carcinoma in situ and papillary lesions) gradually increased from 3.2\% (25/775) in 2011 to $9.5 \%$ $(86 / 901)$ in $2016(p<0.001)$. The mean proportion of high-risk lesions at CNB that were subsequently treated with diagnostic surgical excision was $51.4 \%$ (169/329) and varied between $41.0 \%$ and $64.3 \%$ through the years, but the excision rate for high-risk lesions per 1,000 screens and per 100 recalls increased from 0.25 (2011) to $0.70(2016 ; p<0.001)$ and from 0.81 (2011) to 2.50 (2016; $p<0.001)$, respectively. The proportion of all diagnostic surgical excisions showing in situ or invasive breast cancer was 29.0\% (49/169) and varied from 22.2\% (8/36) in 2014 to $38.5 \%$ (5/13) in 2011. In conclusion, the proportion of high-risk lesions at CNB tripled in a 6-year period, with a concomitant increased excision rate for these lesions. As the proportion of surgical excisions showing in situ or invasive breast cancer did not increase, a rising number of screened women underwent invasive surgical excision with benign outcome.

\section{What's new?}

Screening mammography aims to catch breast cancer early to reduce associated morbidity and mortality. Women with suspect findings at mammography frequently are recalled for further testing with core needle biopsy (CNB). In this investigation, the proportion of high-risk lesions detected at CNB was found to have tripled among women in the Netherlands who underwent mammographic screening between 2011 and 2016. This increase was accompanied by an increase in lesion excision rates. Of excised lesions, little more than $14 \%$ proved to be malignant at two-year follow-up. The remainder of lesions exhibited benign pathology, suggesting that many women underwent potentially unnecessary surgery. 


\section{Introduction}

Many countries have implemented regional or nationwide screening mammography programs with the aim to detect breast malignancy at an early stage to decrease breast cancer related morbidity and mortality.1,2 Recalled women frequently have to undergo some kind of image-guided core needle biopsy in order to obtain a definite diagnosis for the abnormality detected at screening mammography. Women with benign biopsy results are usually encouraged to reattend the screening program and those diagnosed with malignant breast disease generally have an excellent prognosis after appropriate treatment. However, optimal management of so-called high-risk lesions, also known as risk-associated lesions (e.g.; flat epithelial atypia, papillary lesions, radial scar and lobular carcinoma in situ [LCIS]), found at core needle biopsy (CNB) is controversial. ${ }^{3-6}$ Communication between radiologists, pathologists and surgical oncologists is crucial to determine whether a high-risk lesion should either be monitored by regular radiologic follow-up imaging or whether excision can be considered. Stereotactic core needle biopsy (SCNB) is performed more often since the introduction of digital mammography in breast cancer screening, probably because digital mammography has a higher sensitivity for the detection of small calcifications compared to screen-film mammography. ${ }^{7}$ It is not clear, however, to which degree high-risk lesions are more frequently diagnosed in screened women. It also remains indistinct whether these lesions have a significant impact on the diagnostic surgical excision rate to obtain a final tissue diagnosis. Therefore, we determined trends in frequency, management and pathology outcome of high-risk breast lesions found at CNB in women who were recalled at a biennial screening mammography program in the south of the Netherlands. We determined the rate of "upgrade" to ductal carcinoma in situ (DCIS) or invasive carcinoma to support an evidence-based approach to the management of high-risk lesions. "Upgrade" was defined as a change of diagnosis into DCIS or invasive carcinoma at final pathology after diagnostic surgical excision for lesions, which originally were classified as high-risk lesions at CNB or SCNB.

\section{Materials and methods}

\section{Study population and screening procedure}

We included all screening mammography examinations obtained in a southern breast cancer screening region of the Netherlands between January 1, 2011, and 
December 31, 2016. Women aged 50-75 years are invited to attend biennial screening mammography, which is provided free of charge. Details of our nationwide screening program have been published previously. ${ }^{8}$ In summary, screen-film mammography was replaced by full-field digital mammography in 2009-2010. A two-view digital mammogram (mediolateral-oblique view and craniocaudal view) of each breast is obtained by a certified radiographer, after which the examination is assessed by two screening radiologists. Previous screening mammograms are always available for comparison. Radiologists classify mammographic abnormalities in women needing further evaluation (i.e., recall) into one of the following categories: (I) suspicious mass; (II) suspicious calcifications; (III) suspicious mass with calcifications; (IV) asymmetry; (V) architectural distortion; (VI) other. Women with normal findings (BI-RADS 1, Breast Imaging Reporting and Data System) or benign findings (BIRADS 2) are invited to reattend subsequent screening., 90 The BIRADS 3 classification is not used in the Dutch screening program. Women with BI-RADS 0,4 or 5 are recalled for further analysis at a breast unit of a hospital. BI-RADS 0 lesions comprise sharply demarcated masses, architectural distortions visible at one projection only and asymmetries visible at either one or both views. Masses with indistinct margins, suspicious microcalcifications and architectural distortions visible at both views are categorized as BI-RADS 4 lesions whereas BI-RADS 5 lesions consist of spiculated masses and suspicious masses showing calcifications.

\section{Assessment after recall and follow-up}

Twenty-five hospitals were involved in the workup of the recalled women. The majority of these women $(98.8 \%, 11,640 / 11,783)$ were analyzed in one of the seven hospitals centrally located in our screening region. Each of these seven hospitals has a dedicated surgical breast unit and state-of-the-art breast imaging equipment, whereas a total of four pathology departments deliver their services to these hospitals. At the hospital, additional imaging and biopsy procedures may be performed to establish a final diagnosis for the abnormality detected at screening mammography. We used the term CNB to cover all percutaneous histologic biopsy methods; ultrasound-guided CNB (CNB, 14-18G) as well as stereotactic CNB (SCNB, 9-11G). High-risk lesions at CNB were categorized as follows: (I) papillary lesion (consisting of papillary lesions, papillomas and papillomatosis); (II) columnar cell lesion, flat epithelial atypia; (III) atypical ductal hyperplasia; (IV) radial scar, complex sclerosing lesion; (V) LCIS, atypical lobular hyperplasia; (VI) combination of high-risk lesions; (VII) other (e.g., granular cell tumor, atypia without further specification at biopsy). In addition to the feedback that the hospitals gave to the 
screening organization with respect to final outcome, one of the screening radiologists obtained the reports of the radiologic examinations, the biopsy reports and surgical reports of all recalled women through regular visits at these hospitals. The follow-up period of the recalled women was two years, which is the period until the next biennial screening round.

Only women who gave written informed consent to use their data for quality assurance of the screening program and for scientific purposes were included in this analysis. Our study was performed under the national permit for breast cancer screening, which is issued by the Ministry of Health, Welfare and Sports after advice of the Dutch Health Council and did not require an additional ethical approval.

\section{Statistical analysis}

Trends over time and variations between subgroups were expressed using proportions. The chi-square test was used to compare proportional differences, or the Fischer's Exact Test when expected values were too small. Values of $p<0.05$ were considered statistically significant. Statistical analyses were performed using SPSS, version 24.0 (SPSS, Inc., Chicago, IL).

\section{Results}

\section{Overall screening outcome}

A total of 376,519 screens (41,204 initial screens and 335,315 subsequent screens) were obtained between January 1, 2011, and December 31, 2016 (Table 4.1). Invasive breast cancer or DCIS was diagnosed in 2,586 of the 11,783 recalled women (recall rate, $3.1 \%$ ), resulting in 6.9 cancers detected per 1,000 screens and a positive predictive value of recall of $21.9 \%$. Of the 2,586 screen-detected malignancies, 535 (20.7\%) were ductal in situ carcinomas and 2051 (79.3\%) were invasive cancers.

\section{Trends in frequency and outcome of high-risk lesions at CNB}

Of the recalled women $64.8 \%(7,634 / 11,783)$ had been recalled for a suspicious mass and $18.3 \%(2,162 / 11,783)$ for suspicious calcifications (Table 4.2). Over time these percentages varied between 56.4\% (2016) and 72.1\% (2013) and between $14.0 \%$ (2014) and 24.3\% (2011), respectively (Table 4.2). A significant increase in the number of asymmetries as mammographic abnormality was observed the last three years of the study period, from $5.2 \%$ in 2014 to $12.4 \%$ in $2016(p<0.001)$. 


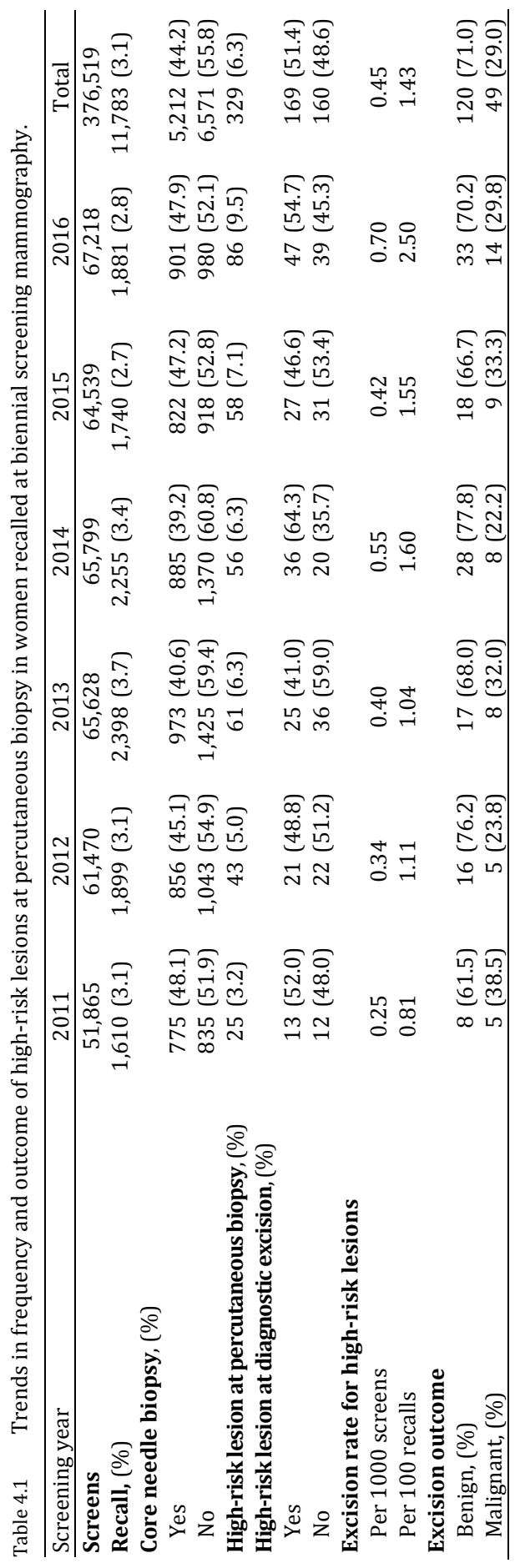




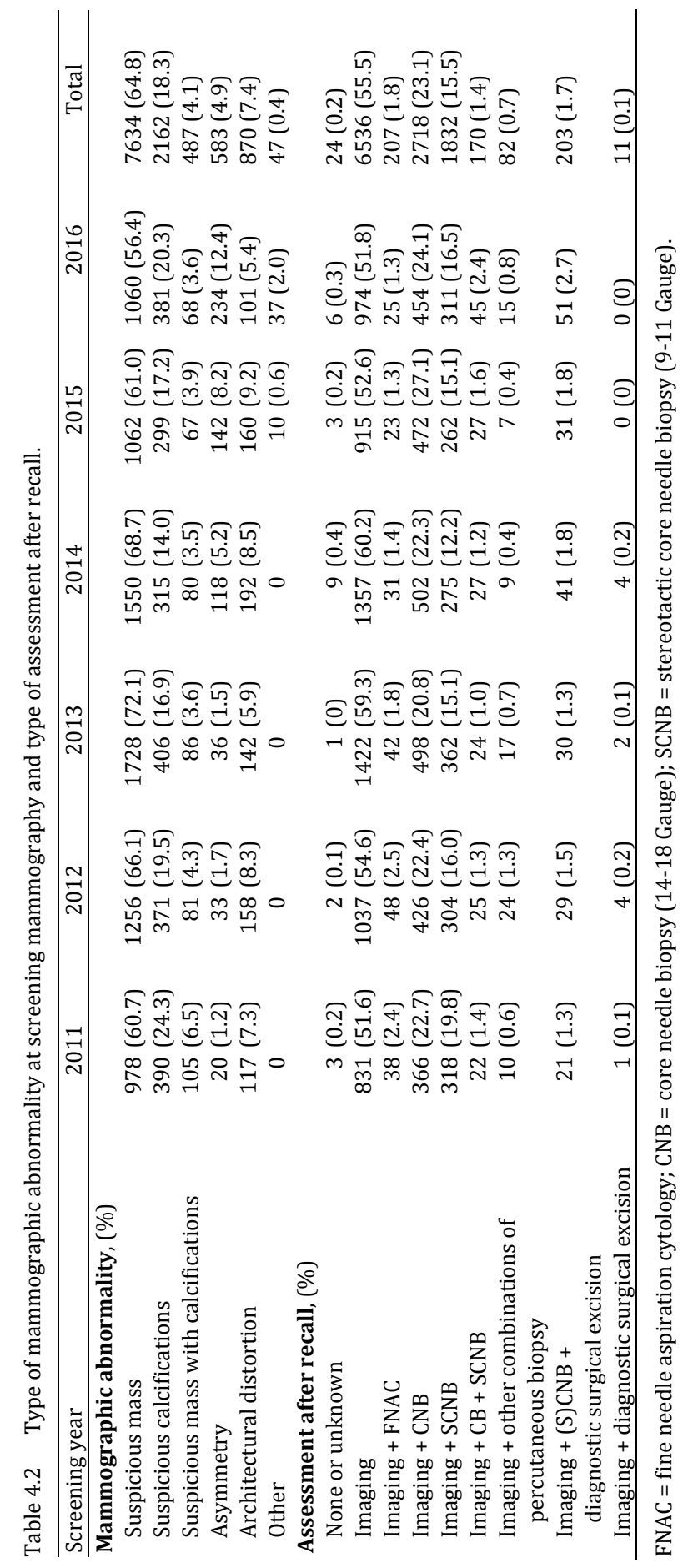


This increase came along with a significant decrease in masses as mammographic abnormality, from $68.7 \%$ in 2014 to $56.4 \%$ in 2016 ( $p<0.001$; Table 4.2). CNB was performed in 5,212 of the 11,783 recalled women $(44.2 \%)$, and varied between $39.2 \%$ (2014) and 48.1\% (2011) through the years (Table 4.1). A majority of these biopsies comprised ultrasound guided CNB (52.1\%, 2,718/5,212; 14-18 Gauge) and SCNB (35.1\%, 1,832/5,212; 9-11 Gauge, Table 4.2). The proportions of CNB and SCNB among all percutaneous biopsy procedures were comparable for the first and last screening year (CNB: 47.2\% in 2011 (366/775) vs. 50.4\% in 2016 (454/901; $p=0.449)$, SCNB: $41.0 \%$ in 2011 (318/775) vs. $34.5 \%$ in $2016(311 / 901 ; p=0.065)$. The proportion of high-risk lesions at CNB gradually increased from $3.2 \%(25 / 775)$ in 2011 to $9.5 \%$ (86/901) in 2016 ( $p<0.001$; Table 4.1). Suspicious masses and suspicious calcifications were the dominant mammographic features at recall in women with high-risk lesions at CNB (Table 4.3). Of the 329 high-risk lesions, $30.4 \%(100 / 329)$ and $55.3 \%(128 / 329)$ presented as a mass or calcification at screening mammography, respectively. During the multidisciplinary meetings, at which clinical, radiologic and biopsy results were correlated with each other, it was decided that additional diagnostic surgical excision was needed in 169 of the 329 women in whom high-risk lesions were found. The proportion of recalled women who underwent CNB followed by additional excision for diagnostic purposes doubled from $1.3 \%$ in $2011(21 / 1,610)$ to $2.7 \%$ in $2016(51 / 1,881, p=0.004$, Table 4.2). The proportion of high-risk lesions at CNB that was subsequently treated with diagnostic surgical excision varied between 41.0 and $64.3 \%$ through the years, with a mean of 51.4\%, (169/329). Diagnostic surgical excision for high-risk lesions per 1,000 screens and per 100 recalls significantly increased from 0.25 in 2011 to 0.70 in $2016(p<0.001)$ and from 0.81 in 2011 to 2.50 in $2016(p<0.001$; Table 4.1), respectively. The malignancy rate of the excisions ranged from $22.2 \%$ in 2014 (8/36) to $38.5 \%$ in 2011 (5/13; p=0.340), with $29.0 \%(49 / 169)$ of all excisions showing DCIS or invasive breast cancer.

Table 4.3 Mammographic abnormality of high-risk breast lesions at screening mammography.

\begin{tabular}{lcc}
\hline Mammographic lesion at recall & $n(\%)$ & $\begin{array}{c}\text { High-risk lesions, mammographic } \\
\text { abnormality at recall, } n(\%)^{*}\end{array}$ \\
\hline Suspicious mass & $7,634(64.8)$ & $100(1.3)$ \\
Suspicious calcifications & $2,162(18.3)$ & $182(8.4)$ \\
Suspicious mass with calcifications & $487(4.1)$ & $27(5.5)$ \\
Asymmetry & $583(4.9)$ & $4(0.7)$ \\
Architectural distortion & $870(7.4)$ & $11(1.3)$ \\
Other & $47(0.4)$ & $5(10.6)$ \\
\hline Total & 11,783 & 329 \\
\hline
\end{tabular}

* As proportion of total number of women recalled for this specific mammographic abnormality. 


\section{Histologic subtypes of high-risk breast lesions at CNB and outcome at two-year follow-up}

The most frequently diagnosed histologic subtypes among the 329 high-risk breast lesions at CNB were papillary lesions (35.3\%) and columnar cell lesions/flat epithelial atypia (24.0\%), followed by atypical ductal hyperplasia (19.1\%) and a combination of high-risk lesions (11.6\%; Table 4.4). Of the 329 high-risk lesions at CNB, whereof 169 were excised, 14.9\% (49/329) proved to be malignant at twoyear follow-up. The rate of upgrade to DCIS or invasive carcinoma was highest for CNB yielding atypical ductal hyperplasia (34.9\%; 22/63, 18 DCIS and four invasive carcinomas), followed by "other" lesions (30.0\%; 3/10, all invasive carcinomas) and papillary lesions (16.4\%; 19/116, 14 DCIS and five invasive carcinomas). The 41 malignancies, diagnosed in women with atypical ductal hyperplasia or papillary lesions at CNB, comprised 32 DCIS (of which 20 low grade) and nine invasive cancers (of which four low grade; Table 4.5). The histologic subtypes of high-risk breast lesions and year of diagnosis at CNB are presented in Table 4.6. No clear increase or decrease was observed in the diagnosis of the different histologic subtypes through the years, except for columnar cell lesions and flat epithelial atypia that were only diagnosed from 2012 onwards.

Table 4.4 Histologic subtypes of high-risk lesions at core needle biopsy and outcome at two-year follow-up.

\begin{tabular}{lccc}
\hline Histology & $n(\%)$ & Benign, $n(\%)$ & Malignant, $n(\%)$ \\
\hline Papillary lesion & $116(35.3)$ & $97(83.6)$ & $19(16.4)$ \\
Columnar cell lesion, flat epithelial atypia & $79(24.0)$ & $78(98.7)$ & $1(1.3)$ \\
Atypical ductal hyperplasia & $63(19.1)$ & $41(65.1)$ & $22(34.9)$ \\
Radial scar, complex sclerosing lesion & $10(3.0)$ & $9(90.0)$ & $1(10.0)$ \\
Lobular carcinoma in situ, atypical lobular & $13(4.0)$ & $13(100)$ & 0 \\
hyperplasia & & & \\
Combination of high-risk lesions & $38(11.6)$ & $35(92.1)$ & $3(7.9)$ \\
Other & $10(3.0)$ & $7(70.0)$ & $3(30.0)$ \\
Total & 329 & $280(85.1)$ & $49(14.9)$ \\
\hline
\end{tabular}

Table 4.5 Type and grading of malignancy in women with high-risk lesions at core needle biopsy.

\begin{tabular}{|c|c|c|c|c|c|c|}
\hline \multirow[t]{2}{*}{ Histology at percutaneous biopsy, $n$} & \multicolumn{3}{|c|}{ Ductal carcinoma in-situ } & \multicolumn{3}{|c|}{ Invasive cancer } \\
\hline & low & intermediate & high & $\mathrm{I}$ & II & III \\
\hline Papillary lesion & 10 & 3 & 1 & 2 & 1 & 2 \\
\hline Columnar cell lesion, flat epithelial atypia & 1 & & & & & \\
\hline Atypical ductal hyperplasia & 10 & 8 & & 2 & 2 & \\
\hline Radial scar, complex sclerosing lesion & & & & 1 & & \\
\hline Combination of high-risk lesions & 3 & & & & & \\
\hline Other & & & & 1 & & 2 \\
\hline Total & 24 & 11 & 1 & 6 & 3 & 4 \\
\hline
\end{tabular}




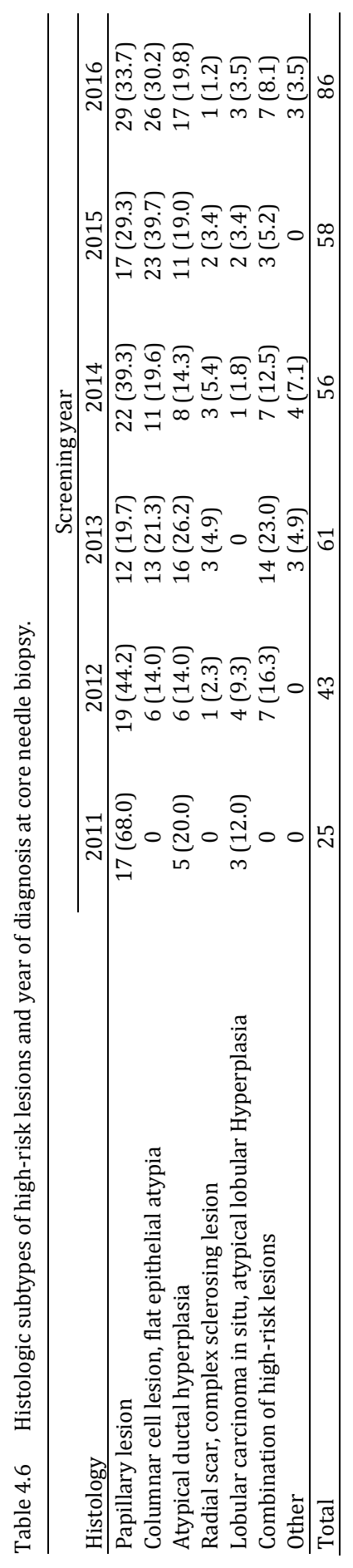




\section{Tumor characteristics of breast cancers diagnosed after diagnostic surgical excision of high-risk lesions}

The 49 high-risk lesions that were upgraded to malignancy at diagnostic surgical excision comprised 36 cases of DCIS and 13 invasive cancers (Table 4.7). The majority of these cancers were low grade DCIS or grade I invasive cancers $(61.2 \%$, $30 / 49$, Table 4.5). The proportion of DCIS was significantly higher in this group than in women whose CNB had yielded an unequivocal malignant diagnosis (73.5\%; 36/49 vs. $19.7 \%$; 500/2,537; $p<0.001)$ and DCIS grading was more favorable in the first group $(p<0.001)$. Invasive cancers were more frequently of the ductal type and more frequently showed axillary lymph node metastasis in women with proven breast cancer at CNB $(p<0.001)$ compared to women with high-risk lesions at CNB (Table 4.7). Estrogen and progesterone receptor status of invasive cancers, tumor size and type of surgical treatment (breast-conserving surgery vs. mastectomy) were comparable for both groups.

In one woman, who underwent radiologic follow up of a columnar cell lesion, an invasive ductal cancer (18 $\mathrm{mm}, \mathrm{B} \& \mathrm{R}$ grade II, no lymph node metastasis) was diagnosed at the previous biopsy site two years after recall. At two-year follow-up, no breast cancer was diagnosed in the remaining 159 women without surgical intervention for their high-risk lesions.

Table 4.7 Comparison of tumor characteristics and type of surgery among women with a high-risk lesion versus malignancy at percutaneous biopsy.

\begin{tabular}{lccc}
\hline & $\begin{array}{c}\text { High-risk } \\
\text { lesion at biopsy }\end{array}$ & $\begin{array}{c}\text { Cancer at } \\
\text { biopsy }\end{array}$ & $P$-value \\
\hline Cancers & 49 & 2537 & \\
Tumor type (\%) & & & $<0.001$ \\
$\quad$ DCIS & $36(73.5)$ & $500(19.7)$ & \\
Invasive & $13(26.5)$ & $2037(80.3)$ & \\
Unknown & $0(0)$ & $0(0)$ & $<0.001$ \\
DCIS grading (\%) & & & \\
Low grade & $24(66.7)$ & $79(15.8)$ & \\
Intermediate grade & $11(30.6)$ & $181(36.2)$ & \\
High grade & $1(2.7)$ & $240(48.0)$ & \\
Type of invasive cancer (\%) & $9(69.2)$ & $1597(78.4)$ & \\
Ductal & $0(0)$ & $261(12.8)$ & \\
Lobular & $0(0)$ & $65(3.2)$ & \\
Mixed ductal/lobular & $4(30.7)$ & $114(5.6)$ & \\
Other & $0(0)$ & $0(0)$ & \\
Unknown & & & \\
Tumor size of invasive cancers (\%) & $12(92.3)$ & $1622(79.6)$ & \\
T1a-c & $1(7.7)$ & $411(20.2)$ & \\
T2+ & $0(0)$ & $49.2)$ & \\
Unknown & & &
\end{tabular}


Table 4.7 (continued)

\begin{tabular}{|c|c|c|c|}
\hline & $\begin{array}{c}\text { High-risk } \\
\text { lesion at biopsy }\end{array}$ & $\begin{array}{c}\text { Cancer at } \\
\text { biopsy }\end{array}$ & $P$-value \\
\hline Lymph-node status of invasive cancers (\%) & & & $<0.001$ \\
\hline $\mathrm{N}+$ & $0(0)$ & 447 (21.9) & \\
\hline No & $9(69.2)$ & $1543(75.7)$ & \\
\hline Unknown & $4(30.8)$ & $47(2.3)$ & \\
\hline Grade (\%) & & & 0.172 \\
\hline $\mathrm{B} \& \mathrm{R} I$ & $6(46.2)$ & $889(43.6)$ & \\
\hline B\&R II & $3(23.1)$ & $889(43.6)$ & \\
\hline B\&R III & $4(20.7)$ & $238(11.7)$ & \\
\hline Unknown & $0(0)$ & $21(1.0)$ & \\
\hline Estrogen receptor $(\%)$ & & & 0.065 \\
\hline Positive & $9(69.2)$ & $1838(90.2)$ & \\
\hline Negative & $4(30.8)$ & 189 (9.3) & \\
\hline Unknown & $0(0)$ & $10(0.5)$ & \\
\hline Progesterone receptor (\%) & & & 0.114 \\
\hline Positive & $6(38.5)$ & $1469(72.1)$ & \\
\hline Negative & $7(61.5)$ & $558(27.4)$ & \\
\hline Unknown & $0(0)$ & $10(0.5)$ & \\
\hline Her2/Neu receptor (\%) & & & 0.166 \\
\hline Positive & $3(23.1)$ & $185(9.1)$ & \\
\hline Negative & $10(76.9)$ & $1842(90.4)$ & \\
\hline Unknown & $0(0)$ & $10(0.5)$ & \\
\hline Triple receptor - negative (\%) & $3(21.4)$ & $129(6.3)$ & 0.739 \\
\hline Type of final surgical treatment, (\%) & & & 0.207 \\
\hline Breast conserving surgery & $41(83.7)$ & $2067(81.5)$ & \\
\hline Mastectomy & $6(12.2)$ & $437(17.2)$ & \\
\hline No surgery performed* & $2(4.1)$ & $28(1.1)$ & \\
\hline Unknown & $0(0)$ & $5(0.2)$ & \\
\hline
\end{tabular}

DCIS = ductal carcinoma in-situ; B\&R = Bloom \& Richardson. $*$ upgraded after follow up with repeated stereotactic biopsy

\section{Discussion}

In a six-year screening period, we observed a threefold increase in the proportion of high-risk lesions diagnosed at CNB. The excision rate for these lesions per 1,000 screens and per 100 recalls also tripled. The overall upgrade rates of highrisk breast lesions to (in situ) malignancy after excision was 29.0\%. Tumor characteristics were distinctively different for cancers diagnosed after upgrading of a high-risk lesion compared to cancers with an unequivocal malignant outcome at CNB.

A Dutch study, performed shortly after the implementation of full-field digital screening mammography, reported that microcalcifications were more often diagnosed, compared to screen-film mammography. This resulted in more CNB, 
which was associated with an increase in the absolute number of columnar cell lesions during the digital screening period. ${ }^{11}$ We found that the incidence of highrisk lesions at CNB continued to increase, even many years after the transition from screen-film to digital screening mammography. Weber et al. also found that the recall rate for suspicious calcifications remained significantly higher at digital screening, resulting in a permanently higher CNB rate for these lesions per 1,000 screens, compared to the period of screen-film mammography. ${ }^{7}$ We observed a significant increase in the number of asymmetries as mammographic abnormality during the last three years of inclusion, as well as a significant decrease in the number of suspicious masses as reason for recall. This finding, however, does not explain the gradual increase in the proportion of high-risk lesions, as the vast majority of these lesions presented as a suspicious mass or suspicious calcifications at screening mammography. The type of radiologic assessment at recall showed no significant changes through the years, therefore this parameter cannot explain the increase in the proportion of high-risk lesions. A possible explanation might be the increased awareness for both the detection and report of high-risk lesions at CNB among pathologists. ${ }^{12}$ The four departments of pathology from which data were derived for this study did not change their scoring protocol during the study period. In 2016, a protocol for structured reporting for surgical breast specimen was introduced in the Netherlands. However, the increase of high-risk lesion already started several years before the introduction of this protocol.

The optimal management of high-risk lesions remains a subject of debate. Falomo et al. reported serious inconsistencies in the management of these lesions at academic institutions across the United States, with surgical excision rates ranging from $39 \%$ to $95 \%$ between centers. ${ }^{5}$ Several studies advocate radiologic imaging follow-up for nonatypical papillomas as the malignancy rate of these lesions may be less than $2.5 \%, 13,14$ whereas others have found that up to $33 \%$ of these lesions may prove malignant and therefore recommend complete surgical excision. ${ }^{15}$ Considerable variation in the upgrading of flat epithelial atypia, atypical ductal hyperplasia, LCIS/atypical lobular hyperplasia and radial scar to malignancy has been reported (flat epithelial atypia: 0\%-15\%, atypical ductal hyperplasia: 22\%$32 \%$, LCIS/atypical lobular hyperplasia: 2\%-29\%, radial scar: 0\%-23\%), resulting in mixed recommendations that range from radiologic surveillance to diagnostic surgical excision of every high-risk lesion. ${ }^{16-26}$ In our series, $29 \%$ of excised highrisk lesions proved to be malignant; $20.7 \%$ DCIS and $8.3 \%$ invasive breast cancer, respectively. Other studies report a somewhat lower likelihood of upgrading to malignancy of $20 \%-22 \% \cdot{ }^{18,19}$ However, comparisons between studies may be 
hampered by the use of different biopsy techniques and differences in the distribution of the subtypes of high-risk lesions found at biopsy.

As the proportion of high-risk lesions being upgraded to malignancy remained stable over the years, the increased excision rate of these lesions resulted in an increasing number of women with a benign outcome after diagnostic surgical excision. Although a recent US study found that reattendance to a screening mammography program is not lower in women with benign surgical excision after recall, ${ }^{6}$ the use of this type of excision for diagnostic purposes should be kept to a minimum as it lowers the sensitivity of future screening mammography for cancer detection. ${ }^{27}$

Tumor characteristics were generally more favorable for high-risk lesions upstaged to breast cancer than for cancers with an unequivocal diagnosis of malignancy at CNB, with a higher proportion of DCIS and the absence of lymph node positive invasive cancers in the first group in case of simultaneous sentinel lymph node biopsy. Tumor stage and grading of invasive cancers, as well as type of final surgical treatment, were comparable for both groups. Although almost half of the upstaged high-risk lesions comprised low grade DCIS, the presence of intermediate grade and high grade invasive cancers on the other hand may lead surgical oncologists to decide for lesion excision rather than radiologic and clinical surveillance. With the changing opinion of surgical excision for low grade DCIS towards close surveillance in the near future, low grade DCIS could have been included as a high-risk lesion in our study. However, the clinical trials comparing surgery with active surveillance of DCIS $^{28,29}$ are still ongoing and none have reported any results yet confirming the safety of active surveillance. As a consequence, surgical excision was and still is the most widely accepted treatment for low grade DCIS. Taking all of the aforementioned into account we felt that considering low grade DCIS as high-risk lesions is not justified yet.

However, considering the fact that close follow up of low grade DCIS currently is subject of several prospective studies, ${ }^{28,29}$ our study shows that when a diagnostic surgical excision of high-risk lesions at CNB is performed, more than $85 \%$ of all excisions (71\% [120/169] benign pathology and 14.2\% [24/169] low grade DCIS) may be preventable in the near future. In order to decrease this number of potentially unnecessary surgical excisions, one may opt for vacuum-assisted excision of high-risk lesions as an alternative to surgical excision. ${ }^{30-32}$

Our study has certain strengths and limitations. To the best of our knowledge, it is the first study that describes trends in the detection of high-risk lesions in a screened population. Furthermore, two-year follow-up was virtually complete for all recalled women. On the other hand, comparison of the management and 
outcome of these lesions with other studies is limited as they show considerable heterogeneity in the type of biopsy procedures and subtyping of high-risk lesions.

Although we included a large consecutive series of screening mammograms, no more than 329 high-risk lesions were diagnosed leaving some of the subgroups too small for a proper analysis. Moreover, only multiple (more than one) papillomas in the same breast are associated with a higher risk of developing breast cancer. Unfortunately, we were not able to fully discriminate solitary papilloma from multiple papillomas in all cases, which is a limitation for the papillary lesion group. In conclusion, a significant increase in the proportion of high-risk lesions detected at CNB was observed, with a concomitant increased excision rate for these lesions resulting in an increasing number of screened women who underwent invasive diagnostic surgical excision with benign outcome at final pathology. Larger studies are needed to define evidence-based practice recommendations for the management of high-risk lesions detected at CNB. 


\section{References}

1. Dowling EC, Klabunde C, Patnick J, et al. Breast and cervical cancer screening programme implementation in 16 countries. J Med Screen 2010;17:139-146.

2. Sankatsing VDV, van Ravesteyn NT, Heijnsdijk EAM, et al. The effect of populationbased mammography screening in Dutch municipalities on breast cancer mortality: 20 years of followup. Int J Cancer 2017;141:671-677.

3. Neal L, Sandhu NP, Hieken TJ, et al. Diagnosis and management of benign, atypical, and indeterminate breast lesions detected on core needle biopsy. Mayo Clin Proc 2014;89:536-547.

4. Calhoun BC. Core needle biopsy of the breast: an evaluation of contemporary data. Surg Pathol Clin 2018;11:1-16.

5. Falomo E, Adejumo C, Carson KA, et al. Variability in the management recommendations given for high-risk breast lesions detected on imageguided Core needle biopsy at U.S. academic institutions. Curr Probl Diagn Radiol 2019;48(5):462-466.

6. Gao Y, Albert M, Young Lin LL, et al. What happens after a diagnosis of high-risk breast lesion at stereotactic vacuum-assisted biopsy? An observational study of postdiagnosis management and imaging adherence. Radiology 2018;287:423-431.

7. Weber RJ, Nederend J, Voogd AC, et al. Screening outcome and surgical treatment during and after the transition from screen-film to digital screening mammography in the south of The Netherlands. Int J Cancer 2015;137:135-143.

8. Klompenhouwer EG, Voogd AC, den Heeten GJ, et al. Blinded double reading yields a higher programme sensitivity than non-blinded double reading at digital screening mammography: a prospected population based study in the south of The Netherlands. Eur J Cancer 2015;51: 391-399.

9. BI-RADS Committee. ACR BI-RADS atlas: breast imaging reporting and data system, 5th edn. Reston, VA: American College of Radiology, 2013.

10. BI-RADS Committee. ACR BI-RADS atlas: breast imaging reporting and data system, 4 th edn. Reston, VA: American College of Radiology, 2003.

11. Verschuur-Maes $\mathrm{AH}$, van Gils $\mathrm{CH}$, van den Bosch $\mathrm{MA}$, et al. Digital mammography: more microcalcifications, more columnar cell lesions without atypia. Mod Pathol 2011;24:1191-1197.

12. Reisch LM, Carney PA, Oster NV, et al. Medical malpractice concerns and defensive medicine: a nationwide survey of breast pathologists. Am J Clin Pathol 2015;144:916-922.

13. Pareja F, Corben AD, Brennan SB, et al. Breast intraductal papillomas without atypia in radiologicpathologic concordant core-needle biopsies: rate of upgrade to carcinoma at excision. Cancer 2016;122:2819-2827.

14. Grimm LJ, Bookhout CE, Bentley RC, et al. Concordant, non-atypical breast papillomas do not require surgical excision: a 10-year multiinstitution study and review of the literature. Clin Imaging 2018;51:180-185.

15. Shiino S, Tsuda H, Yoshida M, et al. Intraductal papillomas on core biopsy can be upgraded to malignancy on subsequent excisional biopsy regardless of the presence of atypical features. Pathol Int 2015;65:293-300.

16. Shah-Khan MG, Geiger XJ, Reynolds C, et al. Long-term follow-up of lobular neoplasia (atypical lobular hyperplasia/lobular carcinoma in situ) diagnosed on core needle biopsy. Ann Surg Oncol 2012;19:3131-3138.

17. Murray MP, Luedtke C, Liberman L, et al. Classic lobular carcinoma in situ and atypical lobular hyperplasia at percutaneous breast core biopsy: outcomes of prospective excision. Cancer 2013;119:1073-1079.

18. Lourenco AP, Khalil H, Sanford M, et al. Highrisk lesions at MRI-guided breast biopsy: frequency and rate of underestimation. AJR Am J Roentgenol 2014;203:682-686.

19. Heller SL, Elias K, Gupta A, et al. Outcome of high-risk lesions at MRI-guided 9-gauge vacuumassisted breast biopsy. Am J Roentgenol 2014;202:237-245. 
20. Sen LQ, Berg WA, Hooley RJ, et al. Core breast biopsies showing lobular carcinoma in situ should be excised and surveillance is reasonable for atypical lobular hyperplasia. Am J Roentgenol 2016;207:1132-1145.

21. Mooney KL, Bassett LW, Apple SK. Upgrade rates of high-risk breast lesions diagnosed on core needle biopsy: a single-institution experience and literature review. Mod Pathol 2016;29: 1471-1484.

22. Donaldson AR, Sieck L, Booth CN, et al. Radial scars diagnosed on breast core biopsy: frequency of atypia and carcinoma on excision and implications for management. Breast (Edinburgh, Scotland) 2016;30:201-207.

23. Rudin AV, Hoskin TL, Fahy A, et al. Flat epithelial Atypia on Core biopsy and upgrade to cancer: a systematic review and meta-analysis. Ann Surg Oncol 2017;24:3549-3558.

24. Ouldamer L, Poisson E, Arbion F, et al. All pure flat atypical atypia lesions of the breast diagnosed using percutaneous vacuum-assisted breast biopsy do not need surgical excision. Breast (Edinburgh, Scotland). 2018;40:4-9.

25. Speer ME, Huang ML, Dogan BE, et al. High risk breast lesions identified on MRI-guided vacuumassisted needle biopsy: outcome of surgical excision and imaging follow-up. Br J Radiol 2018;91:20180300.

26. Chou WYY, Veis DJ, Aft R. Radial scar on imageguided breast biopsy: is surgical excision necessary? Breast Cancer Res Treat 2018;170:313-320.

27. van Breest Smallenburg V, Duijm LE, Voogd AC, et al. Lower sensitivity of screening mammography after previous benign breast surgery. Int J Cancer 2012;130:122-128.

28. Elshof LE, Tryfonidis K, Slaets L, et al. Feasibility of a prospective, randomised, open-label, international multicentre, phase III, non-inferiority trial to assess the safety of active surveillance for low risk ductal carcinoma in situ—the LORD study. Eur J Cancer 2015;51:1497-1510.

29. Francis A, Thomas J, Fallowfield L, et al. Addressing overtreatment of screen-detected DCIS; the LORIS trial. Eur J Cancer 2015;51:2296-2303.

30. Rageth CJ, O'Flynn EA, Comstock C, et al. First international consensus conference on lesions of uncertain malignant potential in the breast (B3 lesions). Breast Cancer Res Treat 2016;159: 203-213.

31. Pieri A, Hemming D, Westgarth J, et al. Vacuumassisted biopsy is a viable alternative to surgical biopsy in the investigation of breast lesions of uncertain malignant potential. Surgeon 2017;15: 59-64.

32. Rageth CJ, O’Flynn EAM, Pinker K, et al. Second international consensus conference on lesions of uncertain malignant potential in the breast (B3 lesions). Breast Cancer Res Treat 2019;174: 279-296. 


$$
\text { yo }
$$




\section{FIVE}

Recall and outcome of screen-detected microcalcifications during two decades of mammography screening in the Netherlands national breast screening program 


\section{Abstract}

Background

Trends in the detection of suspicious microcalcifications at mammography screening and the yield of these lesions after recall are unknown.

Purpose

To determine trends in recall and outcome of screen-detected microcalcifications during 20 years of mammography screening.

Materials and methods

The authors performed a retrospective analysis of a consecutive series of 817,656 screening examinations (January 1997 to January 2017) in a national breast screening program. In 2009-2010 (transition period), screen-film mammography (SFM) was gradually replaced by full-field digital mammography (FFDM). The recalls of suspicious microcalcifications from all radiology reports and pathologic outcome of recalled women with two-year follow-up were analyzed. Screening outcome in the era of SFM (1997-2008), the transition period (2009-2010), and the era of FFDM (2011-2016) were compared. Trends over time and variations between the SFM and FFDM periods were expressed by using proportions with 95\% confidence intervals (CI). In cases where the analysis based on the CI confirmed clear periods (eg, before and after introduction of FFDM), pre- and postchange outcomes were compared by using chi-square tests.

Results

A total of 18,592 women (median age, 59 years; interquartile range, 14 years) were recalled at mammography screening, 3556 of whom had suspicious microcalcifications. The recall rate for microcalcifications increased from $0.1 \%$ in $1997-1998$ to $0.5 \%$ in $2015-2016(p<.001)$. This was temporally associated with the change from SFM to FFDM. The recalls yielding ductal carcinoma in situ (DCIS) increased from 0.3 per 1000 screening examinations with SFM to 1.1 per 1000 screening examinations with FFDM $(p<0.001)$, resulting in a decrease in the positive predictive value for recall for suspicious microcalcifications from $51 \%$ to $33 \%(p<0.001)$. More than half of all DCIS lesions were high grade $(52.6 \% ; 393$ of 747). The distribution of DCIS grades was stable during the 20 -year screening period $(p=0.36)$.

\section{Conclusion}

The recall rate for suspicious microcalcifications at mammographic screening increased during the past two decades, whereas the ductal carcinoma in situ detection rate increased less rapidly, resulting in a lower positive predictive value for recall. 


\section{Introduction}

Fine calcifications of the breast, so-called microcalcifications, were first described by the German surgeon Salomon in 1913. ${ }^{1}$ They are defined as tiny grouped calcareous deposits in terminal ductal lobular units of the breast and originate from intraluminal secretions or necrosis of epithelial cells. Microcalcifications visible at mammography may be an early sign-and sometimes even the only sign-of underlying early breast cancer or ductal carcinoma in situ (DCIS). ${ }^{2-4}$ Up to $90 \%$ of DCIS is not palpable and is diagnosed at the work-up of suspicious microcalcifications seen at mammography.5,6

Following the introduction of a nationwide biennial mammography screening program in the Netherlands in 1989, a considerable increase in the incidence of DCIS has been reported.7,8

Moreover, the replacement of screen-film mammography (SFM) by full-field digital mammography (FFDM) in the Dutch mammography screening program between 2009 and 2010 (transition period) further contributed to this increase. ${ }^{7-9}$

Since 1995, data on all screened women in the southern region of the Netherlands have been recorded in a database. This database is used for quality assurance and improvement of the screening program. We have recently reported on the overall trends in incidence and tumor grade of screen-detected DCIS and invasive carcinoma and the use of surgical excision biopsies during two decades of mammography screening. ${ }^{9,10}$

Most DCIS lesions are detected at mammography screening by the presence of microcalcifications. However, not all microcalcifications found at screening are related to underlying DCIS. Little is known about the trends in the detection of microcalcifications at mammography screening and the yield of these findings after recall. Digital mammography has a higher sensitivity than SFM for the detection of microcalcifications, resulting in increased recall rates for calcifications during the transition from SFM to FFDM screening. ${ }^{11}$ Furthermore, once microcalcificationassociated DCIS is diagnosed, the potential for overdiagnosis and overtreatment, especially with low grade DCIS, is a serious concern.

Therefore, the purpose of this study was to determine the trends in recall of suspicious microcalcifications and their outcomes during two decades of mammography screening. We analyzed the yield of microcalcifications, expressed as the cancer detection rate (CDR; the number of [pre]malignant abnormalities per 1000 screening examinations) and the histologic grade at current digital mammography screening compared with that in the era of SFM. More specifically, we determined to which degree the changes in recall of microcalcifications and the 
histologic grade of DCIS, observed during the transition from SFM screening to digital screening, persisted several years after this transition.

\section{Materials and methods}

\section{Mammography screening program and study cohort}

A biennial nationwide mammography screening program was introduced in the Netherlands between 1989 and 1996 for all women aged 50-70 years. Between 1998 and 1999, the upper age limit was extended to 75 years. In the southern part of the Netherlands, SFM was gradually replaced by FFDM between May 2009 and April 2010. The Dutch screening program has been described in more detail previously.7,12-14 In summary, all screening mammograms are obtained by certified radiographers, after which the images are routinely double-read by certified screening radiologists. The radiologists classify the mammographic abnormality in case of recall (suspicious mass, suspicious microcalcifications, suspicious mass in combination with microcalcifications, asymmetry, architectural distortion, or other suspicious abnormality). A Breast Imaging Reporting and Data System (BIRADS) category is routinely provided in clinical breast imaging reports after 2001.15,16 Recalled women are then referred by their general practitioner to a hospital breast unit for further analysis. In case of a false-positive recall, a woman returns to the screening program and is screened with the same frequency (biennial) as all other women who attend the program.

We retrospectively analyzed all women who attended the breast cancer screening program at four specialized breast cancer screening units in a southern part of the Netherlands between January 1997 and January 2017. Our study population consisted of a consecutive series of 817,656 screening examinations. Women participating in the screening program were offered the option to opt out of the use of their data for quality assessment and scientific purposes. Three recalled women refrained from giving permission and were excluded from analysis. According to the Dutch Central Committee on Research involving Human Subjects, ethical approval was not required for our study.

The authors declare no conflict of interest. This research did not receive any specific grant from funding agencies in the public, commercial, or not-for-profit sectors. 


\section{Follow-up of recalled women}

During a two year follow-up period (until the next biennial screening examination), we collected the radiology reports, type of biopsy methods with their outcome, and breast surgery reports of all recalled women. The screening organization routinely received the follow-up data from the hospitals at which the women were analyzed after recall. To complete two year follow-up, one of the radiologists (LD, with $>25$ years of experience in breast imaging) and several radiology residents collected additional reports, which were not received by the screening organization, through visits at these departments. All data were then entered into a database, which was created for quality control of the screening program and scientific purposes by the radiologist. The quality of data entry was not reviewed.

If a woman was recalled for more than one ipsilateral lesion or for one lesion in the right breast and one in the left breast (bilateral) during the same screening round, the mammographic lesion with the highest suspicion at mammography screening was considered as the index lesion for recall. For the purpose of this study, we scored one screening abnormality per recalled woman. If a woman was recalled again in a subsequent screening round, this counted as a new recall. A total of 60 women were recalled twice, and two were recalled three times. Only four women, one of whom had microcalcifications, experienced a repeated recall within the same two year period.

Screen-detected cancers were divided into DCIS and invasive cancers. Lobular carcinoma in situ is considered a benign lesion. Details on the methods for the detection of interval cancers in our screened cohort have been published previously. ${ }^{17,18}$

\section{Statistical analysis}

The main outcome measure of this study was the number of microcalcification recalls per 1000 screening examinations and positive predictive value (PPV) of microcalcification recalls during two decades of mammography screening. These trends are shown as graphs and reported as absolute numbers, proportions, PPVs with 95\% confidence intervals (CI), and rates per 1000 screening examinations for women screened from 1997 until 2017. Evaluation of the CIs over time, treating nonoverlapping $\mathrm{CIs}$ as evidence of difference, then provides conservative assessment of trends ${ }^{19}$ that fit the graphical presentation and does not go beyond the limitations in the data. To allow clear interpretation of the data, results are presented separately for first (initial) screening examinations of participating women and subsequent screening examinations. The limitations of the data did not 
allow further refinement, and thus correlations due to the same women being screened more than once could not be modeled. In case the analysis based on CIs enabled clear differentiation of separate periods, such as before (through 2007 and 2008) and after (from 2011 to 2012) introduction of FFDM, pre- and postchange outcomes were compared by using chi-square tests in addition to summary statistics. Interpretation of the tests is exploratory, rather than confirmatory. Preoperative DCIS confirmation was evaluated descriptively only.

The median differences and interquartile ranges were calculated for continuous variables. Statistical analyses were performed by using commercially available software (SPSS, version 22.0; SPSS, Chicago, Ill).

\section{Results}

\section{Overall screening results}

A total of 817,656 mammography screening examinations were performed between January 1997 and January 2017. Of those 817,656 examinations, 97,541 (11.9\%) were initial screening examinations and 720,115 (88.1\%) were subsequent screening examinations. The median age of recalled women was 59 years (interquartile range, 14). Figure 5.1 shows a flowchart of the study participants.

The number of screening examinations increased from 48,721 in 1997-1998 to 131,757 in 2015-2016 (Table 5.1). Of the 817,656 women, 18,592 (2.3\%) were recalled for further analysis of a suspicious lesion at mammography screening; the overall recall proportion was 4.7\% (95\% CI: 4.6\%-4.9\%; 4612/97,541) at initial screening examination and 1.9\% (95\% CI: 1.9\%-1.9\%; 13,980/720,115) at subsequent screening examinations.

From the trend analysis (Table 5.1), the recall rate for initial screening examinations increased from 2.3\% $(1039 / 46,155)$ during the SFM period (1997$1998)$ to $5.5 \%(558 / 10,182)$ during the transition period $(p<0.001)$ and to $7.3 \%$ $(3015 / 41,204)$ during the FFDM period (2011-2016; $p<0.001)$. The recall rate for subsequent screening examinations increased in the same period, from $1.1 \%$ $(3413 / 304,854)$ in the SFM period to $2.3 \%(1801 / 79,946 ; p<0.001)$ in the transition period and to $2.6 \%(8766 / 335,315)$ in the FFDM period $(p<0.001$; Table 5.1). Combined, these led to an increase of the overall recall rate from $1.3 \%$ $(4452 / 351,009)$ during the SFM period to $3.1 \%(11,781 / 376,519)$ during the FFDM period $(p<0.001)$. 


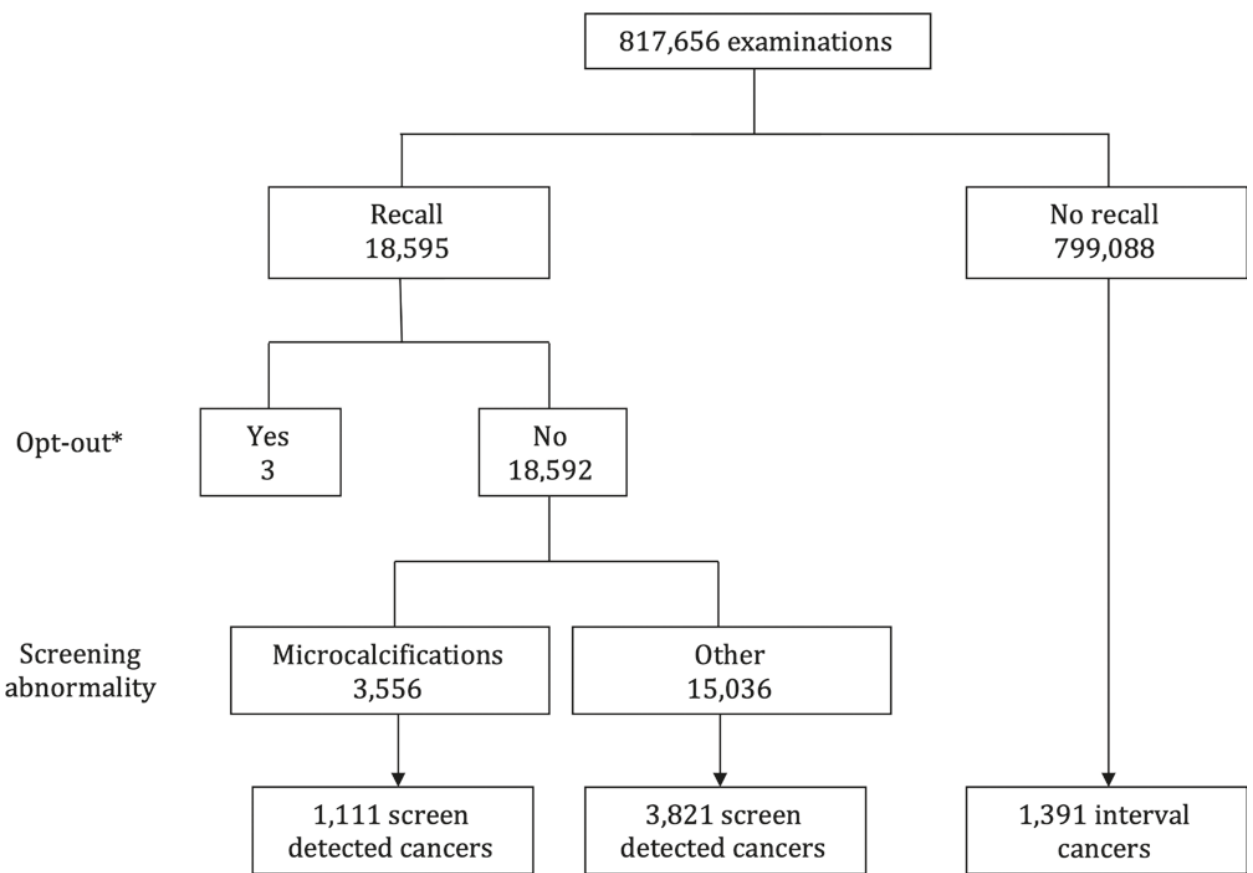

Figure 5.1 Flowchart of the study population. * The screening program requires women to 'opt-out' of mammography screening and/or use of their data.

\section{Trends in recall of suspicious microcalcifications}

Of the 817,656 women who underwent screening examinations, $3556(0.4 \%)$ were recalled because of microcalcifications. The absolute number of women recalled with microcalcification abnormalities increased from 51 in 1997-1998 $0.1 \%$ of 48,721 screening examinations) to 680 in $2015-2016$ ( $0.5 \%$ of 131,757 screening examinations (Table 5.2). The trend in proportion of recalls for microcalcifications was very similar to the trend for recalls overall, with an increase from $0.2 \%(95 \%$ CI: $0.1 \%-0.3 \%$; $17 / 9602$ ) for initial screening examinations in 1997-1998 to $1.3 \%$ (95\% CI: 1.1\%-1.4\%; 179/220) in 2015-2016 (Table 5.2) (SFM period vs. FFDM period, $p<0.001$ ). Subsequent screening examinations showed a similar pattern but with substantially smaller proportions. 


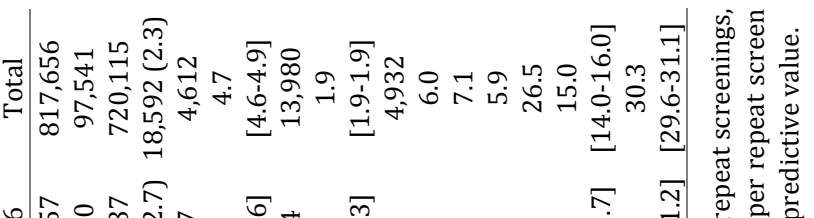

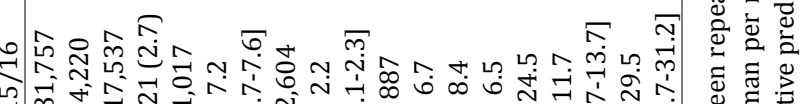

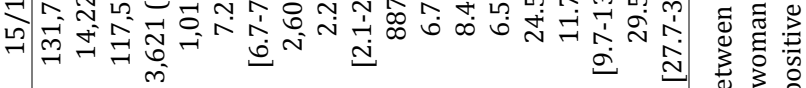

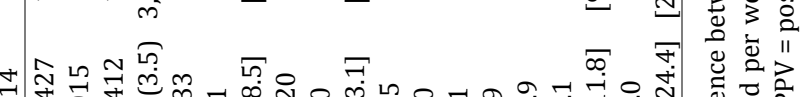

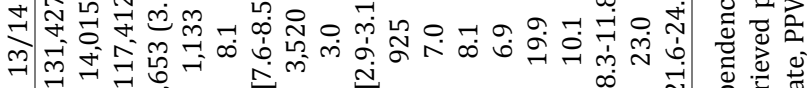

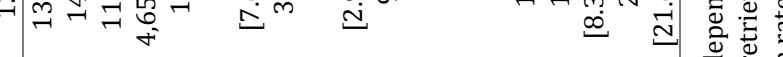

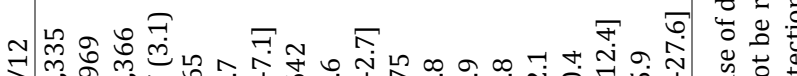

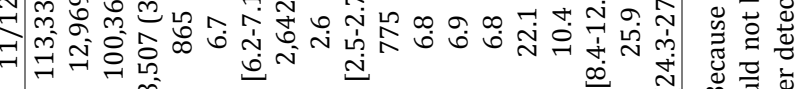

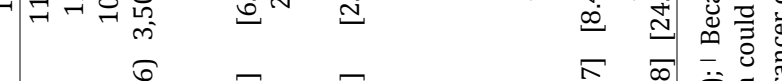

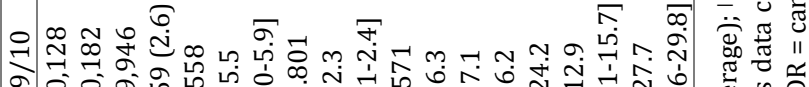

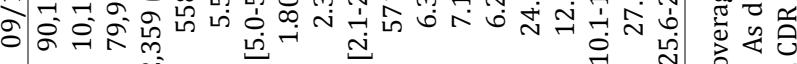
œ

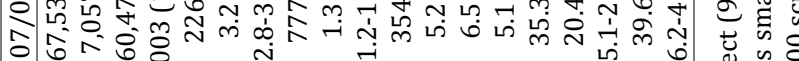
$\circ$ 이 $\quad$ i

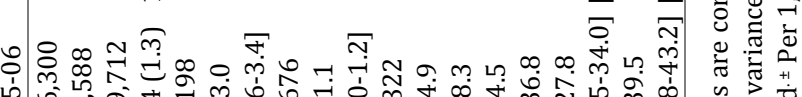

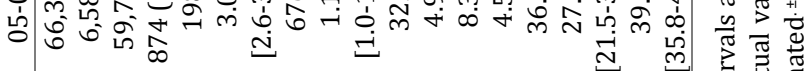

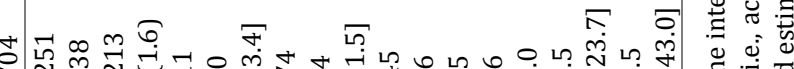

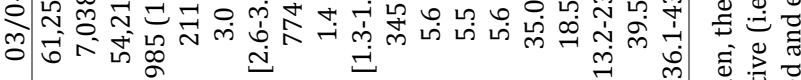

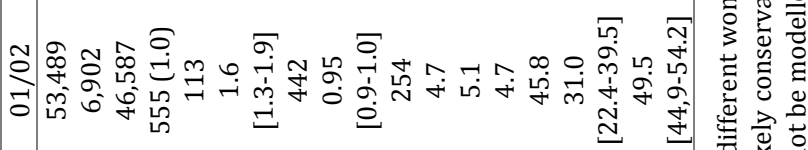

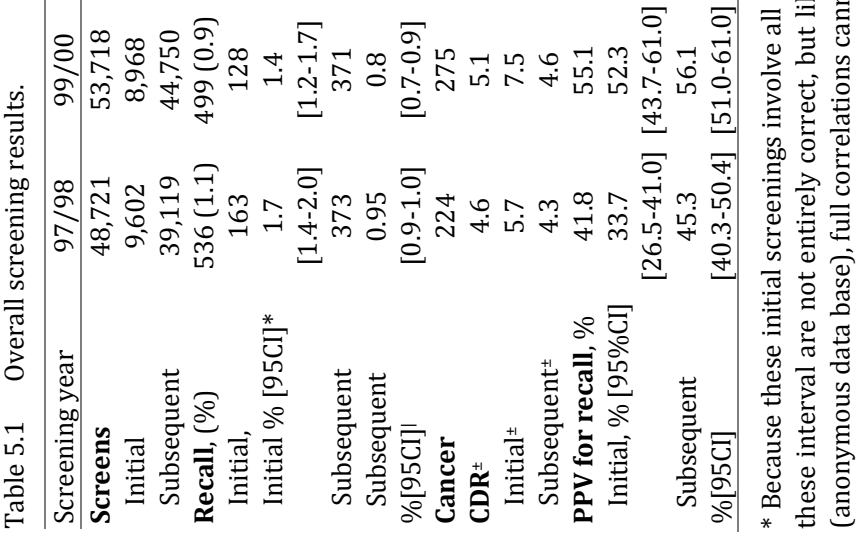




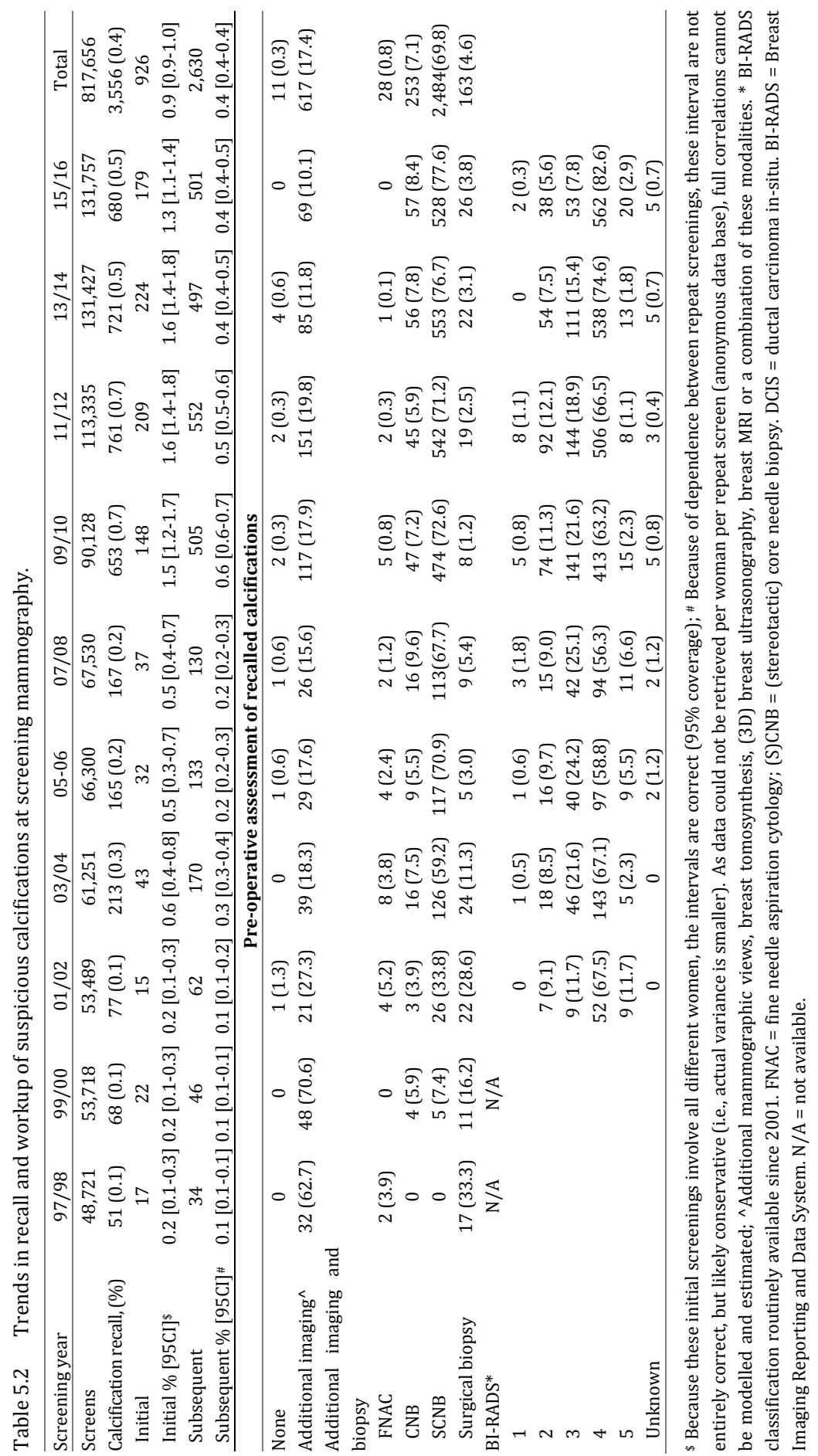




\section{Outcome after recall}

Breast cancer was diagnosed in 4932 recalled women (screen-detected cancers) and 1391 nonrecalled women (interval cancers), yielding an overall CDR of 6.0 per 1000 screening examinations $(4932 / 817,656)$ (Table 5.1) and a program sensitivity of $78.0 \%$ (4932/6323). If the proportions reported earlier are translated into $\mathrm{CDR}$, the rates for initial screening examinations increased from 6.4 per 1000 screening examinations $(297 / 46,155)$ in the SFM period to 7.8 per 1000 screening examinations $(323 / 41,204)$ in the FFDM period $(p=0.01)$ and the CDR for subsequent screening examinations increased from 4.8 per 1000 screening examinations $(1477 / 304,854)$ to 6.8 per 1000 screening examinations (2264/335,315), respectively $(p<0.001)$.

Similarly, although the recall rate of suspicious microcalcifications increased from 2.1 per 1000 screening examinations $(741 / 351,009)$ in the SFM period to 5.7 per 1000 screening examinations $(2162 / 376,519)$ in the FFDM period $(p<0.001)$, the DCIS detection rate increased from 0.9 per 1000 screening examinations $(321 / 351,009)$ to 1.7 per 1000 screening examinations $(637 / 376,519$; $\mathrm{p}<0.001)$, respectively (Figure 5.2). In 2009-2010, an increased recall rate for suspicious microcalcifications to 7.2 per 1000 screening examinations (653/90,128; $p<0.001$ vs. the SFM period) was observed, as well as an increase in the DCIS detection rate to 1.7 per 1000 screening examinations $(153 / 90,128 ; p<0.001$ vs. the SFM period). These changes were temporally associated with the introduction of digital mammography. To more closely assess the change in the DCIS detection rate given the apparent shift after the introduction of FFDM, a chi-square test comparing detection rates during the SFM period and FFDM period showed that detection rates significantly increased after the introduction of FFDM ( $p<0.001$ for both initial and subsequent screening examinations).

The PPV for overall recall was $26.5 \%(4932 / 18,592)$. Table 5.1 shows the PPVs and 95\% CIs for all recalls and for initial and subsequent screening examinations. The PPV for all recalls decreased from $41.8 \%$ (224/536) in 1997-1998 to $24.5 \%$ (887/3621) in 2015-2016. In the comparison of the SFM and the FFDM periods, the PPV for all recalls decreased from $39.8 \%(1774 / 4452)$ to $22.0 \%(2587 / 11,781)$ $(p<0.001)$.

As shown in Figure 5.3, the PPV for microcalcification recalls showed a similar decreasing trend over the years, from $51.0 \%$ (26/51) in 1997-1998 to $32.6 \%$ (222/680) in 2015-2016 (43.3\%; 321/741 during the SFM period vs. $29.5 \%$ $637 / 2162$ during the FFDM period; $p<0.001$ ). 


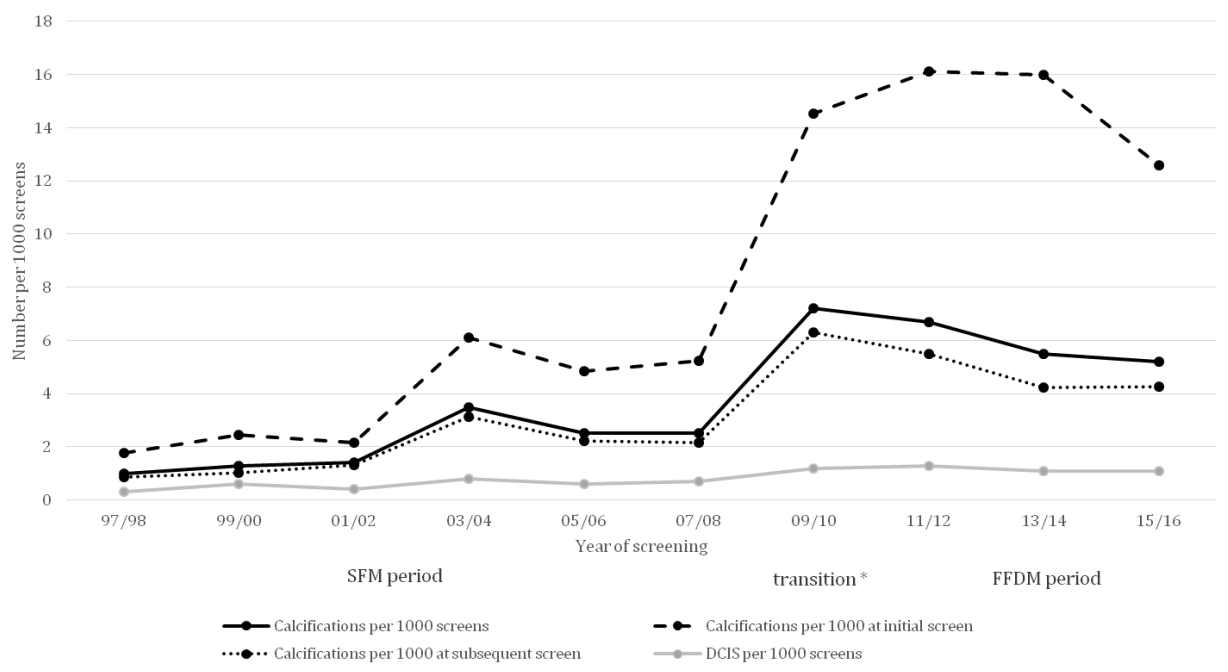

Figure 5.2 Trends in recall of calcifications and DCIS yield per 1000 screening examinations. SFM = screen-film mammography; FFDM = full-field digital mammography; DCIS = ductal carcinoma in-situ. * The transition from SFM to FFDM screening mammography took place between 2009 and 2010 .

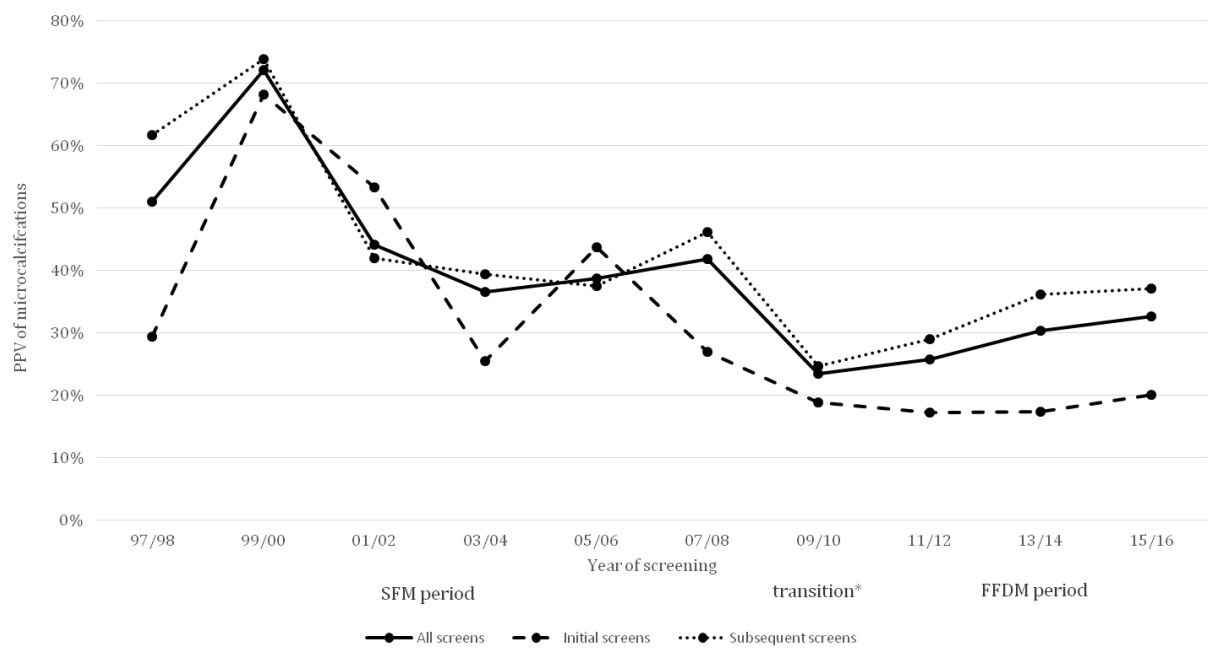

Figure 5.3 Trends in positive predictive value of microcalcification recalls. PPV = positive predictive value; $\mathrm{SFM}=$ screen-film mammography; FFDM = full-field digital mammography. ${ }^{*}$ The transition from SFM to FFDM screening mammography took place between 2009 and 2010 . 


\section{Trends in diagnostic work-up of microcalcifications}

Of the 3556 women recalled for suspicious microcalcifications, 617 (17.4\%) underwent additional imaging (additional mammographic views, tomosynthesis, breast US, breast MRI, or any combination of these modalities) as the only diagnostic procedure (Table 5.2).

Stereotactic core needle biopsy ( $\mathrm{SCNB}$ ) was the most frequently used type of biopsy, and a total of 2484 SCNB procedures were performed (Table 5.2). The SCNB rate per 1000 screening examinations increased from $0.4(150 / 351,009)$ during the SFM period to $1.2(109 / 90,128)$ during the transition period $(p<0.001)$, remaining stable in the FFDM period $(1.2 ; 451 / 176,519)$. The proportion of women who underwent SCNB for microcalcifications increased from 0\% (0/51) in 1997-1998 to $77.6 \%(528 / 680)$ in $2015-2016(p<0.001)$.

A total of 1111 suspicious microcalcifications proved to be (pre)malignant (31.2\%; $1111 / 3556)$ and consisted of 747 DCIS (67.2\%) and 364 invasive cancers (32.8\%) (Table 5.3). The preoperative confirmation of DCIS with percutaneous biopsy increased over the years, from $5.9 \%(1 / 17)$ in $1997-1998$ to $91.8 \%(135 / 147)$ in 2015-2016 ( $p<0.001)$ (Table 5.3).

\section{Trends in surgical treatment of DCIS}

Of all 747 women with DCIS lesions that presented with suspicious calcifications, $561(75.1 \%)$ were treated with breast conserving surgery and $173(23.2 \%)$ with mastectomy. The remaining thirteen women $(1.7 \%)$ did not undergo surgical treatment (Table 5.3). The lowest proportion of breast conserving surgery for screen-detected DCIS was observed in women in the first cohort of 1997-1998 (59\%; 10/17) and subsequently varied between $70 \%(28 / 40)$ and $81 \%(38 / 47)$ afterward.

\section{DCIS characteristics}

The median DCIS size was $19 \mathrm{~mm}$ (range, 1-130 mm). Of the 747 DCIS lesions, 393 (52.6\%) were high grade, 233 (31.2\%) were intermediate grade, and $116(15.5 \%)$ were low grade (Table 5.3). This distribution of low, intermediate, and high grade DCIS did not change during the whole study period (SFM vs. FFDM period, $p=0.36$ ). The distributions of DCIS lesions according to histologic grade per 1000 screening examinations in the SFM and FFDM periods were $0.1(41 / 351,009)$ and 0.3 $(102 / 376,519)$, respectively, for low grade DCIS $(p<0.001) ; 0.2(58 / 351,009)$ and $0.5(192 / 376,519)$ for intermediate grade DCIS $(p<0.001)$; and $0.5(175 / 351,009)$ and $0.6(241 / 376,519 ; p=0.01)$ for high grade DCIS (Figure 5.4). Following SCNB, 
resection specimens showed no residual DCIS in 36 of the 734 women who underwent surgical treatment (4.9\%). Of these 36 women, 10 (28\%) had low grade DCIS at SCNB (Figure 5.5), 14 (39\%) had intermediate grade DCIS, and 12 (33\%) had high grade DCIS.

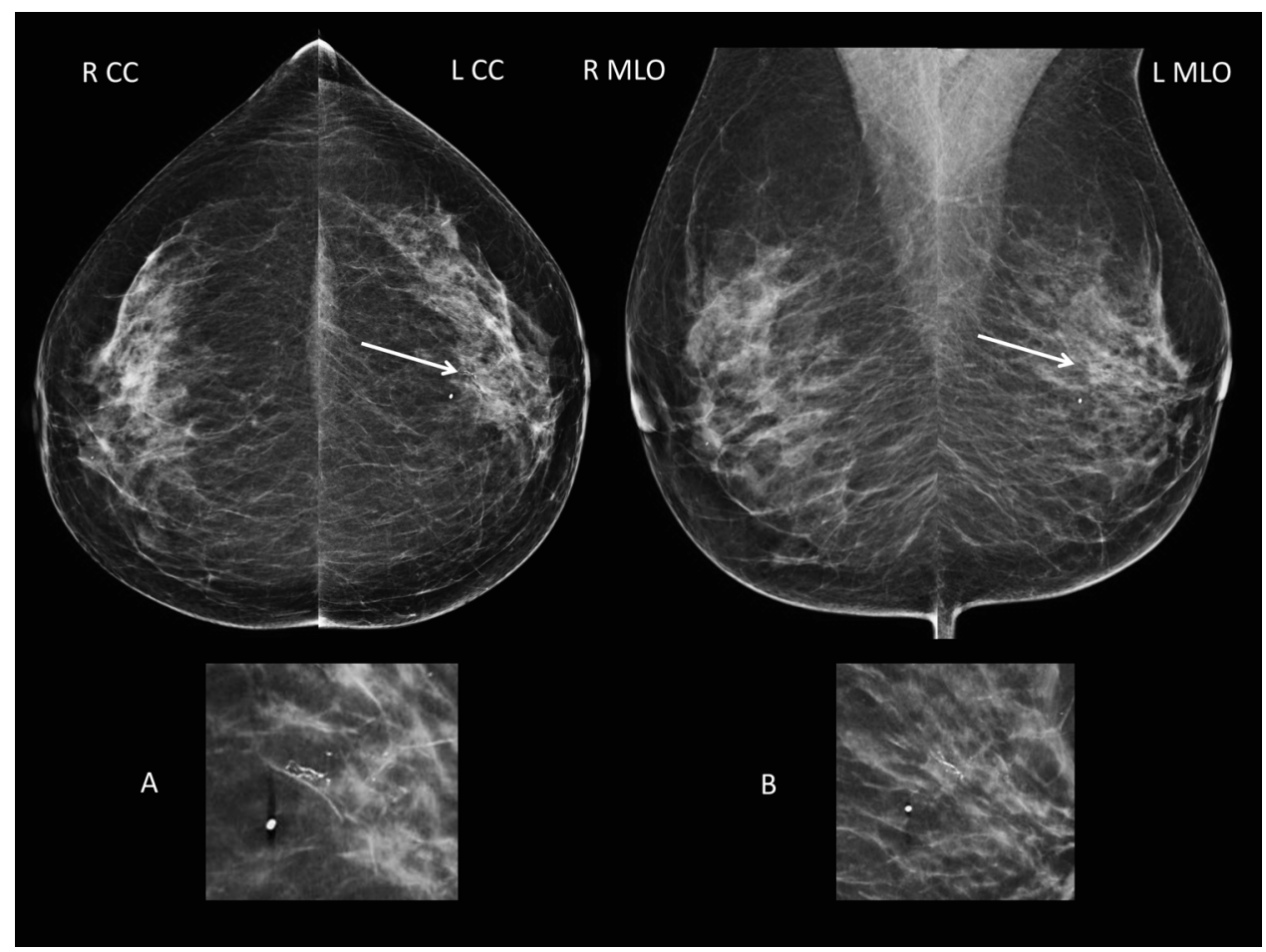

Figure 5.4 Two-view screening mammograms in, $A$, craniocaudal (CC) and, $B$, mediolateral oblique (MLO) views show fine linear calcifications located centrally in left breast (arrow). Calcifications are more clearly visible on spot magnification views (insets). Stereotactic vacuum-assisted core needle biopsy ( 9 gauge) revealed high grade ductal carcinoma in situ. The surgical specimen was $25 \mathrm{~mm}$. 


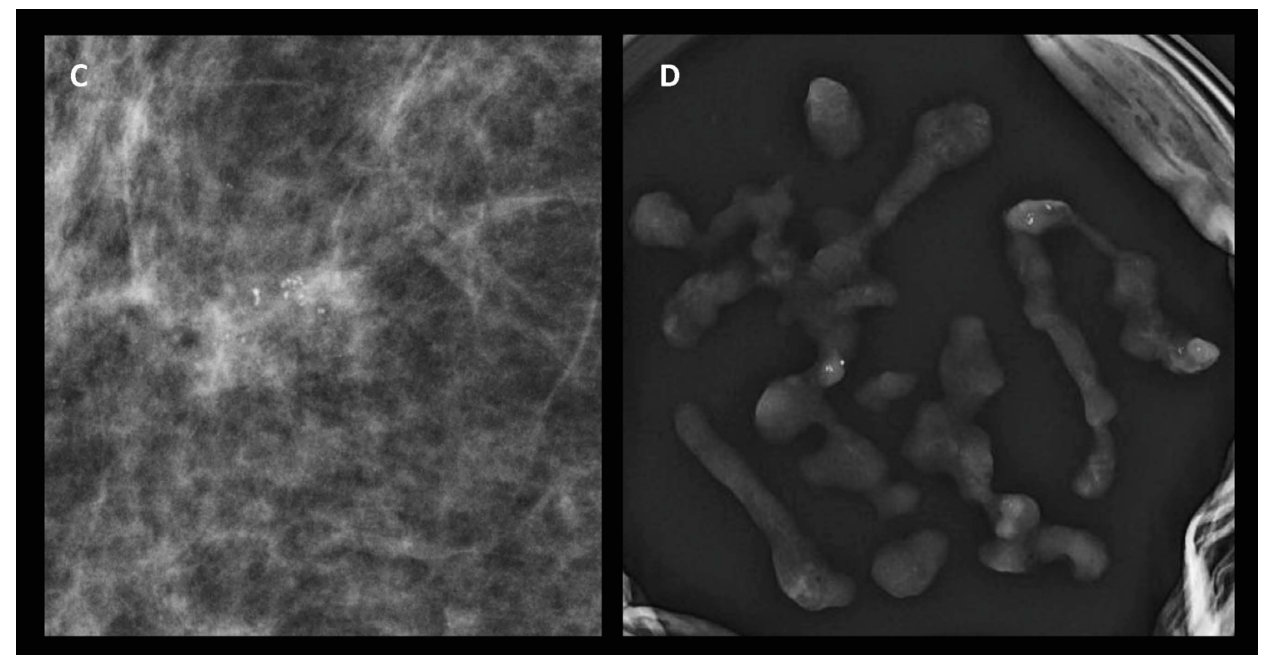

Figure 5.5 C, Spot magnification view shows grouped amorphic calcifications detected at mammography screening. Stereotactic vacuum-assisted core needle biopsy (9 gauge) yielded multiple specimens with calcifications. $D$, Photomicrograph shows usual ductal hyperplasia and adenosis.

\section{Discussion}

This retrospective twenty-year analysis of screen-detected microcalcifications in the southern part of the Netherlands showed a fivefold increase in the recall rate for suspicious microcalcifications from $0.1 \%$ (1997-1998, the screen-film mammography $[\mathrm{SFM}]$ period) to $0.5 \%$ (2015-2016, the full-field digital mammography [FFDM] period) $(p<0.001)$. Recalls yielding ductal carcinoma in situ (DCIS) increased from 0.3 per 1000 screening examinations $(17 / 48,721)$ in the SFM period to 1.1 per 1000 screening examinations $(147 / 131,757)$ in the FFDM period $(p<0.001)$, resulting in a decrease in the positive predictive value of recall for suspicious microcalcifications from $51 \%$ to $33 \%(p<0.001)$. Overall, one-third of all recalled microcalcifications proved to be (pre)malignant. Almost $70 \%$ of those recalled microcalcifications were DCIS. The distribution in DCIS grade was stable during the 20-year screening period $(p=0.36)$, with more than half $(53 \%)$ being high grade.

When comparing the SFM period with the FFDM period, the increase in the number of DCIS per 1000 screening examinations was most pronounced for low grade DCIS, 
which rose threefold in comparison with the lesser increase of both intermediateand high grade DCIS.

Almost all patients with microcalcification-associated DCIS are treated with surgery, the majority consisting of breast-conserving treatment. SCNB has replaced surgical excision biopsies and is currently the preferred technique for the diagnosis of microcalcification-associated breast abnormality. ${ }^{20-24}$ However, given the observed decrease in PPV for microcalcification recalls, one might question whether all recalled microcalcifications necessitate biopsy. Unfortunately, any underlying malignancy cannot always be ruled out with additional breast imaging, making SCNB the preferred minimally invasive technique to obtain tissue for pathologic examination.

Several studies showed that FFDM may be more effective than SFM for the detection of microcalcifications, as was also demonstrated in this study. Another explanation for the increased recall rate of microcalcifications may be the performance of routine two-view mammography (mediolateral oblique and craniocaudal views) of each breast since the start of FFDM in 2009-2010. In the SFM period, all women attending the program for the first time underwent twoview mammography, whereas subsequent screening examinations consisted of a routine mediolateral oblique view of each breast and additional craniocaudal views only if indicated ${ }^{3,25,26}$. Depending on the characteristics of mammography screening programs, adding tomosynthesis to conventional FFDM may have a beneficial impact on recall rate and cancer detection. ${ }^{27}$ However, breast tomosynthesis has not yet been implemented in the Dutch screening program.

The increased detection of DCIS also resulted in a rise in the number of low grade DCIS and thus probably some degree of overdiagnosis, which may pose therapeutic dilemmas for clinicians and may lead to overtreatment. As ongoing studies investigate the possibility of close surveillance of low grade and even intermediate grade DCIS 28,29 , better discrimination of microcalcifications to prevent SCNB for suspected low grade DCIS based on radiologic features might be a next step in deescalating treatment. High grade DCIS is more often associated with specific abnormal mammographic features, such as necrosis, rod and linear branch shapes, or coarse granular microcalcifications. 5,30-32

On the other hand, more than half of DCIS related to suspicious microcalcifications in our study showed high grade histopathologic characteristics. As the detection and subsequent treatment of high grade DCIS may reduce further development to high grade invasive carcinoma, histologic analysis of screen-detected microcalcifications carries substantial clinical value. ${ }^{9}$ Consequently, SCNB is still considered mandatory in the work-up of these lesions to date because it is not yet 
clear to which degree histologic features of DCIS can be estimated by using the patterns of microcalcifications alone. ${ }^{30}$

Surgery, including additional radiation therapy in case of breast-conserving surgery, remains the recommended choice for DCIS treatment. ${ }^{33}$ Most women with DCIS in our study were treated with breast-conserving surgery. In almost 5\% of all surgically treated women, no residual DCIS was found in the surgical specimen, suggesting that all DCIS was removed at SCNB as has also been described in a recent study by Dubrovsky et $a .^{34}$ in $14 \%$ of all surgically treated women. In the study by Dubrovsky et al., omission of additional radiation therapy did not alter the local recurrence rate. Vacuum-assisted excision biopsy devices can remove more tissue than SCNB and may be the future therapy for patients with small groups of clustered microcalcification-associated DCIS. ${ }^{35,36}$ A wait-and see strategy for low grade and intermediate grade DCIS may be favored over surgical intervention if subsequent mammography shows no residual calcifications.

Our study has some limitations. Unfortunately, individual data at a woman level could not be retrieved for repeat screening examinations. Therefore, possible within-subject dependencies of the data in repeat screening examinations could not be modeled and estimated. Given these limitations in the data, we could only analyze all subsequent screening examinations (which may be dependent) as one group. Furthermore, we were not able to reliably retrieve the detailed radiologic features on morphologic characteristics and distribution of microcalcifications because they were not specified in our data.

Characterizing radiologic features of suspicious microcalcifications to search for patterns that correlate with more aggressive underlying disease might be a desirable next step toward a more selective use of SCNB in case of screen-detected microcalcifications. Because it is not yet clear to what extent histologic features of DCIS can be estimated by the patterns of microcalcifications alone, SCNB is still considered mandatory in the work-up of these lesions to date.

In conclusion, the recall rate of suspicious microcalcifications at mammographic screening significantly increased over the past two decades, while the ductal carcinoma in situ detection rate increased less rapidly at the expense of a lower positive predictive value of recall. 


\section{References}

1. Knipe H, Kruger G. Albert Salomon. http://radiopaedia.org/articles/dralbert- salomon-1. Accessed April 2019.

2. Castronovo V, Bellahcene A. Evidence that breast cancer associated microcalcifications are mineralized malignant cells. Int J Oncol 1998;12(2):305-308.

3. Del Turco MR, Mantellini P, Ciatto $S$, et al. Full-field digital versus screenfilm mammography: comparative accuracy in concurrent screening cohorts. AJR Am J Roentgenol 2007;189(4): 860-866.

4. Morgan MP, Cooke MM, McCarthy GM. Microcalcifications associated with breast cancer: an epiphenomenon or biologically significant feature of selected tumors? J Mammary Gland Biol Neoplasia 2005;10(2):181-187.

5. Rauch GM, Hobbs BP, Kuerer HM, et al. Microcalcifications in 1657 patients with pure ductal carcinoma in situ of the breast: correlation with clinical, histopathologic, biologic features, and local recurrence. Ann Surg Oncol 2016;23(2):482-489.

6. Hofvind S, Iversen BF, Eriksen L, Styr BM, Kjellevold K, Kurz KD. Mammographic morphology and distribution of calcifications in ductal carcinoma in situ diagnosed in organized screening. Acta Radiol 2011;52(5):481-487.

7. van Steenbergen LN, Voogd AC, Roukema JA, et al. Screening caused rising incidence rates of ductal carcinoma in situ of the breast. Breast Cancer Res Treat 2009;115(1):181-183.

8. Hong YK, McMasters KM, Egger ME, Ajkay N. Ductal carcinoma in situ current trends, controversies, and review of literature. Am J Surg 2018;216(5):998-1003.

9. Luiten JD, Voogd AC, Luiten EJT, Duijm LEM. Trends in incidence and tumour grade in screendetected ductal carcinoma in situ and invasive breast cancer. Breast Cancer Res Treat 2017;166(1):307-314.

10. Luiten JD, Voogd AC, Tjan-Heijnen VCG, Wesseling J, Luiten EJT, Duijm LEM. Utility of diagnostic breast excision biopsies during two decades of screening mammography. Breast 2019;46:157162. https://doi. org/10.1016/j.breast.2019.05.018.

11. van Luijt PA, Fracheboud J, Heijnsdijk EA, den Heeten GJ, de Koning HJ; National Evaluation Team for Breast Cancer Screening in Netherlands Study Group (NETB). Nation-wide data on screening performance during the transition to digital mammography: observations in 6 million screens. Eur J Cancer 2013;49(16):3517-3525.

12. Jing H, Yang Y, Wernick MN, Yarusso LM, Nishikawa RM. A comparison study of image features between FFDM and film mammogram images. Med Phys 2012;39(7):4386-4394.

13. Setz-Pels W, Duijm LE, Coebergh JW, Rutten M, Nederend J, Voogd AC. Re-attendance after falsepositive screening mammography: a populationbased study in the Netherlands. Br J Cancer 2013;109(8):2044-2050.

14. Nederend J, Duijm LE, Louwman MW, Groenewoud JH, Donkers-van Rossum AB, Voogd AC. Impact of transition from analog screening mammography to digital screening mammography on screening outcome in the Netherlands: a population-based study. Ann Oncol 2012;23(12): 3098-3103.

15. BI-RADS Committee. ACR BI-RADS atlas: Breast Imaging Reporting And Data System. 5th ed. Reston, Va: American College of Radiology, 2013.

16. Timmers JM, van Doorne-Nagtegaal HJ, Zonderland HM, et al. The Breast Imaging Reporting and Data System (BI-RADS) in the Dutch breast cancer screening programme: its role as an assessment and stratification tool. Eur Radiol 2012;22(8):1717-1723.

17. Klompenhouwer EG, Voogd AC, den Heeten GJ, et al. Blinded double reading yields a higher programme sensitivity than non-blinded double reading at digital screening mammography: a prospected population based study in the south of the Netherlands. Eur J Cancer 2015;51(3): 391-399.

18. van Bommel RMG, Voogd AC, Nederend J, et al. Incidence and tumour characteristics of bilateral and unilateral interval breast cancers at screening mammography. Breast 2018;38:101-106. 
19. Knol MJ, Pestman WR, Grobbee DE. The (mis)use of overlap of confidence intervals to assess effect modification. Eur J Epidemiol 2011;26(4):253-254.

20. Mikhail RA, Nathan RC, Weiss M, et al. Stereotactic core needle biopsy of mammographic breast lesions as a viable alternative to surgical biopsy. Ann Surg Oncol 1994;1(5):363-367.

21. Liberman L, Dershaw DD, Rosen PP, Cohen MA, Hann LE, Abramson AF. Stereotaxic core biopsy of impalpable spiculated breast masses. AJR Am J Roentgenol 1995;165(3):551-554.

22. Meyer JE, Smith DN, Lester SC, et al. Large-core needle biopsy of nonpalpable breast lesions. JAMA 1999;281(17):1638-1641.

23. Rakha EA, Ellis IO. An overview of assessment of prognostic and predictive factors in breast cancer needle core biopsy specimens. J Clin Pathol 2007;60(12):1300-1306.

24. van Breest Smallenburg V, Nederend J, Voogd AC, et al. Trends in breast biopsies for abnormalities detected at screening mammography: a populationbased study in the Netherlands. Br J Cancer 2013;109(1):242-248.

25. Sala M, Domingo L, Macià F, Comas M, Burón A, Castells X. Does digital mammography suppose an advance in early diagnosis? Trends in performance indicators 6 years after digitalization. Eur Radiol 2015;25(3):850-859.

26. Bluekens AM, Holland R, Karssemeijer N, Broeders MJ, den Heeten GJ. Comparison of digital screening mammography and screen-film mammography in the early detection of clinically relevant cancers: a multicenter study. Radiology 2012;265(3):707-714.

27. Li T, Marinovich ML, Houssami N. Digital breast tomosynthesis (3D mammography) for breast cancer screening and for assessment of screen-recalled findings: review of the evidence. Expert Rev Anticancer Ther 2018;18(8):785-791.

28. Elshof LE, Tryfonidis K, Slaets L, et al. Feasibility of a prospective, randomised, open-label, international multicentre, phase III, non-inferiority trial to assess the safety of active surveillance for low risk ductal carcinoma in situ - The LORD study. Eur J Cancer 2015;51(12):1497-1510.

29. Francis A, Thomas J, Fallowfield L, et al. Addressing overtreatment of screen detected DCIS; the LORIS trial. Eur J Cancer 2015;51(16):2296-2303.

30. Szynglarewicz B, Kasprzak P, Biecek P, Halon A, Matkowski R. Screendetected ductal carcinoma in situ found on stereotactic vacuum-assisted biopsy of suspicious microcalcifications without mass: radiological-histological correlation. Radiol Oncol 2016;50(2):145-152.

31. Evans A, Clements $\mathrm{K}$, Maxwell A, et al. Lesion size is a major determinant of the mammographic features of ductal carcinoma in situ: findings from the Sloane project. Clin Radiol 2010;65(3): 181-184.

32. Tang X, Yamashita T, Hara M, Kumaki N, Tokuda Y, Masuda S. Histopathological characteristics of breast ductal carcinoma in situ and association with imaging findings. Breast Cancer 2016; 23(3):491-498.

33. Richtlijn mammacarcinoom. Federatie Medisch Specialisten. https://richtlijnendatabase. nl/richtlijn/borstkanker/dcis.html. Published January 7, 2018. Accessed June 12, 2018.

34. Dubrovsky E, Nguyen P, Chun J, et al. Ductal carcinoma in situ on core needle biopsy only with no residual disease at surgery. Breast J 2018;24(6):971-975.

35. Rageth CJ, O’Flynn EA, Comstock C, et al. First International Consensus Conference on lesions of uncertain malignant potential in the breast (B3 lesions). Breast Cancer Res Treat 2016;159(2): 203-213.

36. Rageth CJ, O'Flynn EAM, Pinker K, et al. Second International Consensus Conference on lesions of uncertain malignant potential in the breast (B3 lesions). Breast Cancer Res Treat 2019;174(2): 279-296 [Published correction appears in Breast Cancer Res Treat 2019;176(2):481-482.]. 


$$
\text { yo }
$$




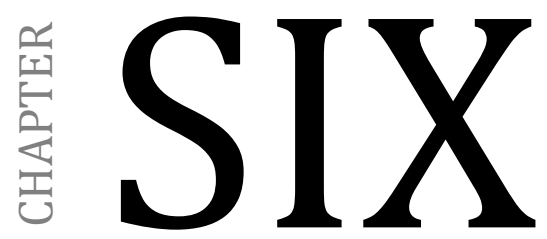

Iodine seed- versus wire-guided localization in breast-conserving surgery for non-palpable ductal carcinoma in situ

Jacky D. Luiten

Maarten A. Beek

Adri C. Voogd

Paul D. Gobardhan

Ernest J.T. Luiten 


\section{Abstract}

Background

Breast conserving surgery (BCS) for isolated non-palpable ductal carcinoma in situ (DCIS) is associated with high rates of incomplete surgical resection in comparison with unifocal invasive breast cancer. Therefore, accurate preoperative localization of the lesion is very important to facilitate adequate resection. Wire-guided localization (WGL) remains the standard for localization of DCIS. Recently, iodine125 seed-guided localization (I-125 GL) was introduced as an alternative localization technique. The aim of this study was to compare the efficacy of these localization techniques in the resection of DCIS by BCS.

\section{Methods}

Between March 2006 and June 2013, 169 patients with non-palpable DCIS were treated with BCS. Only patients with pure DCIS on both preoperative core biopsy and definitive pathology were included.

Results

WGL was performed in 78 patients and I-125 GL in 91 patients. The groups did not differ with respect to age, size of DCIS or type of imaging used. Patients in the I-125 GL group had a significantly lower risk of extensively involved resection margins than those in the WGL group (4\% vs. $13 \%$ respectively; $\mathrm{p}=0.048$ ).

\section{Conclusion}

In patients treated with BCS for non-palpable DCIS, localization with iodine-125 seeds is superior to the WGL technique in reducing the risk of extensively involved resection margins. 


\section{Introduction}

Improved imaging techniques in combination with nationwide mammographic screening have led to increased detection rates of ductal carcinoma in situ (DCIS). ${ }^{1-3}$ The majority of non-palpable DCIS lesions discovered in breast cancer screening programs are identified by the presence of microcalcifications on mammograms.

In contrast to invasive breast cancer, DCIS is often diffusely spread and the margins are therefore less discrete. ${ }^{4}$ Consequently, surgical removal of DCIS is more often associated with incomplete resection than invasive breast cancer. ${ }^{5}$ Accurate preoperative localization of the lesion is essential to enable adequate surgical resection of non-palpable DCIS. ${ }^{6}$

Wire-guided localization (WGL) of non-palpable invasive breast tumors or DCIS is currently the most frequently used technique. ${ }^{7}$ To locate the lesion, a hook wire is placed under ultrasound or stereotactic guidance by a radiologist before surgery. Subsequently, the surgeon can excise the lesion guided by the wire.

In recent years, an alternative localization technique has been developed for nonpalpable breast lesions, which can also be used to mark the cancer area in patients receiving neoadjuvant chemotherapy before the start of treatment.8,9 This technique consists of the implantation of a slightly radioactive iodine- 125 seed. The aim of the present study was to compare the efficacy of iodine- 125 seed-guided localization (I-125 GL) and WGL for localization of non-palpable DCIS.

\section{Methods}

Between March 2006 and June 2013, 945 women were diagnosed with nonpalpable invasive cancer or DCIS. Only patients with pure DCIS, on both preoperative core biopsy and definitive pathology, were included in the present study. Furthermore, only lesions localized by either I-125 GL or WGL were analyzed. Patients with DCIS excised by the radioguided occult lesion localization technique were not included owing to small numbers $(n=3) .{ }^{6}$ Approval for this study was provided by the local ethics committee of Amphia Hospital.

\section{Endpoints}

The primary endpoint was complete resection of the DCIS lesion on final pathology. According to Dutch guidelines for the treatment of breast cancer, the status of the resection margins is defined by the extent of the tumor-free resection margin ${ }^{10}$. Focally involved margins are defined by tumors extending to the inked resection 
margin over a distance of $4 \mathrm{~mm}$ or less. Extensively involved margins include those in which tumor involvement of the inked margins extends beyond $4 \mathrm{~mm}$. According to the Dutch guidelines, patients with focally involved resection margins are recommended to undergo either additional boost radiotherapy or additional surgical treatment. Additional surgical treatment is always recommended for patients with extensively involved resection margins.

The median volume of the excised specimen was compared and calculated from an ellipsoid formula using the three dimensions measured by the pathologist: $4 / 3 \pi$ (0.5 length $\times 0.5$ width $\times 0.5$ height). 6,11

\section{Guidewire and iodine-125 seed placement and detection}

The WGL technique involved a radiologist placing a hook wire under stereotactic or ultrasound guidance immediately preceding surgery, or the day before. In the latter situation, the hook wire, which was placed in the center of the lesion or as near to this as possible, was taped to the skin of the breast to prevent dislocation.

For I-125 GL, a titanium seed containing 7MBq iodine-125 (BrachySource ${ }^{\circledR}$; Bard, Covington, Georgia, USA) was injected into or near the tumor, as described previously. ${ }^{8,9}$ Iodine- 125 is a $27-\mathrm{keV}$ source of $\gamma$ radiation with a half-life of 60 days. The cylindrical seed (length $4.5 \mathrm{~mm}$, diameter $0.8 \mathrm{~mm}$ ) was inserted into the lesion under ultrasound or stereotactic guidance using an 18G needle. The tip was sealed with sterile bone wax to prevent the seed being lost before insertion into the breast. If judged necessary, for instance in women with widespread segmental disease, the lesion was marked by two or three iodine seeds placed at the borders of the microcalcifications. After seed implantation, confirming mammography was carried out. Before incision and during the excision, a hand-held $\gamma$-probe (Eurorad, Eckbolsheim, France) was used to determine the location of the iodine-125 seed in three dimensions.

The seed implantation was done under direct responsibility of the Nuclear Medicine Department and according to the hospital's license for the application of radiation in medical procedures under Dutch law. ${ }^{12}$

\section{Statistical analysis}

Continuous data are presented as mean (SD) or median (range), and were compared using Mann-Whitney $U$-test. Proportional differences between I-125 GL and WGL groups were analyzed by chi-square test. $p<0.050$ was considered statistically significant. SPSS ${ }^{\circledR}$ version 21.0 was used for statistical analysis (IBM, Armonk, New York, USA). 


\section{Results}

A total of 169 patients fulfilled the inclusion criteria for the study. Patients in the WGL group were diagnosed between March 2006 and November 2011, and those in the I-125 GL group from April 2010 to June 2013. DCIS was localized using the I-125 GL technique in 91 patients and by WGL in 78 patients. The mean age in the I-125 GL and WGL groups was 60 and 60 years respectively ( $p=0.833$; Table 6.1). In both groups, the majority of the DCIS lesions were diagnosed by screening mammography (74\% in the I-125 group vs. $88 \%$ in the WGL group), and the majority presented as microcalcifications (93\% and 95\% respectively).

Table 6.1 Baseline characteristics.

\begin{tabular}{|c|c|c|c|}
\hline Characteristic & $\begin{array}{c}\text { WGL } \\
(n=78)\end{array}$ & $\begin{array}{c}\mathrm{I}-125 \\
(n=91)\end{array}$ & $p$-value \\
\hline Age (years)* & $60(9)$ & $60(8)$ & $0.833^{\#}$ \\
\hline Diameter DCIS (mm) ${ }^{a}$ & $16.54(11.8)$ & $19.17(16.4)$ & $0.100^{\#}$ \\
\hline \multicolumn{4}{|l|}{ Mode of detection } \\
\hline Screening program & $69(88)$ & $67(74)$ & 0.048 \\
\hline High risk screening & $1(1)$ & $8(9)$ & \\
\hline Follow-up after breast cancer & $6(8)$ & $9(10)$ & \\
\hline Symptomatic $^{+}$ & $2(3)$ & $7(8)$ & \\
\hline Findings at mammography & & & 0.232 \\
\hline Microcalcifications & $74(95)$ & $85(93)$ & \\
\hline Density or architectural distortion & $4(5)$ & $6(7)^{\$}$ & \\
\hline Localization guidance & & & 0.028 \\
\hline Ultrasound & $20(26)$ & $38(42)$ & \\
\hline Stereotactically & $58(74)$ & $53(58)$ & \\
\hline \multicolumn{4}{|l|}{ No. of seeds used } \\
\hline 1 & - & $70(77)$ & \\
\hline 2 & - & $16(18)$ & \\
\hline 3 & - & $5(5)$ & \\
\hline
\end{tabular}

Values in parentheses are percentages unless indicated otherwise. ${ }^{*}$ values are mean (SD); + breast discomfort or nipple discharge; $\$$ One patient was diagnosed by MRI; p-values are chi-square test, except \# Mann-Whitney U-test.

\section{Surgery}

Fifteen surgeons carried out the operations, of whom six performed 142 (84.0\%) of the procedures, $80(88 \%)$ in the I-125 GL group and 62 (79\%) in the WGL group $(p=0.136)$. The median duration of surgery was $40 \mathrm{~min}$ using the I-125 GL technique compared to $50 \mathrm{~min}$ with WGL $(p=0.723)$. The median volume of resected breast tissue was $53.53 \mathrm{~cm}^{3}$ (1.26-904.78) in the I-125 GL group and 47.00 $\mathrm{cm}^{3}(0.52-188.50)$ in the WGL group $(p=0.070)$. There was no seed migration or loss of seeds during or after resection. Dislocation or loss of the wire in the WGL group was not investigated. 


\section{Surgical margins}

A histologically complete resection of DCIS was achieved in 75 (82\%) of 91 patients in the I-125 GL group compared with 58 (74\%) of 78 in the WGL group $(p=0.139$; Table 6.2). Focally involved margins were found in 12 patients (13\%) and ten patients $(13 \%)$ respectively $(p=0.944)$. Resection margins were involved extensively in four patients (4\%) following I-125 GL and ten (13\%) after WGL $(p=0.048)$.

Table 6.2 Final histology of surgical resection margins of DCIS.

\begin{tabular}{lcc}
\hline Margin status & $\begin{array}{c}\text { WGL } \\
(\mathrm{n}=78)\end{array}$ & $\begin{array}{c}\mathrm{I}-125 \mathrm{GL} \\
(\mathrm{n}=91)\end{array}$ \\
\hline Complete resection & $58(74)$ & $75(82)$ \\
Focally involved margins & $10(13)$ & $12(13)$ \\
Extensively involved margins & $10(13)$ & $4(4)$ \\
\hline
\end{tabular}

Values in parentheses are percentages unless indicated otherwise. $p=0.048$ (extensively involved margins versus complete resection and focally involved margins, $\chi^{2}$ test).

\section{Additional treatment owing to involved margins}

Eight of the twelve patients with focally involved resection margins in the I-125 GL group and seven of the ten with focally involved resection margins in the WGL group received additional boost radiotherapy (Table 6.3). All patients with extensively involved resection margins underwent additional surgery by either a re-excision or mastectomy. In the I-125 GL group, re-excision revealed residual DCIS in three patients and no residual DCIS was detected in one woman who had a mastectomy. In the WGL group, residual DCIS was detected in two of the three women who underwent re-excisions, and four of the seven who had a mastectomy.

Table 6.3 Additional local therapy following incomplete resection.

\begin{tabular}{lcc}
\hline & $\begin{array}{c}\text { WGL } \\
(\mathrm{n}=78)\end{array}$ & $\begin{array}{c}\mathrm{I}-125 \mathrm{GL} \\
(\mathrm{n}=91)\end{array}$ \\
\hline Focally involved margins (\%) & $10(13)$ & $12(13)$ \\
Re-excision & 2 & 4 \\
Breast amputation & 1 & 0 \\
Boost radiotherapy & 7 & 8 \\
Extensively involved margins (\%) & $10(13)$ & $4(4)$ \\
Re-excision & 3 & 3 \\
Breast amputation & 7 & 1 \\
Boost radiotherapy & 0 & 0 \\
\hline
\end{tabular}

Values in parentheses are percentages unless indicated otherwise 


\section{Discussion}

This single-center retrospective cohort study compared I-125 GL with WGL of nonpalpable DCIS during BCS. Patients who had I-125 GL had a significantly lower risk of extensively involved resection margins than those whose lesions were localized by WGL. This resulted in fewer patients requiring additional surgical treatment.

Although WGL is a commonly used localization technique, it has several limitations. ${ }^{13}$ Exact placement of the guidewire can be more demanding for radiologists, especially as the hook of the wire precludes repositioning. Consequently, the procedure can be hampered by the fact that the surgeon cannot exactly define the location of the lesion in relation to the tip of the wire during the surgery. ${ }^{14}$ Finding the tip of the guidewire can also be challenging. Furthermore, guidewires may dislocate or can be lost before or during surgery, leaving the surgeon without any reliable tool to locate the lesion. Wires placed under ultrasound or stereotactic guidance may sometimes also enter the breast at a considerable distance from the lesion, which renders the surgical procedure rather cumbersome, requiring extensive dissection to follow the tract of the wire towards the tip. ${ }^{15}$ It has also been reported by breast surgeons familiar with both techniques that the surgical procedure with iodine- 125 seeds is easier to perform. ${ }^{16}$

In contrast to guidewires, an iodine-125 seed can be localized exactly in three dimensions using a hand-held $\gamma$-probe. This allows the surgeon to navigate accurately towards the lesion. An additional advantage of this technique is the possibility of using two or more seeds, which makes it possible to mark the exact location and diameter of the lesion. ${ }^{17}$ This allows surgeons to extend BCS to even larger DCIS lesions. Finally, iodine-125 seeds can be used not only for non-palpable breast lesions, including both invasive breast cancer and DCIS, but also several months before surgery to mark original tumor borders in patients who will subsequently be treated with neoadjuvant chemotherapy. ${ }^{8,18}$

Apart from the surgical technique, patient comfort is also of importance when judging the quality of healthcare. In patient-reported outcomes, insertion of the hook wire used in WGL has been reported as uncomfortable and painful. ${ }^{6}$ The wire sticks out of the breast and has to be secured by tape to keep it in place until surgery. This procedure not only causes discomfort, but also the wire is at risk of dislocation or being lost. ${ }^{7}$ Wires are placed by a radiologist and the procedure can be time-consuming, potentially disturbing operating theatre scheduling as it is preferably carried out immediately preceding surgery.

A weakness of this study is its retrospective nonrandomized design. However, it reflects the real-world experience of these localization techniques among surgeons 
experienced in using both methods in daily practice. As the I-125 GL technique was introduced later, a learning curve effect for the use of iodine-125 seeds cannot be ruled out, which might have affected some of the variables analyzed, such as duration of operation. Moreover, iodine-125 seeds might have been used to mark large DCIS lesions, which were not considered suitable for BCS surgery using the WGL technique.

The present study adds to the existing literature that the I-125 GL technique may be preferred over WGL, as the method has been shown to significantly reduce the risk of extensively involved resection margins after BCS, and the need for additional surgery in women with DCIS. 


\section{References}

1. Campbell ID, Royle GT, Coddington R, Theaker J, Rubin CM, Guyer PB et al. Technique and results of localization biopsy in a breast screening programme. Br J Surg 1991;78:1113-1115.

2. Fracheboud J, de Koning HJ, Beemsterboer PM, Boer R, Hendriks JH, Verbeek AL et al. Nation-wide breast cancer screening in the Netherlands: results of initial and subsequent screening 1990-1995. National Evaluation Team for Breast Cancer Screening. Int J Cancer 1998;75:694-698.

3. van Steenbergen LN, Voogd AC, Roukema JA, Louwman WJ, Duijm LE, Coebergh JW et al. Screening caused rising incidence rates of ductal carcinoma in situ of the breast. Breast Cancer Res Treat 2009;115:181-183.

4. van Riet YE, Jansen FH, van Beek M, van de Velde CJ, Rutten HJ, Nieuwenhuijzen GA. Localization of non-palpable breast cancer using a radiolabelled titanium seed. Br J Surg 2010;97:1240-1245.

5. van der Heiden-van der Loo M, de Munck L, Visser O, Westenend PJ, van Dalen T, Menke MB et al. Variation between hospitals in surgical margins after first breast-conserving surgery in the Netherlands. Breast Cancer Res Treat 2012;131:691-698.

6. Postma EL, Verkooijen HM, van Esser S, Hobbelink MG, van der Schelling GP, Koelemij R et al. Efficacy of 'radioguided occult lesion localisation' (ROLL) versus 'wire-guided localisation' (WGL) in breast conserving surgery for non-palpable breast cancer: a randomised controlled multicentre trial. Breast Cancer Res Treat 2012;136:469-478.

7. Sajid MS, Parampalli U, Haider Z, Bonomi R. Comparison of radioguided occult lesion localization (ROLL) and wire localization for non-palpable breast cancers: a meta-analysis. J Surg Oncol 2012;105:852-858.

8. Gobardhan PD, deWall LL, van der Laan L, ten Tije AJ, van der Meer DC, Tetteroo E et al. The role of radioactive iodine-125 seed localization in breast-conserving therapy following neoadjuvant chemotherapy. Ann Oncol 2013;24:668-673.

9. Gray RJ, Giuliano R, Dauway EL, Cox CE, Reintgen DS. Radioguidance for nonpalpable primary lesions and sentinel lymph node(s). Am J Surg 2001;182:404-406.

10. NABON. Richtlijn mammacarcinoom; 2008. http://www.oncoline.nl/ [accessed 1 March 2015].

11. Wapnir IL,Wartenberg DE, Greco RS. Three dimensional staging of breast cancer. Breast Cancer Res Treat 1996;41:15-19.

12. Overheid.nl. Besluit van 16 juli 2001, houdende vaststelling van het besluit stralingsbescherming, 12. http://wetten.overheid.nl/BWBR0012702/ [accessed 1 March 2015].

13. Verkooijen HM, Peeters PH, Buskens E, Koot VC, Borel Rinkes IH, MaliWP et al. Diagnostic accuracy of large-core needle biopsy for nonpalpable breast disease: a meta-analysis. $\mathrm{Br} \mathrm{J}$ Cancer 2000;82:1017-1021.

14. Thind CR, Desmond S, Harris O, Nadeem R, Chagla LS, Audisio RA. Radio-guided localization of clinically occult breast lesions (ROLL): a DGH experience. Clin Radiol 2005;60:681-686.

15. Ocal K, Dag A, Turkmenoglu O, Gunay EC, Yucel E, Duce MN. Radioguided occult lesion localization versus wire-guided localization for non-palpable breast lesions: randomized controlled trial. Clinics (Sao Paulo) 2011;66:1003-1007.

16. Lovrics PJ, Goldsmith CH, Hodgson N, McCready D, Gohla G, Boylan C et al. A multicentered, randomized, controlled trial comparing radioguided seed localization to standard wire localization for nonpalpable, invasive and in situ breast carcinomas. Ann Surg Oncol 2011;18:3407-3414.

17. Lovrics PJ, Cornacchi SD, Vora R, Goldsmith CH, Kahnamoui K. Systematic review of radioguided surgery for non-palpable breast cancer. Eur J Surg Oncol 2011;37:388-397.

18. Gobardhan PD, Djamin RS, Romme PJ, deWit PE, de Groot HG, Adriaensen T et al. The use of iodine seed (I-125) as a marker for the localisation of lung nodules in minimal invasive pulmonary surgery. Eur J Surg Oncol 2013;39:945-950. 


$$
\text { yo }
$$




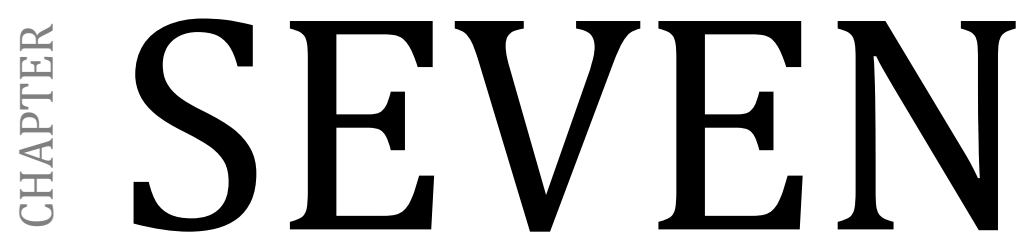

\section{Patterns of treatment and outcome of ductal carcinoma in situ in the Netherlands}

Jacky D. Luiten

Ernest J.T. Luiten

Maurice J.C. van der Sangen

Willem Vreuls

Lucien E.M. Duijm

Vivianne C.G. Tjan-Heijnen

Adri C. Voogd 


\section{Abstract}

Purpose

To spare DCIS patients from overtreatment, treatment de-escalated over the years. This study evaluate the influence of these developments on the patterns of care in the treatment of DCIS with particular interest in the use of breast conserving surgery (BCS), radiotherapy following BCS and the use and type of axillary staging.

\section{Methods}

In this large population-based cohort study all women, aged 50-74 years diagnosed with DCIS from January 1989 until January 2019, were analyzed per two-year cohort.

\section{Results}

A total of 30,417 women were diagnosed with DCIS. The proportion of patients undergoing BCS increased from $47.7 \%$ in $1995-1996$ to $72.7 \%$ in $2017-2018$ $(p<0.001)$. Adjuvant radiotherapy following BCS increased from 28.9\% (1995$1996)$ to $89.6 \%$ (2011-2012) and subsequently decreased to $74.9 \%$ (2017-2018; $p<0.001$ ). Since its introduction, the use of sentinel lymph node biopsy (SLNB) increased to $63.1 \%$ in $2013-2014$ and subsequently decreased to $52.8 \%$ in 2017 $2018(p<0.001)$. Axillary surgery is already omitted in $55.8 \%$ of the patients undergoing BCS nowadays. The five-year invasive relapse-free survival (iRFS) for BCS with adjuvant radiotherapy in the period 1989-2010, was 98.7\% [CI 98.4\%99.0\%], compared to $95.0 \%$ [CI 94.1\%-95.8\%] for BCS only $(p<0.001)$. In 20112018, this was 99.3\% [CI 99.1\%-99.5\%] and 98.8\% [CI 98.2\%-99.4\%] respectively $(p=0.01)$.

\section{Conclusion}

This study shows a shift toward less extensive treatment. DCIS is increasingly treated with BCS and less often followed by additional radiotherapy. The absence of radiotherapy still results in excellent iRFS.

Axillary surgery is increasingly omitted in DCIS patients. 


\section{Introduction}

Ductal carcinoma in situ (DCIS) is defined as an intraductal neoplastic proliferation of cells. ${ }^{1}$ In most cases, DCIS of the breast are associated with the presence of suspicious calcifications on mammography. Calcifications are the result of precipitations of calcium-salts in intraluminal secretions or necrosis of epithelial cells. ${ }^{2}$

The nation-wide biennial mammographic screening program in the Netherlands for women aged 50-70 years was set up between 1989 and 1996. In 1999, the upper age limit was extended to 75 years. The program led to a sharp increase in the detection rate of DCIS, which was reinforced by the replacement of screen-film mammography by full-field digital mammography in 2009-2010.3,4 Autopsy studies have shown that DCIS often does not progress to invasive disease. ${ }^{5}$ Sometimes a fraction of all preclinical DCIS may even regress spontaneously. ${ }^{6}$ The aforementioned implies that part of the observed increase in the diagnosis and treatment of DCIS may be partly unnecessary and could be seen as overdiagnosis, thereby resulting in avoidable treatment-related morbidity. ${ }^{7,8}$ However, predicting which DCIS lesions will regress and which will proceed to invasive breast cancer is hardly possible yet. Therefore, almost all patients with DCIS undergo surgical treatment.

According to the guidelines, adequate treatment of DCIS consists of mastectomy or breast conserving surgery (BCS), pursuing complete microscopic tumor excision. In case of BCS additional whole-breast radiotherapy is standard of care.9,10 The recommendation for adjuvant radiotherapy is based on the results of several randomized controlled trials, showing a reduction of the incidence of both in situ and invasive local recurrence by half. ${ }^{11-13}$ Fifteen-year ipsilateral local recurrence rates following BCS with adjuvant radiotherapy for DCIS vary between $7 \%$ and 11\%.14 Contralateral invasive breast cancer incidence fifteen-years after DCIS diagnosis was approximately $6.5 \%$, compared to $3.4 \%$ in the general population. ${ }^{14}$ There is no evidence which supports performing SNB in patients with pure DCIS in final pathology. ${ }^{15}$ Axillary lymph node dissection (ALND), which used to be the gold standard, was therefore replaced by sentinel lymph node biopsy (SLNB) in the late 1990s. Today SLNB for patients with DCIS may be considered in the presence of clinical risk factors for an invasive component or for those who will undergo mastectomy. ${ }^{16}$

The aim of this population-based study was to evaluate patterns of care in the treatment of DCIS in the Netherlands since the introduction of the national screening program with particular interest in the use of BCS, radiotherapy 
following BCS and the use and type of axillary staging. Additionally, we analyzed the risk of invasive local relapse in patients undergoing BCS.

\section{Methods}

\section{Study population}

In this population based retrospective cohort study, data and records of all newly diagnosed women with DCIS in the Netherlands were retrieved from the Netherlands Cancer Registry (NCR). The NCR contains all new cases of in situ and invasive malignancies and data on patient, tumor and treatment characteristics. ${ }^{17}$ Data are available on a national level since 1989. Patients were included in the NCR database, after notification by the nationwide Dutch Pathology Archive of Histoand Cytopathology (PALGA). ${ }^{18}$ Specially trained data managers collected data from patient files in Dutch hospitals. The NCR routinely collected information on the occurrence of invasive relapse and the date of death. Follow-up for these endpoints was completed until January 2019.

In the Netherlands, the first round of a population-based screening program for breast cancer was implemented during 1989-1996, offering free of charge biennial mammography to women aged 50-70 years. Since 1999 women aged 70-75 years are also invited. Screen-film mammography was replaced by full-field digital mammography in 2009-2010. Since digital mammography a two-view mammography (medio-lateral-oblique view and cranio-caudal view) of each breast is obtained by a certified radiographer and the examination is assessed by two screening radiologists. For the current study, all screen-detected and clinically detected DCIS from January 1989 until January 2019 in women aged 50-75 years were included. Whether a patient was detected by screening was adequately registered before 2011.

For further analysis on subgroups we excluded all two-year cohorts with more than $20 \%$ missing data. This meant that for analyses of the type of local treatment and ALND patients treated before 1995 were excluded. For analysis on grade, we only included patients diagnosed from 2001 onwards. And for the analysis on SLNB, patients were included since 2005. Women with sentinel lymph node (SLN) involvement could not be included in our analyses, as in these cases the diagnosis of DCIS was overwritten by invasive breast cancer in the NCR database. 


\section{Statistical analysis}

Patients were categorized by two-year cohorts based on date of diagnosis.

Trends in breast surgery were studied and expressed as proportion of all patients per two-year cohort. The trends in use of adjuvant radiotherapy were expressed as proportions of all patients undergoing BCS per two-year cohort. Trends in use of radiotherapy was also categorized by grade. Trends in axillary surgery were categorized per type of axillary treatment, within those categories, trends in treatment were expressed as proportion of all patients. Trends in axillary treatment was also categorized by type of breast surgery. When trends were compared, missing data was excluded for all subgroups.

Statistical analyses were performed using SPSS, version 24.0 (SPSS, Inc., Chicago, USA). Chi-square analyses were performed to compare proportional differences in categorical variables between groups. $P$-values less than 0.05 were considered statistically significant. Kaplan-Meier analyses, were performed to estimate the cumulative risk of invasive local recurrence, expressed as invasive relapse-free survival (iRFS) [with 95\% confidence interval] following BCS. Differences in the iRFS between periods of diagnosis and between patients with and without breast radiotherapy following BCS were compared by means of the two-tailed log-rank test.

\section{Results}

Between January 1989 and January 2019, 30,417 women aged 50-74 years were diagnosed with DCIS in the Netherlands. Baseline characteristics of these patients are shown in Table 7.1. Since 2011, 75.1\% $(10,444 / 13,913)$ of all patients had been detected by the national screening program. The number of new cases increased from 379 in $1989-1990$ to 3,573 in 2017-2018. Of all patients $48.7 \%$ $(11,238 / 23,065)$ was high grade, $34.5 \%(7,953 / 23,065)$ intermediate grade and $16.8 \%(3,874 / 23,065)$ low grade. 
Table 7.1 Baseline characteristics.

\begin{tabular}{|c|c|c|c|}
\hline & \multicolumn{2}{|c|}{ Total (\%) } & Missing data excluded (\%) \\
\hline Period of diagnosis & \multicolumn{2}{|c|}{$n=30,417$} & \\
\hline $1989-1990$ & 379 & $(1,3)$ & \\
\hline 1991-1992 & 713 & $(2,5)$ & \\
\hline 1993-1994 & 968 & $(3,4)$ & \\
\hline 1995-1996 & 1.084 & $(3,8)$ & \\
\hline 1997-1998 & 1.270 & $(4,5)$ & \\
\hline $1999-2000$ & 1.502 & $(5,3)$ & \\
\hline $2001-2002$ & 1.555 & $(5,5)$ & \\
\hline $2003-2004$ & 1.750 & $(6,2)$ & \\
\hline $2005-2006$ & 1.872 & $(6,6)$ & \\
\hline 2007-2008 & 2.180 & $(7,7)$ & \\
\hline $2009-2010$ & 2.818 & $(9,9)$ & \\
\hline 2011-2012 & 3.238 & $(11,4)$ & \\
\hline $2013-2014$ & 3.690 & $(13,0)$ & \\
\hline $2015-2016$ & 3.825 & $(13,5)$ & \\
\hline 2017-2018 & 3.573 & $(12,6)$ & \\
\hline Screen detected $^{\wedge}$ & \multicolumn{2}{|c|}{$n=14,326$} & \\
\hline Yes & 10,444 & $(72.9)$ & \\
\hline No & 3,469 & $(24.9)$ & \\
\hline Unknown & 413 & $(2.9)$ & \\
\hline Treatment $^{\#}$ & \multicolumn{2}{|c|}{$n=28,357$} & $n=27,783$ \\
\hline Mastectomy & 9,790 & $(34.5)$ & $(35.2)$ \\
\hline BCS + radiotherapy & 13,859 & $(48.9)$ & (49.9) \\
\hline BCS only & 3,760 & (13.3) & (13.5) \\
\hline No treatment & 374 & $(1.3)$ & $(1.3)$ \\
\hline Unknown & 574 & $(2.0)$ & \\
\hline DCIS grade* & \multicolumn{2}{|c|}{$n=24,501$} & $n=23,065$ \\
\hline Low & 3,874 & $(15.8)$ & $(16.8)$ \\
\hline Intermediate & 7,953 & $(32.5)$ & $(34.5)$ \\
\hline High & 11,238 & $(45.9)$ & $(48.7)$ \\
\hline Unknown & 1,436 & $(5.9)$ & \\
\hline \multicolumn{4}{|l|}{ Axillary treatment } \\
\hline ALND $\#$ & \multicolumn{2}{|c|}{$n=28,357$} & $n=27,920$ \\
\hline Yes & 872 & $(3.1)$ & (3.1) \\
\hline No & 27,048 & $(95.4)$ & $(96.9)$ \\
\hline Unknown & 437 & $(1.5)$ & \\
\hline $\mathrm{SLNB}^{ \pm}$ & \multicolumn{2}{|c|}{$n=21,196$} & $n=19,971$ \\
\hline Yes & 11,340 & (39.1) & (56.8) \\
\hline No & 8,631 & $(30.4)$ & $(43.2)$ \\
\hline Unknown & 1,225 & $(4.3)$ & \\
\hline
\end{tabular}

$\wedge$ data available since 2011; \# data available 1995; * data available since 2001; ${ }^{ \pm}$data available since 2005.

\section{Breast surgery and radiotherapy for DCIS}

Since 1995 type of surgery was not specified in $2.0 \%(574 / 28,357)$ of all women diagnosed with DCIS, resulting in 27,783 women for whom type of treatment was registered. A mastectomy was performed in 9,790 (35.2\%) women, 17,619 (63,4\%) 
underwent BCS and 374 (1.3\%) did not receive any surgical treatment (Figure 7.1). The percentage of patients undergoing BCS increased from 47.7\% (460/965) in $1995-1996$ to $72.7 \%(2,474 / 3,404)$ in $2017-2018(p<0.001)$.

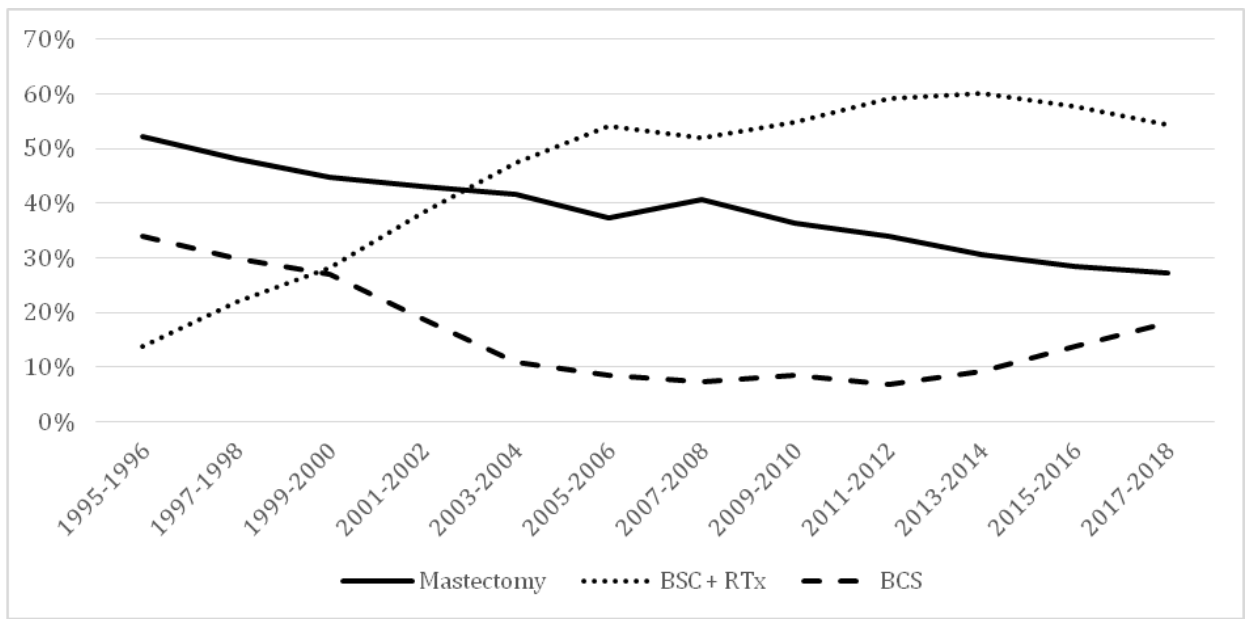

Figure 7.1 Trends in type of surgical treatment. BCS = breast conserving surgery; RTx = radiotherapy.

Among patients undergoing BCS, 78.7\% (13,859/17,619) received adjuvant radiotherapy. This proportion increased from $28.9 \%(133 / 460)$ in 1995-1996 to $89.6 \%(1,890 / 2,110)$ in $2011-2012(p<0.001)$ and decreased again to $74.9 \%$ $(1,854 / 2,474)$ in 2017-2018 $(p<0.001)$. Figure 7.2 shows the trend in use of radiotherapy after BCS since 2001 , divided by DCIS grade. For low grade DCIS the number of patient receiving adjuvant radiotherapy increased from $41.5 \%(68 / 164)$ in $2001-2002$ to $77.3 \%(170 / 220)$ in $2007-2008(p<0.001)$ which steadily decreased in more recent years to $30.5 \%(127 / 416)$ in $2017-2018(p<0.001)$. For intermediate and high grade DCIS, the use of radiotherapy remained rather stable ( $p=0.72$ and $p=0.09$ respectively).

When comparing use of BCS in the different gradings in 2017-2018, 30.5\% $(127 / 416)$ of all low grade DCIS was treated with BCS including adjuvant radiotherapy, compared to $76.7 \%$ (758/988) of all intermediate grade DCIS $(p<0.001)$ and $93.9 \%(918 / 978)$ of all high grade DCIS $(p=0.002)$. 


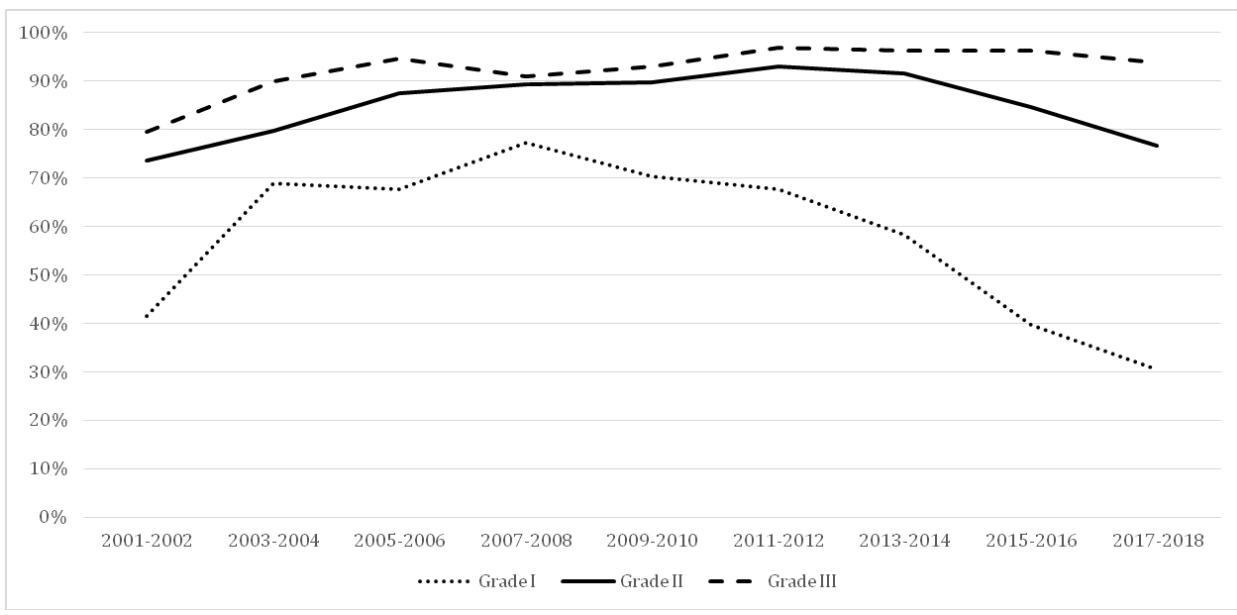

Figure 7.2 Trends in the use of radiotherapy after breast conserving surgery divide by grade since 2001.

\section{Axillary surgery in DCIS}

Since 1995, 872 (3.1\%; 872/28,357) women underwent ALND. When excluding all missing data since 1995 ( $n=437 ; 1.5 \%$ ) the proportion of women undergoing ALND decreased over the years from $23.0 \%(223 / 1,084)$ in $1995-1996$ to less than $1 \%$ $(27 / 2,806)$ in $2009-2010$ and later $(p<0.001)$. SLNB was performed in 11,340 women since 2005 (53.5\%; 11,340/21,196). The proportion of patients undergoing SLNB rapidly increased since its introduction in $1997-1998$ to $63.1 \%(2,328 / 3,690)$ in $2013-2014$ and subsequently decreased to $52.8 \%(1,888 / 3,573)$ in $2017-2018$ $(p<0.001)$.

Overall, $20.2 \%(684 / 3,393)$ of all patients with low grade DCIS underwent SLNB compared to $45.1 \%(3,197 / 7,087)$ of those with intermediate DCIS and $71.9 \%$ $(7,031 / 9,778)$ of those with high grade DCIS $(p<0.001)$. Figure 7.3 shows the trend in SLNB use categorized by DCIS grade since 2005. When categorized by type of breast surgery, as shown in Figure $7.4,75.1 \%(5,058 / 6,732)$ of all patients who underwent a mastectomy since 2005 underwent SLNB, compared to $45.0 \%$ $(6,270 / 13,922)$ of the patients who underwent BCS $(p<0.001)$.

In recent years, an increasing number of patients did not receive any axillary surgery. When focusing on BCS only, 52.3\% (6.900 /13.187) of all women did not receive axillary surgery since 2005 . In 2013-2014 axillary surgery was omitted in $45.6 \%(1,140 / 2,498)$, compared to $55.8 \%$ in $2017-2018(1,381 / 2,474 ; p<0.001$; Figure 7.5). 


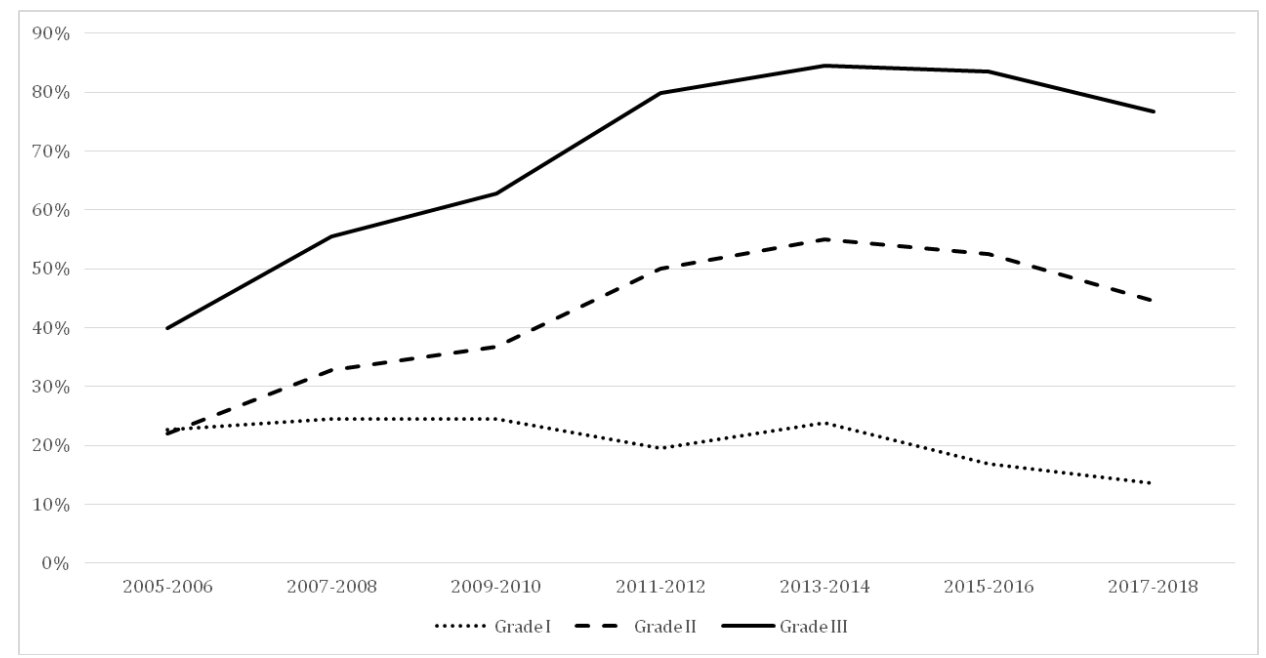

Figure 7.3 Trends in sentinel lymph node biopsy divided by grade.

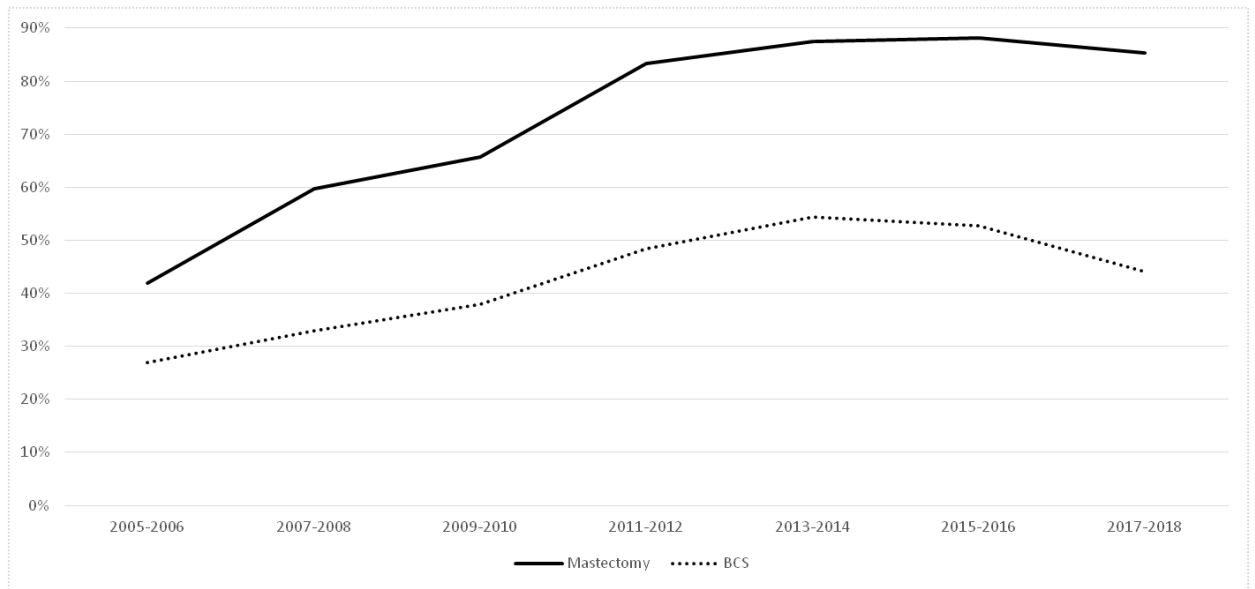

Figure 7.4 Trends in sentinel lymph node biopsy divided by type of surgical treatment. 


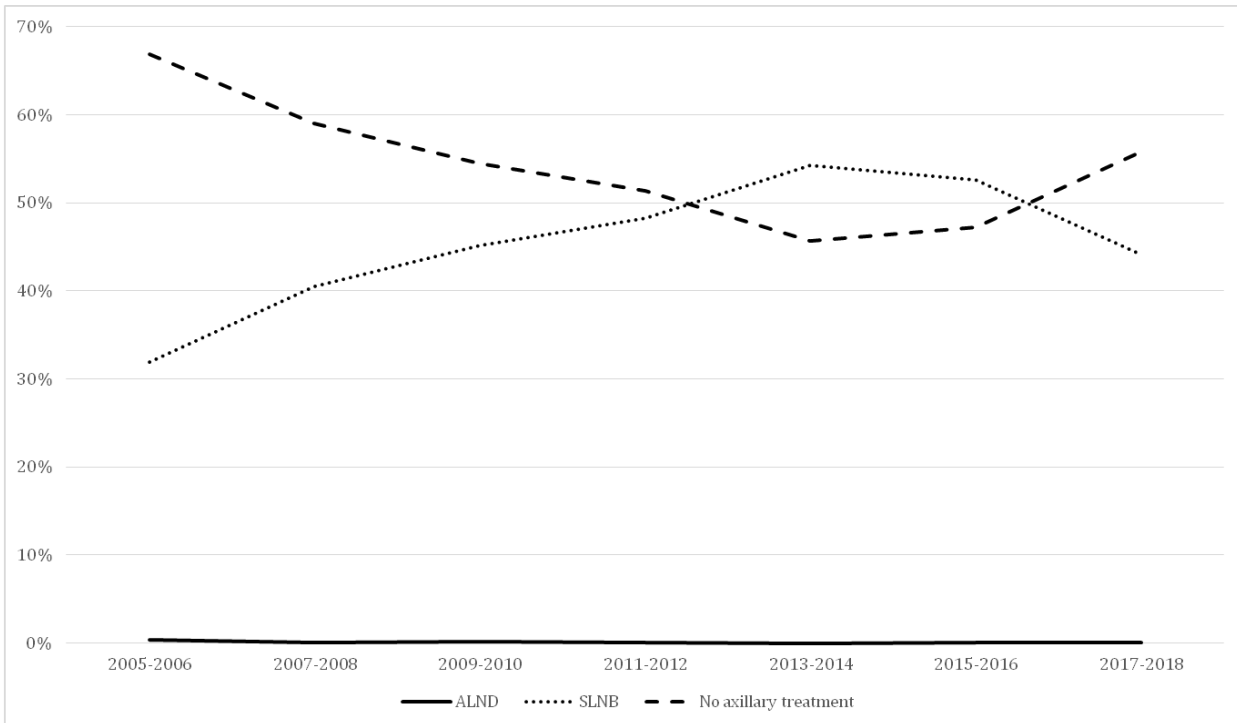

Figure 7.5 Trends in axillary treatment in breast conserving surgery.

ALND = axillary lymph node dissection; SLNB = sentinel lymph node biopsy.

\section{Risk of invasive local recurrence}

For the period 1989-2010, iRFS analysis comparing BCS with and without adjuvant radiotherapy showed a five-year iRFS rate of 98.7\% [CI 98.4\%-99.0\%] for women undergoing BCS with adjuvant radiotherapy, compared to 95.0\% [CI 94.1\%-95.8\%] for women undergoing BCS only $(p<0.001$; Figure $7.6 \mathrm{a})$. The ten-year iRFS rates were 96.6\% [CI 96.2\%-97.0\%] vs. 90.2\% [CI 89.0\%-91.5\%] respectively $(p<0.001)$. The fifteen-year iRFS rate was $94.2 \%$ [93.6\%-94.8\%] compared to $87.1 \%$ [CI $85.6 \%-88.6 \%$ ] respectively $(p<0.001)$.

For the period 2011-2018, the five-year iRFS rate was 99.3\% [CI 99.1\%-99.5\%] for women undergoing BCS with adjuvant radiotherapy, compared to $98.8 \%$ [CI 98.2\%-99.4\%] for women undergoing BCS only ( $p=0.01$; Figure 7.6b). 
Patterns of treatment and outcome of ductal carcinoma in situ in the Netherlands | 105

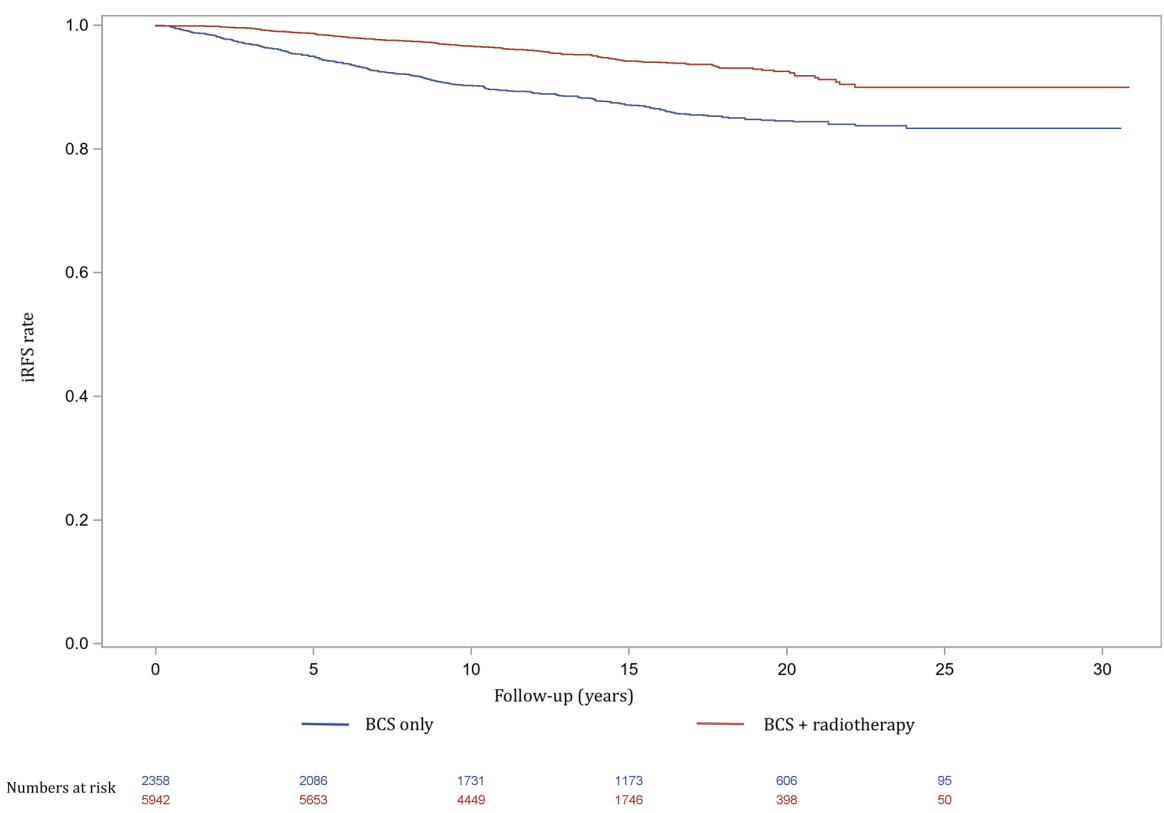

Figure 7.6a Invasive relapse free survival for the period 1989-2010, including numbers at risk.

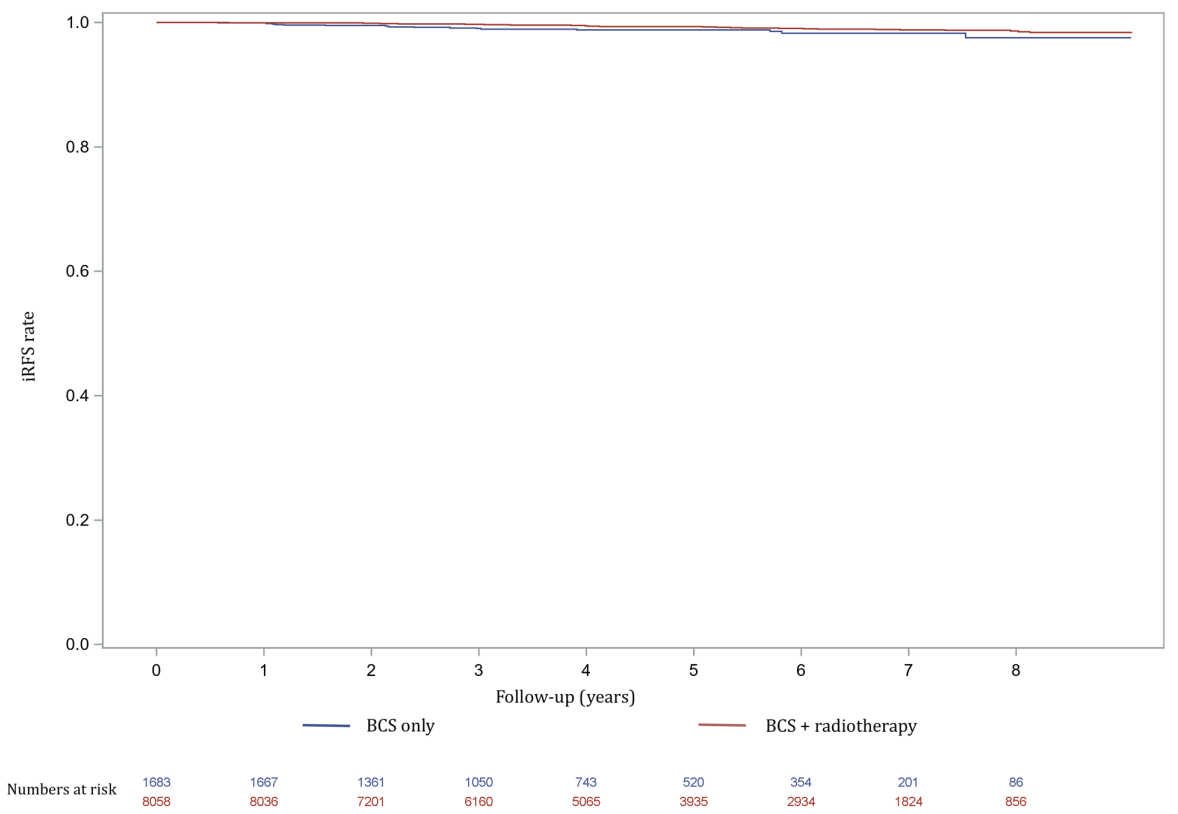

Figure 7.6b Invasive relapse free survival for the period 2011-2018, including numbers at risk. 


\section{Discussion}

This large population-based study among patients aged 50-75 years shows a tenfold increase in the numbers of patients with DCIS in the Netherlands the last three-decades. The use of BCS increased from $47.7 \%$ in $1995-1996$ to $72.7 \%$ in 2017-2018. Among patients undergoing BCS a sharp rise in the use of adjuvant radiotherapy was observed from $28.9 \%$ in 1995-1996 to almost 90\% in 2011-2012, followed by a drop to $74.9 \%$ in the most recent years. ALND has been replaced by SLNB over the years, which itself is increasingly replaced by no axillary surgery $(55.8 \%)$ in patients undergoing BCS in 2017-2018.

Patients diagnosed with DCIS have become significantly more likely to receive BCS, which is in accordance with the findings in previously published studies. ${ }^{19,20}$ BCS has become the preferred surgical treatment for invasive breast cancer, after several randomized clinical trials had shown that BCS with radiotherapy offers the same overall survival rate as mastectomy alone. ${ }^{21,22}$ These findings may have had a positive effect on the use of BCS for DCIS as well. Another likely explanation might be that digital mammography screening detects lesions with smaller tumor sizes, which therefore may be more suitable for BCS. ${ }^{23,24}$ Unfortunately, our data did not include information on the extent of DCIS lesions.

Even though adjuvant radiotherapy following BCS is still considered as a standard therapeutic option in most treatment guidelines, the guidelines also state that radiotherapy can be omitted in cases of DCIS $<10 \mathrm{~mm}$, low- and intermediate grade and excised with adequate margins. ${ }^{10}$ We observed a decrease in the proportion of patients receiving additional radiotherapy the last five years. iRFS analyses showed that the risk of invasive local recurrence was dependent on the use adjuvant radiotherapy and that this association was much stronger for the patients diagnosed in the older period (1989-2010). The absolute difference in the 5-year risk of local recurrence between patients with and without adjuvant radiotherapy was only $0.5 \%(0.7 \%$ vs. $1.2 \%$, respectively) for the patients treated since 2011 . A possible explanation for the low risk of invasive local recurrence in the recent period might be increased consensus on the relevance to obtain tumor-negative resection margins after $\mathrm{BCS} .{ }^{25}$ Another explanation might be the higher sensitivity of digital mammography, resulting in the detection of smaller lesions. This drives the discussion about omitting radiotherapy in a larger proportion of the patients undergoing BCS.

For the survival analysis 2011 was chosen as cut-off point, because digital mammography was fully implemented in the Netherlands since then. 
Four randomized controlled trials on adjuvant radiotherapy in DCIS patients have been published.11,12,26,27 An overview of these trials showed that additional radiotherapy halves the risk of an ipsilateral breast event (invasive and noninvasive). However, it has not been shown to improve breast cancer overall survival. ${ }^{28}$

If no survival benefit is found, the reduced risk of local recurrence following radiotherapy must be weighed against the disadvantages. The most common side effect of radiation is acute skin toxicity within weeks after treatment. Radiation can also have negative cosmetics effects due to development of skin pigmentation, telangiectasia, fibrosis and retraction. ${ }^{29}$ Furthermore, breast radiotherapy might increase the risk of primary lung cancer among smokers and left-sided breast cancer radiotherapy is proven to be cardiotoxic. ${ }^{30,31}$ Because of this long-term side effect the average mean heart dose of left-sided whole breast radiotherapy, which used to be $5.4 \mathrm{Gray}^{32}$, is much lower nowadays with the use of deep inspiration breath hold technique (reduction of 3.4 Gray) and partial breast irradiation. ${ }^{33}$

Over the years, research focused on the identification of subgroups of patients with favorable features for whom the risk of invasive recurrence in the absence of radiotherapy is so low that radiotherapy can safely be omitted. ${ }^{34}$ A recent observational study in 2016 suggests a possible survival benefit of radiotherapy, which may be most important when certain risk factors are present. ${ }^{35}$ Factors such as tumor size, age and nuclear grade were used to produce a recurrence risk scoring system, known as the patient prognostic score. Significant improvements in survival after radiotherapy were only observed in patients with higher nuclear grade, younger age, and larger tumor size. The magnitude of the survival difference with radiotherapy was significantly correlated with this prognostic score $(p<0.001) .^{35}$ Therefore, it is recommended to tailor radiotherapy on patient factors, tumor biology and the prognostic score. ${ }^{35,36}$

Since pure DCIS is not accompanied by nodal involvement, de-escalating axillary treatment in DCIS patients is justified. ALND is no longer part of the standard treatment for DCIS, as is also illustrated by our study, showing a replacement of ALND by SLNB. In most recent years we also observed a significant declined in axillary staging by any surgical procedure. The trend to omit SLNB is probably initiated by the rather low incidence of SLN involvement, ranging from 0 to $10 \%$ between different studies. ${ }^{37-39}$ Unfortunately, we were not able to report on SLN involvement, as in case of any SLN involvement the diagnosis of DCIS was overwritten by invasive breast cancer in the NCR database.

Even if the SLN is found positive in patients with a preoperative diagnosis of DCIS, it is most frequently presents as isolated tumor cells or micrometastases (defined 
as small metastases sized $0.2-2.0 \mathrm{~mm}$ ), which are of limited prognostic value on disease free and overall survival. ${ }^{15}$ Therefore, we agree with a recent study by Van Roozendaal et al. who suggest to omit SLNB completely in patients with DCIS undergoing BCS, as preforming a delayed SLNB following lumpectomy if invasive cancer is shown is nowadays considered a feasible option. ${ }^{39}$ In patients undergoing mastectomy, SLNB cannot reliably be performed afterwards and therefore may still need to be performed in DCIS patient undergoing a mastectomy. ${ }^{9}$

Our study suggests that many clinicians use DCIS grade not only to consider the use of additional radiotherapy, but also the use of SLNB. Ongoing clinical trials aiming to identify a subgroup of low risk DCIS also base identification of this subgroup on histologic grade. ${ }^{40,41}$ DCIS grading is based on morphologic characteristics, such as growth pattern, cytoplasmatic feature, nuclear pleomorphism and mitotic activity. Since diagnostic criteria are not always clear, differences in morphological interpretation do make the accuracy of DCIS grading questionable. ${ }^{42,43}$ Consequently, histologic grading of DCIS is currently not meeting high enough standards. ${ }^{44}$ Improvement of the accuracy is extremely relevant, since grade is the most important determinant for the management of DCIS at the moment. Recent studies on molecular alteration driving the progression of DCIS towards invasive breast cancer, show that gene expression profiling can possibly improve the ability to predict progression to invasive breast cancer. ${ }^{45-47}$ This suggests that more effective methods of detecting, diagnosing and treating DCIS can be developed based on targeting these genes, resulting in more individualized treatments in the near future. However, gene expression profiling is still very expensive and recent studies suggest that the use of a free-of-charge online Nomogram (available online at www.nomograms.org) is concordant with those obtained using the commercially available DCIS scores for women aged 50 years or older with small DCIS $(\leq 2.5 \mathrm{~cm}) \cdot 48$

This study has several limitations. The study population, selected from the NCR, was not manually controlled using the PALGA database. A previous study by Elshof et al., also using data from the NCR, has shown that not all DCIS patients in the NCR database consisted of pure DCIS when checked in the PALGA database. ${ }^{14}$ Therefore, our results on the iRFS must be interpreted considering this misclassification, especially in the older years, which may have caused a too low iRFS rate. Furthermore, the follow-up in our iRFS analysis for recent years (2011-2018) is still short. In addition, the iRFS analysis only contains invasive relapses. Data on non-invasive relapse was not available. Data on overall survival were not included in this study, since it has already been described that DCIS patients have a higher 
risk of dying from breast cancer compared with the general female population, but absolute ten-year risks are very low. ${ }^{49}$

In conclusion, the use of BCS, radiotherapy and axillary staging in patients with DCIS varies over time. The incidence of BCS increased over the years with a decline in the use of adjuvant radiotherapy and SLNB, especially for low grade DCIS, in more recent years. The lack of consensus in recent literature reflects our limited knowledge about the natural progression of untreated DCIS. Because of this dilemma, current treatment protocols may be too defensive and result in overtreatment of many women. Therefore, more research is needed to help prevent overdiagnosis and overtreatment in the future. 


\section{References}

1. van Luijt PA, Heijnsdijk EA, Fracheboud J et al: The distribution of ductal carcinoma in situ (DCIS) grade in 4232 women and its impact on overdiagnosis in breast cancer screening. Breast Cancer Res 2016;18(1):47.

2. Henrot P, Leroux A, Barlier C et al: Breast microcalcifications: the lesions in anatomical pathology. Diagn Interv Imaging 2014;95(2):141-152.

3. Jing H. YY, Wernick M.N., Yarusso L.M., Nishikawa R.M.: A comparison study of image features between FFDM and film mammogram images. Med Phys 2012;39(7):4386-4394.

4. Bleyer A, Welch HG: Effect of three decades of screening mammography on breast-cancer incidence. N Engl J Med 2012;367(21):1998-2005.

5. Hollingsworth A: Overestimating Overdiagnosis in Breast Cancer Screening. Cureus 2017; 9(1):e966.

6. de Gelder R: Predicting the Benefits and Harms of Breast Cancer Screening: Current debates and future directions. Ph.D. thesis. Erasmus MC: University Medical Center Rotterdam; 2012.

7. Seigneurin A, Labarere J, Francois 0 et al: Overdiagnosis and overtreatment associated with breast cancer mammography screening: A simulation study with calibration to population-based data. Breast (Edinburgh, Scotland) 2016;28:60-66.

8. Duffy SW, Agbaje O, Tabar L et al: Overdiagnosis and overtreatment of breast cancer: estimates of overdiagnosis from two trials of mammographic screening for breast cancer. Breast Cancer Res 2005;7(6):258-265.

9. NABON. Federatie Medisch Specialisten - Richtlijn mammacarcinoom Last updated 01-07-2018. Available from: https://richtlijnendatabase.nl/richtlijn/borstkanker/dcis.html.

10. Cardoso F, Kyriakides S, Ohno S et al: Early breast cancer: ESMO Clinical Practice Guidelines for diagnosis, treatment and follow-up. Ann Oncol 2019;30(10):1674.

11. Donker M, Litiere S, Werutsky G et al: Breast-conserving treatment with or without radiotherapy in ductal carcinoma In Situ: 15-year recurrence rates and outcome after a recurrence, from the EORTC 10853 randomized phase III trial. J Clin Oncol 2013;31(32):4054-4059.

12. Warnberg F, Garmo H, Emdin S et al: Effect of radiotherapy after breast-conserving surgery for ductal carcinoma in situ: 20 years follow-up in the randomized SweDCIS Trial. J Clin Oncol 2014; 32(32):3613-3618.

13. Holmberg L, Garmo H, Granstrand B et al: Absolute risk reductions for local recurrence after postoperative radiotherapy after sector resection for ductal carcinoma in situ of the breast. J Clin Oncol 2008;26(8):1247-1252.

14. Elshof LE, Schaapveld M, Schmidt MK et al: Subsequent risk of ipsilateral and contralateral invasive breast cancer after treatment for ductal carcinoma in situ: incidence and the effect of radiotherapy in a population-based cohort of 10,090 women. Breast Cancer Res Treat 2016;159(3):553-563.

15. Meretoja TJ, Heikkila PS, Salmenkivi K, Leidenius MH. Outcome of patients with ductal carcinoma in situ and sentinel node biopsy. Ann Surg Oncol 2012;19(7):2345-2351.

16. Lyman GH, Somerfield MR, Bosserman LD et al: Sentinel Lymph Node Biopsy for Patients With Early-Stage Breast Cancer: American Society of Clinical Oncology Clinical Practice Guideline Update. J Clin Oncol 2017;35(5):561-564.

17. IKNL. Netherlands Cancer Registry Available from: https://www.iknl.nl/en/ncr.

18. PALGA Foundation [https://www.palga.nl/en/about-stichting-palga/stichting-palga.html]

19. van Steenbergen LN, Voogd AC, Roukema JA et al: Time trends and inter-hospital variation in treatment and axillary staging of patients with ductal carcinoma in situ of the breast in the era of screening in Southern Netherlands. Breast (Edinburgh, Scotland) 2014;23(1):63-68.

20. Rakovitch E, Pignol JP, Chartier C et al: The management of ductal carcinoma in situ of the breast: a screened population-based analysis. Breast Cancer Res Treat 2007;101(3):335-347.

21. van Dongen JA, Voogd AC, Fentiman IS et al: Long-term results of a randomized trial comparing breast-conserving therapy with mastectomy: European Organization for Research and Treatment of Cancer 10801 trial. J Natl Cancer Inst 2000;92(14):1143-1150. 
22. Veronesi U, Cascinelli N, Mariani L et al: Twenty-year follow-up of a randomized study comparing breast-conserving surgery with radical mastectomy for early breast cancer. N Engl J Med 2002; 347(16):1227-1232.

23. Del Turco MR, Mantellini $\mathrm{P}$, Ciatto $\mathrm{S}$ et al: Full-field digital versus screen-film mammography: comparative accuracy in concurrent screening cohorts. AJR Am J Roentgenol 2007;189(4):860-866.

24. Karssemeijer N, Bluekens AM, Beijerinck D et al: Breast cancer screening results 5 years after introduction of digital mammography in a population-based screening program. Radiology 2009; 253(2):353-358.

25. Morrow M, Van Zee KJ, Solin LJ et al: Society of Surgical Oncology-American Society for Radiation Oncology-American Society of Clinical Oncology Consensus Guideline on Margins for BreastConserving Surgery With Whole-Breast Irradiation in Ductal Carcinoma in Situ. Pract Radiat Oncol 2016;6(5):287-295.

26. Cuzick J, Sestak I, Pinder SE, Ellis IO, Forsyth S, Bundred NJ, Forbes JF, Bishop H, Fentiman IS, George WD. Effect of tamoxifen and radiotherapy in women with locally excised ductal carcinoma in situ: long-term results from the UK/ANZ DCIS trial. Lancet Oncol 2011;12(1):21-29.

27. Wapnir IL, Dignam JJ, Fisher B et al: Long-term outcomes of invasive ipsilateral breast tumor recurrences after lumpectomy in NSABP B-17 and B-24 randomized clinical trials for DCIS. J Natl Cancer Inst 2011;103(6):478-488.

28. Correa $\mathrm{C}$, McGale $\mathrm{P}$, Taylor $\mathrm{C}$ et al: Overview of the randomized trials of radiotherapy in ductal carcinoma in situ of the breast. J Natl Cancer Inst Monogr 2010;2010(41):162-177.

29. Hamdi M, Wolfli J, Van Landuyt K: Partial mastectomy reconstruction. Clin Plast Surg 2007; 34(1):51-62; abstract vi.

30. Kaufman EL, Jacobson JS, Hershman DL et al: Effect of breast cancer radiotherapy and cigarette smoking on risk of second primary lung cancer. J Clin Oncol 2008;26(3):392-398.

31. Taylor C, Correa C, Duane FK et al: Estimating the Risks of Breast Cancer Radiotherapy: Evidence From Modern Radiation Doses to the Lungs and Heart and From Previous Randomized Trials. J Clin Oncol 2017;35(15):1641-1649.

32. Taylor CW, Wang Z, Macaulay E et al: Exposure of the Heart in Breast Cancer Radiation Therapy: A Systematic Review of Heart Doses Published During 2003 to 2013. Int J Radiat Oncol Biol Phys 2015;93(4):845-853.

33. Smyth LM, Knight KA, Aarons YK et al: The cardiac dose-sparing benefits of deep inspiration breath-hold in left breast irradiation: a systematic review. J Med Radiat Sci 2015;62(1):66-73.

34. Silverstein MJ: An argument against routine use of radiotherapy for ductal carcinoma in situ. Oncology (Williston Park) 2003;17(11):1511-1533; discussion 1533-1514, 1539, 1542 passim.

35. Sagara Y, Freedman RA, Vaz-Luis I et al: Patient Prognostic Score and Associations With Survival Improvement Offered by Radiotherapy After Breast-Conserving Surgery for Ductal Carcinoma In Situ: A Population-Based Longitudinal Cohort Study. J Clin Oncol 2016;34(11):1190-1196.

36. van Maaren MC, Lagendijk M, Tilanus-Linthorst MMA et al: Breast cancer-related deaths according to grade in ductal carcinoma in situ: A Dutch population-based study on patients diagnosed between 1999 and 2012. Eur J Cancer 2018;101:134-142.

37. Francis AM, Haugen CE, Grimes LM et al: Is Sentinel Lymph Node Dissection Warranted for Patients with a Diagnosis of Ductal Carcinoma In Situ? Ann Surg Oncol 2015;22(13):4270-4279.

38. Holm-Rasmussen EV, Jensen MB, Balslev E et al: Risk factors of sentinel and non-sentinel lymph node metastases in patients with ductal carcinoma in situ of the breast: A nationwide study. Breast (Edinburgh, Scotland) 2018;42:128-132.

39. van Roozendaal LM, Goorts B, Klinkert M et al: Sentinel lymph node biopsy can be omitted in DCIS patients treated with breast conserving therapy. Breast Cancer Res Treat 2016;156(3):517-525.

40. Elshof LE, Tryfonidis K, Slaets L et al: Feasibility of a prospective, randomised, open-label, international multicentre, phase III, non-inferiority trial to assess the safety of active surveillance for low risk ductal carcinoma in situ - The LORD study. Eur J Cancer 2015;51(12):1497-1510.

41. Francis A, Thomas J, Fallowfield L et al: Addressing overtreatment of screen-detected DCIS; the LORIS trial. Eur J Cancer 2015;51(16):2296-2303.

42. Van de Vijver MJ, Peterse H: The diagnosis and management of pre-invasive breast disease: pathological diagnosis--problems with existing classifications. Breast Cancer Res 2003;5(5):269. 
43. Pinder SE, Ellis IO: The diagnosis and management of pre-invasive breast disease: ductal carcinoma in situ (DCIS) and atypical ductal hyperplasia (ADH)--current definitions and classification. Breast Cancer Res 2003;5(5):254-257.

44. van Dooijeweert C, van Diest PJ, Willems SM et al: Significant inter- and intra-laboratory variation in grading of ductal carcinoma in situ of the breast: a nationwide study of 4901 patients in the Netherlands. Breast Cancer Res Treat 2019;174(2):479-488.

45. Doebar SC, Sieuwerts AM, de Weerd V et al: Gene Expression Differences between Ductal Carcinoma in Situ with and without Progression to Invasive Breast Cancer. Am J Pathol 2017; 187(7):1648-1655.

46. Nofech-Mozes S, Hanna W, Rakovitch E: Molecular Evaluation of Breast Ductal Carcinoma in Situ with Oncotype DX DCIS. Am J Pathol 2018;189(5):975-980.

47. Rakovitch E, Gray R, Baehner FL et al: Refined estimates of local recurrence risks by DCIS score adjusting for clinicopathological features: a combined analysis of ECOG-ACRIN E5194 and Ontario DCIS cohort studies. Breast Cancer Res Treat 2018;169(2):359-369.

48. Van Zee KJ, Zabor EC, Di Donato R et al: Comparison of Local Recurrence Risk Estimates After Breast-Conserving Surgery for DCIS: DCIS Nomogram Versus Refined Oncotype DX Breast DCIS Score. Ann Surg Oncol 2019;26(10):3282-3288.

49. Elshof LE, Schmidt MK, Rutgers EJT et al: Cause-specific Mortality in a Population-based Cohort of 9799 Women Treated for Ductal Carcinoma In Situ. Ann Surg 2018;267(5):952-958. 


$$
\text { yo }
$$




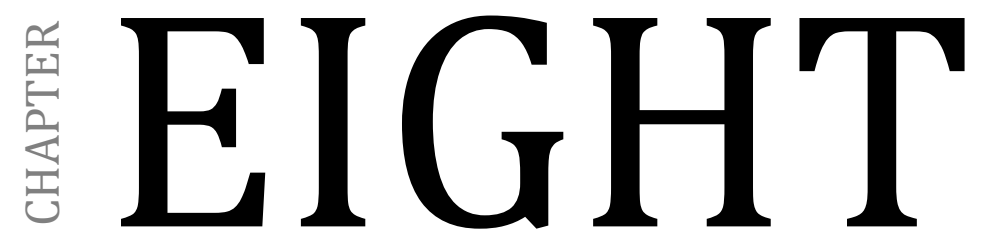

Summary and summary in Dutch

Nederlandse samenvatting 


\section{Summary}

In the Netherlands a nation-wide biennial mammographic screening program for women aged 50-70 years was set up between 1989 and 1996. In 1998-1999, the upper age limit of the program was extended from 70 to 75 years and in 2009-2010 screen film mammography (SFM) was replaced by full field digital mammography (FFDM).

The impact of the transition to digital mammography was analyzed in chapter 2 . The transition was characterized by an increase of the overall detection rate of ductal carcinoma in situ (DCIS) from 0.8 per 1000 to 1.6 per 1000 screens $(p=<0.001)$, as well as an increase of the detection rate of invasive cancers from 4.1 per 1000 to 5.1 per 1000 screens ( $p=0.003)$. The majority of the DCIS lesions detected by screening mammography was high grade $(48.2 \%)$, whereas the majority of the invasive breast cancer was low grade $(45.4 \%)$ or intermediate grade (41.6\%). The grade distribution the years after the transition to FFDM remained stable when compared to the era of SFM screening. It is hypothesized that if high grade DCIS develops towards invasive carcinoma, it is more likely that it will become a high grade rather than a low or intermediate grade carcinoma. ${ }^{1,2}$ Our findings therefore suggest that screening reduces the incidence of high grade invasive carcinoma through early diagnosis and treatment of high grade DCIS.

During the transition from SFM to FFDM the cancer detection rate remained stable, while the absolute number of screening examinations gradually increased from 66,750 in the last SFM period to 131,224 in the first FFDM period. In those same periods, the recall rate increased from $1.3 \%$ to $3.3 \%$. All recalled women require additional radiologic examinations which may be followed by percutaneous or surgical biopsy in order to obtain a definitive pathology result.

Chapter 3 evaluates the use and value of surgical excision biopsies for diagnostic purposes over the last two decades in women undergoing mammographic screening. All recalled women who underwent an excision biopsy from January 1997 to January 2017 were analyzed. It has been postulated that, with the introduction and widespread use of (stereotactic) core needle biopsy ((S)CNB), a surgical excision biopsy would become an obsolete procedure. ${ }^{3,4}$ Therefore, a distinction was made between primary excision biopsies (performed as first diagnostic intervention) and secondary excision biopsies (performed secondary to pathologic findings at percutaneous CNB). Indeed, the use of primary excision biopsies decreased from 4.3 per 1000 screens in 1997-1998 to 0 per 1000 screens 
in 2015-2016. But reversely, the rate of secondary excision biopsies, which initially decreased from 1.0 per 1000 screens in 1997-1998 to 0.3 per 1000 in 2005-2006, was found to increased again to 0.6 per 1000 in 2015-2016 ( $p=0.003)$. Of all secondary excision biopsies, $61.0 \%$ had a benign pathology outcome, and this proportion increased from $40.4 \%$ to $70.2 \%$ over the years. Since the vast majority of currently performed excision biopsies reveals a benign pathology result, the use of secondary excision biopsy should be considered carefully.

Since the introduction of digital mammography SCNB is performed more often, probably because digital mammography has a higher sensitivity for the detection of small lesions and microcalcifications compared to SFM. ${ }^{5}$ Pathologic examination of these small lesions has given rise to a new pathologic classification of so called 'high-risk' lesions. High-risk lesions are defined as being not identical to normal breast tissue, but not fulfilling criteria of either invasive breast cancer or precursor stadia also referred to as DCIS. Examples are flat epithelial atypia, atypical ductal hyperplasia, lobular carcinoma in-situ, papillary lesions and radial scars. Optimal management of these high-risk lesions found at SCNB is controversial due to its rather unknown natural behavior. ${ }^{6-9}$ Chapter 4 analyzes the incidence, management and outcome of high-risk breast lesions during the years 2011-2016. Despite a rather stable proportion of recalled women who underwent SCNB, the proportion of high-risk lesions at (S)CNB results gradually increased from $3.2 \%$ in 2011 to $9.5 \%$ in $2016(p<0.001)$. Subsequently, the excision rate for high-risk lesions per 1000 screens increased from 0.25 to $0.70 \quad(p<0.001)$. Since the proportion of surgical excisions showing in-situ or invasive breast cancer did not increase (overall 29\%), a growing number of screened women who underwent invasive surgical excision had a benign outcome.

The introduction of digital screening mammography resulted in a higher specificity and sensitivity for small lesions, including a better discrimination of fine microcalcifications. ${ }^{10}$ However, the information on trends in the detection of suspicious microcalcifications at mammography screening and the yield of these lesions after recall is limited. Therefore, in chapter $\mathbf{5}$ we analyzed these trends during 20 years of mammography screening. A fivefold increase in the recall for suspicious microcalcifications from $0.1 \%$ in $1997-1998$ to $0.5 \%$ in $2015-2016$ $(p<0.001)$ was found. The recalls yielding DCIS increased from 0.3 per 1000 screens to 1.1 per 1000 screens respectively $(p<0.001)$, resulting in a decrease in the positive predictive value for recall for suspicious microcalcifications from $51 \%$ to $33 \%(p<0.001)$. 
If DCIS is diagnosed and surgical treatment is required, accurate pre-operative localization of the lesion is of utmost importance in order to facilitate adequate resection when breast conserving surgery (BCS) is performed. In chapter 6 two methods for the localization of non-palpable DCIS lesions were compared: wireguided localization (WGL), which is currently the most frequently used localization technique, and radioactive iodine-125 seed guided localization (I-125 GL). Patients in the I-125 GL group had a significantly lower risk of extensively involved resection margins compared to patients in the WGL group $(4.4 \%$ vs. $12.8 \%$; $p=0.048$ ). This resulted in fewer patients in the I-125 GL group who needed an additional surgical treatment. I-125 GL proved to be an attractive alternative to WGL for the resection of non-palpable DCIS in BCS.

In chapter 7 we evaluated the patterns of care in treatment of DCIS since the introduction of the national screening program, using the national data of the Netherlands Cancer Registry. The proportion of DCIS patients undergoing of BCS has increased over the years (47.7\% in $1995-1996$ to $72.7 \%$ in $2017-2018$; $p<0.001$ ) with a decline in the use of adjuvant radiotherapy in more recent years (89.6\% in $2011-2012$ to $74.9 \%$ in $2017-2018$; $p<0.001$ ) especially for low grade DCIS.

Survival analyses showed that the risk of invasive local recurrence was strongly dependent on the use adjuvant radiotherapy, especially for the patients diagnosed in the period 1989-2010 (1.3\% [95\% CI 1.0\%-1.6\%] for patients with vs. 5.8\% [95\% CI 4.8\%-6.7\%] for patients without radiotherapy; $p<0.001$ ). The absolute difference in the risk of local recurrence between patients with and without adjuvant radiotherapy was much smaller for the patients treated in more recent years $(0.7 \%$ [95\% CI $0.5 \%-0.9 \%$ ] vs. $1.2 \%$ [95\% CI $0.6 \%-1.8 \%$ ]; $p=0.01)$. We also observed a de-escalating trend in axillary treatment in DCIS patients, with the replacement of axillary lymph node dissection by sentinel lymph node biopsy. In the most recent years we observed an increasing trend of patients not receiving any axillary staging $36.9 \%$ in $2005-2006$ to $55.8 \%$ in $2017-2018(p<0.001)$.

In order to avoid overtreatment in patients with DCIS, tailoring treatment to the probability of progression is the next step in preventing overtreatment. The main aim for future research should be improving our ability to refrain from invasive treatment, when possible.

Finally, in chapter 8 the results of this thesis are summarized and discussed in chapter 9. 


\section{References}

1. Ellis IO. Intraductal proliferative lesions of the breast: morphology, associated risk and molecular biology. Mod Pathol. 2010;23 Suppl 2:S1-7.

2. Weigel S, Hense HW, Heidrich J, Berkemeyer S, Heindel W, Heidinger O. Digital Mammography Screening: Does Age Influence the Detection Rates of Low-, Intermediate-, and High-Grade Ductal Carcinoma in Situ? Radiology. 2016;278(3):707-713.

3. van Breest Smallenburg V, Nederend J, Voogd AC, Coebergh JW, van Beek M, Jansen FH, et al. Trends in breast biopsies for abnormalities detected at screening mammography: a populationbased study in the Netherlands. Br J Cancer. 2013;109(1):242-248.

4. Crowe JP, Jr., Rim A, Patrick R, Rybicki L, Grundfest S, Kim J, et al. A prospective review of the decline of excisional breast biopsy. Am J Surg. 2002;184(4):353-355.

5. Weber RJ, Nederend J, Voogd AC, Strobbe LJ, Duijm LE. Screening outcome and surgical treatment during and after the transition from screen-film to digital screening mammography in the south of The Netherlands. Int J Cancer. 2015;137(1):135-143.

6. Neal L, Sandhu NP, Hieken TJ, Glazebrook KN, Mac Bride MB, Dilaveri CA, et al. Diagnosis and management of benign, atypical, and indeterminate breast lesions detected on core needle biopsy. Mayo Clin Proc. 2014;89(4):536-547.

7. Calhoun BC. Core Needle Biopsy of the Breast: An Evaluation of Contemporary Data. Surg Pathol Clin. 2018;11(1):1-16.

8. Falomo E, Adejumo C, Carson KA, Harvey S, Mullen L, Myers K. Variability in the Management Recommendations Given for High-risk Breast Lesions Detected on Image-guided Core Needle Biopsy at U.S. Academic Institutions. Curr Probl Diagn Radiol. 2018.

9. Gao Y, Albert M, Young Lin LL, Lewin AA, Babb JS, Heller SL, et al. What Happens after a Diagnosis of High-Risk Breast Lesion at Stereotactic Vacuum-assisted Biopsy? An Observational Study of Postdiagnosis Management and Imaging Adherence. Radiology. 2018;287(2):423-431.

10. Yaffe M, Boyd N. Mammographic breast density and cancer risk: the radiological view. Gynecol Endocrinol. 2005;21 Suppl 1:6-11. 


\section{Summary in Dutch - Nederlandse samenvatting}

In de periode 1989 tot 1996 werd het landelijk bevolkingsonderzoek naar borstkanker in Nederland geïmplementeerd. Aanvankelijk werden alleen vrouwen van 50 tot 70 jaar tweejaarlijks uitgenodigd voor een screeningsmammogram. In de jaren 1998 en 1999 werd de leeftijdsgrens verhoogd van 70 naar 75 jaar. En in de jaren 2009 en 2010 werd de analoge mammografie overal vervangen door de digitale mammografie.

De invloed van de overgang van de analoge naar digitale mammografie werd geanalyseerd in hoofdstuk 2 . Het absolute aantal screeningsmammogrammen nam toe van 66,750 in de laatste analoge periode (2005-2007) naar 131,224 in de eerste digitale periode (2013-2015). In diezelfde periode nam het percentage patiënten dat verwezen werd vanuit screening toe van $1.3 \%$ naar $3.3 \%$. De overgang naar digitale mammografie werd gekarakteriseerd door een toename in de detectie van ductaal carcinoma in situ (DCIS) van 0,8 naar 1,6 per 1000 screeningsmammogrammen $(p=<0,001)$ en daarnaast ook de detectie van invasieve carcinomen nam toe van 4,1 naar 5,1 gevallen per 1000 screeningsmammogrammen $(p=0,003)$. De meerderheid van de door screening gedetecteerde DCIS laesies bleek slecht gedifferentieerd te zijn (48.2\%), in tegenstelling tot de situatie bij invasieve carcinomen waarbij de meerderheid goed (45.4\%) of matig gedifferentieerd was (41.6\%).

Er wordt verondersteld dat slecht gedifferentieerd DCIS een grotere neiging heeft om te ontaarden in een slecht gedifferentieerd invasief carcinoom en dat een goed gedifferentieerd DCIS zich vaker ontwikkelt tot een goed gedifferentieerd invasief carcinoom. ${ }^{1,2}$ Onze bevindingen suggereren dat het huidige screeningsprogramma resulteert in een vroegtijdige opsporing en behandeling van met name slecht gedifferentieerde DCIS, waarvan een deel zich zonder screening tot slecht gedifferentieerd invasief carcinoom ontwikkeld zou hebben.

Alle vrouwen die op basis van de bevindingen op het screeningsmammogram worden verwezen, ondergaan aanvullende radiologische diagnostiek in het ziekenhuis. Bij persisterende twijfel omtrent de aard van de gevonden afwijking kan worden besloten tot het verrichten van een stereotactisch dikke naald biopt of zelfs een chirurgisch biopt om zodoende een definitieve diagnose ter verkrijgen middels pathologisch onderzoek.

Hoofdstuk 3 beschrijft het gebruik en de waarde van een chirurgisch excisiebiopt als diagnosticum bij vrouwen verwezen vanwege een afwijkend screenings- 
mammogram. Alle verwezen vrouwen die een chirurgisch excisiebiopt ondergingen van januari 1997 tot januari 2017 werden geïncludeerd. Er werd verwacht dat vanwege de introductie van het (stereotactische) dikke naald biopt (SCNB; stereotactic core needle biopsy) eind $20^{\mathrm{e}}$ eeuw, het aloude chirurgisch excisiebiopt een achterhaalde procedure zou worden.3,4 Zodoende hebben we onderscheid gemaakt tussen primaire excisiebiopten (uitgevoerd als eerste diagnostische interventie) en secundaire excisiebiopten (uitgevoerd na een SCNB met een afwijkende uitslag, waarbij de aard van de definitieve diagnose onduidelijk bleef). Zoals werd verwacht daalde het gebruik van primaire excisie biopten van 4,3 per 1000 screeningsmammogrammen in 1997-1998 naar 0 per 1000 screeningsmammogrammen in 2015-2016. Het aantal secundaire excisiebiopten daarentegen dat in eerste instantie ook daalde van 1,0 per 1000 in 1997-1998 naar 0,3 per 1000 in 2005-2006 toonde vervolgens weer een stijgende trend tot 0,6 per 1000 screeningsmammogrammen in de periode 2015-2016 (p-0,003). Van alle secundaire excisiebiopten toonde $61,0 \%$ een benigne pathologie uitslag. Dit percentage nam de afgelopen jaren toe van $40,4 \%$ tot $70,2 \%$. Aangezien heden ten dage de overgrote meerderheid van de secundaire excisiebiopten een benigne pathologie uitslag laat zien, dient het gebruik hiervan zorgvuldiger te worden overwogen.

Sinds de introductie van de digitale screening wordt steeds vaker een SCNB verricht. Waarschijnlijk omdat digitale screening een hogere gevoeligheid heeft voor het detecteren van kleine afwijkingen en microcalcificaties vergeleken met analoge mammografie ${ }^{5}$. Histologisch onderzoek van deze kleine afwijkingen heeft geleid tot een nieuwe pathologische classificatie van zogenaamde 'hoog-risico laesies'. Hoog-risico laesies worden gedefinieerd als afwijkingen die enerzijds niet kunnen worden geclassificeerd als eenduidig benigne laesies, maar anderzijds ook niet voldoen aan de criteria van invasieve borstkanker of DCIS. Voorbeelden van hoog-risico laesies zijn cilindercellaesies, atypische ductale hyperplasie, lobulair carcinoom in situ, papillaire laesies en complex scleroserende laesies. Aangezien de natuurlijke ontwikkeling van deze hoog-risico laesies nog grotendeels onbekend is, ${ }^{6-9}$ is de optimale behandeling van deze laesies onderwerp van discussie en geeft aanleiding tot wisselende behandelvoorstellen in een multidisciplinair overleg. Hoofdstuk 4 beschrijft de incidentie, behandeling en definitieve weefseluitkomst van hoog-risico laesies gediagnostiseerd op basis van een SCNB de afgelopen jaren (2011-2016). Ondanks een gelijkblijvend percentage verwezen vrouwen dat een SCNB onderging, steeg het aantal hoog-risico laesies dat hierbij gevonden werd van $3,2 \%$ in 2011 naar 9,5\% in $2016(p<0,001)$. Ook het aantal chirurgische excisies bij hoog-risico laesies steeg in deze periode van 0,25 naar 0,70 per 1000 
screeningsmammogrammen $(p<0,001)$. Het aandeel in-situ of invasieve borstkanker steeg niet en bedroeg gemiddeld 29\%. Dit betekende dat een toenemend aantal gescreende vrouwen een invasieve chirurgische excisie heeft ondergaan vanwege een uiteindelijk benigne afwijking, waarbij de vraag zich opdringt of en in hoeverre hier sprake is van overbehandeling.

De introductie van digitale screening resulteerde in een toegenomen gevoeligheid voor de detectie van kleine afwijkingen, waaronder microcalcificaties ${ }^{10}$. Er was in de literatuur echter slechts beperkte informatie beschikbaar over de trends in detectie van verdachte microcalcificaties op screeningsmammogrammen. Zodoende hebben we in hoofdstuk 5 deze trends over een periode van twintig jaar screening geanalyseerd. De afgelopen jaren werd een vervijfvoudiging in het aantal verwijzingen vanwege verdachte microcalcificaties gevonden van $0,1 \%$ in 1997-1998 naar $0,5 \%$ in 2015-2015 $(p<0,001)$. Het aantal verwijzingen dat daadwerkelijk DCIS betrof steeg minder hard, namelijk van 0,3 per 1000 naar 1,1 per 1000 screeningsmammogrammen $(p<0,001)$, wat resulteerde in een afname van de positief voorspellende waarde van verwijzing vanwege verdachte microcalcificaties van $51 \%$ naar 33\% $(p<0,001)$.

Als DCIS is gediagnostiseerd en een chirurgische behandeling noodzakelijk blijkt te zijn en de afwijking zich leent om te worden behandeld middels een borstsparende operatie, is nauwkeurige preoperatieve lokalisatie van deze afwijkingen van groot belang om in één sessie een radiale resectie te kunnen verrichten. Indien blijkt dat de DCIS zich in ruime mate bevindt in de snijrand van het verwijderde borstklierweefsel, spreken we van "meer dan focale irradicaliteit" en is een tweede operatie noodzakelijk om uiteindelijk te komen tot een radicale excisie. In hoofdstuk 6 worden twee lokalisatie methoden voor niet-palpabele DCIS retrospectief vergeleken. Dit betrof de draad-geleide lokalisatie (WGL; wire-guided localization), wat tot voor kort een veel gebruikte lokalisatiemethode was en radioactieve jodiumzaadjes-125 geleide lokalisatie (I-125GL; iodone-125 guided localization). Patiënten in de I-125 GL-groep bleken significant minder kans te hebben op meer dan focaal irradicale resectievlakken vergeleken met patiënten in de WGL-groep (4,4\% vs. 12,8\%; $p=0.048)$. Dit resulteerde in minder patiënten in de I-125 GL-groep die een aanvullende chirurgische behandeling moesten ondergaan. I-125 GL blijkt zodoende een aantrekkelijk alternatief voor WGL bij patiënten met niet-palpabele DCIS die in aanmerking komen voor een borstsparende operatie. Het gebruik van licht radioactief materiaal is echter onderworpen aan strenge wet- en regelgeving. Inmiddels wordt er ook ervaring opgedaan met andere lokalisatie 
technieken waaronder het gebruik van een magnetisch in plaats van een radioactief zaadje ${ }^{11}$.

In hoofdstuk 7 worden de ontwikkelingen in de behandeling van DCIS sinds de introductie van het bevolkingsonderzoek beschreven, gebruikmakend van nationale data van het Integraal Kankercentrum Nederland (IKNL). Het aantal patiënten met DCIS dat borstsparend werd behandeld is gedurende de jaren fors toegenomen, namelijk van $47,7 \%$ in $1995-1996$ tot $72,7 \%$ in $2017-2018(p<0,001)$. Het gebruik van aanvullende radiotherapie na een borstsparende behandeling daalde de laatste jaren van $89,6 \%$ in $2011-2012$ naar $74,9 \%$ in $2017-2018$ $(p<0,001)$, met name bij patiënten met goed gedifferentieerd DCIS. Het risico op invasieve ziekte na borstsparende behandeling van DCIS bleek sterk afhankelijk te zijn van het gebruik van adjuvante radiotherapie, met name bij patiënten die behandeld waren in de periode 1989-2010 (1,3\% [95\% CI 1,0\%-1,6\%] voor behandeling met radiotherapie versus 5,8\% [95\% CI 4,8\%-6,7\%] voor behandeling zonder radiotherapie; $p<0,001)$. Dit verschil is echter veel kleiner voor patiënten waarbij de laatste jaren (2011-2018) DCIS gediagnostiseerd is $(0,7 \%$ [95\% CI $0,5 \%-0,9 \%$ ] versus $1,2 \%$ [95\% CI 0,6\%-1,8\%]; $p=0,01$ ).

Naar analogie met de behandeling voor invasieve borstkanker heeft bij DCIS een verschuiving in de chirurgische behandeling van de oksel plaatsgevonden, waarbij de okselklierdissectie werd vervangen door een schildwachtklierprocedure. Op basis van het feit dat een pure DCIS, als premaligne laesie geen uitzaaiing naar de okselklier kan geven heeft de laatste jaren ook een toenemend aantal patiënten geen operatieve behandeling van de oksel meer ondergaan. Dit percentage steeg van $36,9 \%$ in $2005-2006$ naar $55,8 \%$ in $2017-2018$ ( $p<0,001)$.

Om overbehandeling van patiënten met DCIS te verminderen zal nog meer maatwerk nodig zijn, gebaseerd op de kans op progressie naar invasief carcinoom. Toekomstig onderzoek zal zich voornamelijk moeten focussen op het verbeteren van het vermogen om waar mogelijk af te zien van operatieve behandeling.

Tot slot worden in hoofdstuk 8 de resultaten uit dit proefschrift samengevat en in hoofdstuk 9 bediscussieerd. 


\section{References}

1. Ellis IO. Intraductal proliferative lesions of the breast: morphology, associated risk and molecular biology. Mod Pathol. 2010;23 Suppl 2:S1-7.

2. Weigel S, Hense HW, Heidrich J, Berkemeyer S, Heindel W, Heidinger O. Digital Mammography Screening: Does Age Influence the Detection Rates of Low-, Intermediate-, and High-Grade Ductal Carcinoma in Situ? Radiology. 2016;278(3):707-713.

3. van Breest Smallenburg V, Nederend J, Voogd AC, Coebergh JW, van Beek M, Jansen FH, et al. Trends in breast biopsies for abnormalities detected at screening mammography: a populationbased study in the Netherlands. Br J Cancer. 2013;109(1):242-248.

4. Crowe JP, Jr., Rim A, Patrick R, Rybicki L, Grundfest S, Kim J, et al. A prospective review of the decline of excisional breast biopsy. Am J Surg. 2002;184(4):353-355.

5. Weber RJ, Nederend J, Voogd AC, Strobbe LJ, Duijm LE. Screening outcome and surgical treatment during and after the transition from screen-film to digital screening mammography in the south of The Netherlands. Int J Cancer. 2015;137(1):135-143.

6. Neal L, Sandhu NP, Hieken TJ, Glazebrook KN, Mac Bride MB, Dilaveri CA, et al. Diagnosis and management of benign, atypical, and indeterminate breast lesions detected on core needle biopsy. Mayo Clin Proc. 2014;89(4):536-547.

7. Calhoun BC. Core Needle Biopsy of the Breast: An Evaluation of Contemporary Data. Surg Pathol Clin. 2018;11(1):1-16.

8. Falomo E, Adejumo C, Carson KA, Harvey S, Mullen L, Myers K. Variability in the Management Recommendations Given for High-risk Breast Lesions Detected on Image-guided Core Needle Biopsy at U.S. Academic Institutions. Curr Probl Diagn Radiol. 2018.

9. Gao Y, Albert M, Young Lin LL, Lewin AA, Babb JS, Heller SL, et al. What Happens after a Diagnosis of High-Risk Breast Lesion at Stereotactic Vacuum-assisted Biopsy? An Observational Study of Postdiagnosis Management and Imaging Adherence. Radiology. 2018;287(2):423-431.

10. Yaffe M, Boyd N. Mammographic breast density and cancer risk: the radiological view. Gynecol Endocrinol. 2005;21 Suppl 1:6-11.

11. Harvey JR, Lim Y, Murphy J, Howe M, Morris J, Goyal A, et al. Safety and feasibility of breast lesion localization using magnetic seeds (Magseed): a multi-centre, open-label cohort study. Breast Cancer Res Treat. 2018;169(3):531-536. 


$$
\text { yo }
$$




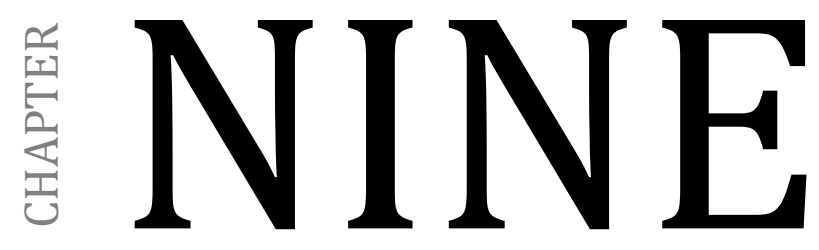

General discussion and future perspectives 


\section{General discussion and future perspectives}

The detection of breast cancer has come a long way since the days of only diagnosing palpable masses. The introduction and widespread use of mammography screening has led to the detection of asymptomatic, nonpalpable disease. The improvement of screening techniques resulted in the detection of even smaller lesions, which has accelerated the shift from breast amputation to breast conserving surgery. And most important, the detection of breast abnormalities at an earlier stage has contributed to the decrease in the mortality rates that are observed in countries in which mammographic screening has been implemented. ${ }^{1}$

However, the improved digital screening techniques also resulted in an increased detection of DCIS and other pre-malignant abnormalities.,3 These subclinical lesions can be divided into progressive and non-progressive lesions. ${ }^{4}$ Progressive subclinical lesions have the potential to present as clinical cancers in a person's lifetime, while non-progressive subclinical lesions remain subclinical or might even regress. ${ }^{4}$ The detection of these non-progressive subclinical lesions leads to overdiagnosis, which is defined as the detection of cancer by screening that would never cause symptoms or harms in the absence of screening. 4,5 Overdiagnosis is an unintended but unavoidable harm of screening mammography. The women who may benefit from early detection and treatment are those with progressive subclinical lesions.

Screening mammography mostly detects high grade DCIS [this thesis, chapter 2]. ${ }^{3}$ It is postulated that, in case DCIS is progressive, low grade DCIS will progress to low grade invasive carcinoma over a long time period, whereas high grade DCIS will more likely develop into high grade invasive carcinoma over a shorter time period. ${ }^{6,7}$ This assumption implies that the detection and subsequent treatment of high grade DCIS will result in a survival benefit. However, it is difficult to judge if the early detection of high grade DCIS by mammography screening confers a true survival benefit or if the lesion is only detected earlier without prolonging the survival time (lead time bias). The lead time of a breast tumor is the length of time from detection by screening until the appearance of clinical symptoms. Not considering lead time will lead to over-optimistic results of screening mammography.

As it is currently not possible to identify which subclinical lesions detected at mammography screening are non-progressive and which are progressive, almost all patients with DCIS are offered treatment. This routine treatment of subclinical lesions will obviously result in overtreatment for certain women. There is no consensus in the literature about the estimated number of breast cancer deaths 
avoided by screening and the estimated number of cases of overdiagnosis and subsequent overtreatment. The ratio of lives saved versus overtreated cases varies from 1 to $0.4-3.8,9$

A disadvantage of mammography screening, besides potential overdiagnosis and overtreatment, are the false positive recalls. These are women recalled for a suspicious abnormality at screening mammography, but whose workup does not reveal (pre-) malignant disease. Keeping in mind the false positive recalls and recalled abnormalities without malignant potential, further diagnostic interventions should be as minimal invasive as possible. Therefore, the recent increase in invasive surgical excision biopsies, following SCNB, is an unfavorable development [this thesis, chapter 3]. This increase is probably related to improved imaging techniques, leading to the detection of smaller breast lesions of unknown clinical significance, the so-called 'high-risk lesions'.10,11 The optimal management of high-risk lesions remains a matter of ongoing debate. Considerable variation in the upgrading of different type of high-risk lesions to malignancy has been reported, resulting in mixed recommendations of either radiologic surveillance or diagnostic surgical excision of every high-risk lesion. ${ }^{12-18}$ Falomo et al. reported serious inconsistencies in the management of these lesions at academic institutions across the United States, with surgical excision rates ranging from 39\% to $95 \%$ between centers. ${ }^{19}$

Since surgical excision is still regarded as the gold standard to obtain a definitive histopathologic diagnosis, routine surgical excision of these high-risk lesions may be considered in order to minimize the risk of missing malignant disease. ${ }^{15}$ However, as the proportion of high-risk lesions being upgraded to malignancy remained stable in our study over the years, the increased excision rate of these lesions resulted in an increasing number of women with a benign outcome following diagnostic surgical excision [this thesis, chapter 4]. The use of this type of excision for diagnostic purposes should be kept to a minimum as it both lowers the sensitivity of future screening mammography for cancer detection as well as it is an invasive procedure, usually performed under general anesthesia. ${ }^{20,21}$

Most DCIS lesions are detected at mammography screening by the presence of microcalcifications. However, not all microcalcifications found at screening are related to underlying DCIS. Digital mammography has a higher sensitivity for the detection of microcalcifications than screen-film mammography, which resulted in a five-fold increased recall rate for suspicious microcalcifications, thereby decreasing the positive predictive value (PPV) of screen-detected microcalcifications by $40 \%$ [this thesis, chapter 5]. Given this observed decrease in PPV, one may raise the question whether all recalled microcalcifications require 
biopsy. Overall, only one third of all recalled microcalcifications proved (pre-) malignant, of which almost 70\% consisted of DCIS [this thesis, chapter 5]. Ongoing studies investigate the possibility of close surveillance of not only low grade but even intermediate grade DCIS. ${ }^{22,23}$ A next step in de-escalating treatment might be a better discrimination of microcalcifications based on radiologic features to prevent invasive biopsy for suspected low grade DCIS. MRI can improve the ability to detect DCIS and its local spread, especially high grade DCIS, and it can be useful for the diagnosis of a possible invasive component in patients initially diagnosed with pure DCIS. ${ }^{24,25}$ MRI is a technique based on tissue contrast enhancement. In breast tissue, increased microvessel density or capillary permeability leads to contrast enhancement. ${ }^{26}$ The vessel density is significantly higher in high grade DCIS compared to low grade DCIS which explains why MRI is more likely to detect high grade DCIS than low grade DCIS. ${ }^{24,27,28} \mathrm{Kuhl}$ et al. reported that $60 \%$ of the DCIS diagnosed by MRI only were high grade, suggesting that MRI helps to detect lesions that might more likely progress to high grade invasive carcinoma. ${ }^{24}$ However, on the other hand, studies have shown that the use of MRI among DCIS patients increases the mastectomy rate and the use of routine MRI is therefore still controversial. $^{29}$ The aforementioned is in contrast to another recent study suggesting that preoperative MRI reduces positives surgical margins and repeat surgery for DCIS without a higher mastectomy rate. ${ }^{30}$ At the moment MRI is not routinely implemented in the pre-operative assessment of DCIS.

Currently, it is not yet clear to which degree histologic features of DCIS can be estimated by the mammographic patterns of microcalcifications alone. Therefore, a minimally invasive SCNB is still considered mandatory in the workup of these lesions to date. ${ }^{31}$

When DCIS is detected, and surgical excision is indicated, breast conserving surgery (BCS) rather than mastectomy may be the preferred surgical procedure. The goal of BCS is to perform a radical resection and thereby preserving the shape of the breast for a satisfactory cosmetic result. In order to perform an adequate resection intraoperative localization of small non-palpable lesions is of utmost importance. Wire guided localization (WGL), introduced in 1965 by Dodd et al. ${ }^{32}$ is worldwide still a frequently used localization technique. ${ }^{33,34}$ In order to locate the lesion, a hook wire is placed under ultrasound or stereotactic guidance by a radiologist. An alternative localization technique is radioguided occult lesion localization (ROLL), which was first described by Luini et al. in $1998 .{ }^{35}$ Prior to surgery ( $<24$ hours) a small volume of radiolabeled technetium (Tc-99m) colloid is injected into the center of the lesion under stereotactic guidance. In 2001 Gray et al. described, a new technique using iodine-125 seed-guided localization (I-125 GL). ${ }^{36,37}$ This 
technique consists of the implantation of a titanium seed containing slightly radioactive iodine ( $\mathrm{I}-125)$. A logistic advantage of this technique is the possibility to place the seed days to weeks in advance of the operation, reducing scheduling conflicts and give the possibility to be used in the neoadjuvant setting.

ROLL and I-125 GL have been compared to the gold standard WGL in several studies. The ROLL study group, which compared ROLL to WGL, concluded that ROLL leads to the excision of larger tissue volumes and therefore cannot replace WGL as standard of care. ${ }^{38}$ A randomized controlled trial published in 2017 comparing WGL and I-125 GL showed similar positive margin rates and no differences in complication rates, but major logistic advantages in favor of I-125 GL. ${ }^{39}$ Moreover, in a systematic review and meta-analysis [which includes chapter 6 of this thesis ] published in 2019, it was concluded that I-125 GL is superior over WGL to gain negative margins and the reduction of re-excisions needed. ${ }^{40}$ Even though the radiation exposure of $\mathrm{I}-125$ is almost negligible, the radiation safety precautions required to set up and support this technique limits its implementation. ${ }^{41}$ An upcoming alternative localization method is magnetic seed localization, consisting of a steel and iron oxide seed detectable using a probe. However further studies are needed to ensure that a magnetic seed is detectable at all depths, which is currently still a limitation of this technique especially for posterior lesions in very large breasts. ${ }^{42}$ Moreover, like any clip, a magnetic seed will cause void artefacts in MRI, which limits the possibilities of imaging follow-up in patients who receive neoadjuvant chemotherapy.

In the last thirty-years, pattern of care in treatment of DCIS shifted toward less extensive treatment, with an increased use of BCS and a decrease in the use of adjuvant radiotherapy in more recent years, as was illustrated by data of the Netherlands Cancer Registry [this thesis, chapter 7]. Analyses of these same data showed that the risk of invasive local recurrence was strongly dependent on the use adjuvant radiotherapy, especially for the patients diagnosed in the period 19892010. The absolute difference in the risk of local recurrence between patients with and without adjuvant radiotherapy however was much smaller for the patients treated in more recent years (2011-2018). This drives the discussion about further limiting the indication for radiotherapy after BCS in the context of reducing overtreatment of DCIS.

Four large randomized controlled trials on adjuvant radiotherapy in DCIS patients have been published. ${ }^{43-46}$ An overview of these trials showed that additional radiotherapy halves the risk of an ipsilateral breast event (invasive and noninvasive cancer). However, it has not been shown to improve breast cancer overall survival. ${ }^{47}$ Over the years, research has focused on the identification of subgroups 
of patients with favorable features for whom the risk of invasive recurrence in the absence of radiotherapy is ultimately low that radiotherapy can safely be omitted. ${ }^{48}$ Our invasive relapse-free survival analysis, shows a very low probability of local recurrence in recent years, suggesting that a good selection of patients who do not require radiotherapy has proven to be possible. However, the majority of patients in whom BCS is performed for DCIS is still receiving radiotherapy, which may possibly be unnecessary in selected cases. Therefore, radiotherapy should be tailored to patient factors, tumor biology and validated prognostic scores on risk of local recurrence.49,50 More research is needed to determine whether the use of radiotherapy can be safely limited further.

Our study also showed a de-escalation in axillary treatment, with a replacement of axillary lymph node dissection by sentinel lymph node biopsy (SLNB) and an observed decline in SLNB in more recent years. This shift is probably related to the reporting of rather low risk of sentinel lymph node involvement, ranging from 0 to $10 \% .51-53$ Even if the SLN is found positive in patients with a preoperative diagnosis of DCIS, it is most frequently reported to present as micrometastases (defined as small metastases sized $0.2-2.0 \mathrm{~mm}$ ), which are of limited clinical value in this respect. ${ }^{54,55}$ Nowadays, a delayed SLNB following lumpectomy if invasive cancer is shown, is considered a feasible option. Therefore, we agree with a recent study by Van Roozendaal et al. who suggest omitting SLNB completely in patients with DCIS undergoing BCS. ${ }^{53}$ In patients undergoing mastectomy SLNB cannot be performed afterwards. Clinical evidence to forego SLNB in these patients is scarce or lacking, therefore SLNB may still need to be performed in DCIS patients with risk factors for invasive disease undergoing a mastectomy.

In conclusion, the use of BCS, radiotherapy and axillary staging in patients with DCIS varies over time. The lack of consensus in recent literature reflects our limited knowledge about the natural course of untreated DCIS. In the interest of shared decision-making patients should be informed about these dilemmas, since current treatment protocols may result in overtreatment of many women. 


\section{Future perspectives}

The purpose of treatment of patients with DCIS is to prevent development of invasive breast cancer. The increasing number of patients with DCIS detected through screening mammography raised the question about the clinical significance of these lesions. Studies on patients in whom DCIS was initially misdiagnosed as benign resulting in no additional treatment following biopsy, suggest that between $50-85 \%$ of all DCIS will never progress to invasive cancer. ${ }^{56}$ However, effective tools to distinguish between DCIS that will progress, and nonhazardous DCIS are presently lacking. The future goal is to prevent overtreatment by safely omitting invasive treatment. Or, even better, biopsy should be made redundant by better interpretation based on imaging. In this future perspective we philosophize about possible future developments within the mammography screening, biopsies, follow-up with surveillance only, diagnostic criteria, genetic profiling and patients' perspectives.

\section{Mammography screening}

At the moment it is not possible to identify which subclinical lesions detected at mammographic screening will progressive into invasive carcinoma. Therefore, almost all patients with suspicious mammographic findings - indicating the likelihood of presence of DCIS - are all recalled for biopsy. If DCIS is confirmed, these patients are generally offered surgical treatment. The most cost-effective way to prevent overtreatment lies at the beginning of the process; the mammographic screening.

The introduction of the more sensitive digital mammography resulted in an increased detection of small lesions, such as microcalcifications. However, not all microcalcifications are related to underlying DCIS. Recent studies found a relationship between the morphology and distribution of microcalcifications and the clinical and histopathologic features of the underlying DCIS. High grade DCIS is more often associated with specific abnormal mammographic features, such as necrosis, rod and linear branch shapes or coarse granular microcalcifications 31,57 59. Conversely, low grade DCIS is associated with round of punctate more diffusely spread microcalcifications. A future step might thus be to classify microcalcifications by radiologic features to prevent an invasive biopsy for suspected low grade DCIS. 


\section{Biopsy and surgery}

Currently, it is not yet clear to which degree histologic features of DCIS can be estimated by the mammographic patterns of microcalcifications alone. Therefore, a SCNB is still considered mandatory in the workup of these lesions to date. ${ }^{31}$

We have shown that when a diagnostic surgical excision of high-risk lesions after a negative SCNB was obtained, approximately $85 \%$ of all excisions did not reveal a clinically significant lesion ( $71 \%$ benign pathology). Moreover, in $14.2 \%$ of the surgical excision biopsies a low grade DCIS was found. For low grade DCIS a wait and see strategy may be favored over surgical intervention. Also, for lesion classifies as flat epithelial atypia, papillary lesions, radial scar or lobular carcinoma in situ; so-called high-risk lesions optimal management of is controversial $11,19,60,61$. Serious inconsistencies in the management of these lesions are reported, with surgical excision rates ranging from $39 \%$ to $95 \%$ between centers. ${ }^{19}$

In addition, our study shows that in almost $5 \%$ of all surgically treated women, no residual DCIS was found in the surgical specimen, suggesting that all DCIS was removed by SCNB. Vacuum assisted excision biopsy devices can remove even more tissue than SCNB and may be the future therapy of choice for the removal of DCIS characterized by small groups of clustered microcalcifications. ${ }^{62,63}$ In order to decrease the number of potentially unnecessary surgical excisions, one may opt for vacuum-assisted excision of high-risk lesions as an alternative to surgical excision. ${ }^{62-64}$ In the future larger studies are needed to define evidence-based practice recommendations of the management of pre-malignant lesions detected at SCNB.

\section{Surveillance follow-up}

It is postulated that if low grade DCIS deteriorates it will more likely progress to low grade invasive carcinoma over a long time period, whereas high grade DCIS might develop into high grade invasive carcinoma over a shorter time period.6,7 Therefore, the question has been raised whether surgical treatment for low- and maybe even intermediate grade DCIS might be considered as overtreatment. It is reasonable to assume that active surveillance is nearly as safe as surgical treatment of screen-detected low grade DCIS. The result of active surveillance is subject of several ongoing clinical trials. ${ }^{22,23,65}$. If these trials show favorable results, uniform histologic grading of DCIS might become of great clinical importance in the near future. 


\section{Pathologic diagnostic criteria of DCIS}

DCIS grading is based on morphologic characteristics, such as growth pattern, cytoplasmic feature, nuclear pleomorphism and mitotic activity. Since diagnostic criteria are not always clear, differences in morphological interpretation make the accuracy of DCIS grading questionable. ${ }^{66,67}$ Substantial inter- and intra-laboratory variations in DCIS grade are reported. ${ }^{68}$ Consequently, histologic grading of DCIS is currently not meeting high enough standards. ${ }^{68}$ Improvement of the accuracy is extremely relevant, when the management of DCIS becomes dependent on histologic grade in the near future.

Grading is a prognostic factor based on histologic examination of a tissue sample. Another option might be predicting individual breast cancer risk factors by molecular genetic markers.

\section{Molecular genetic profiling}

In recent years several studies have focused on identifying molecular genetic marker predicting the risk of personalized risk-based breast cancer screening developing invasive carcinoma after DCIS. Molecular genetic markers in DCIS that might be associated with its aggressiveness are also subject of ongoing studies. ${ }^{69,70}$ Earlier studies suggest that the genetic pathway of pure DCIS may be genetically different from DCIS associated with invasive carcinoma. ${ }^{69}$ This implies that gene sequencing might help to distinguish between different sub-types of DCIS. This will enable the classification of women into groups of varying risk of breast cancer, which in the future may result in the implementation of a and prevention program. ${ }^{71}$

The Oncotype DX DCIS score is a multi-gene assay, which might help to distinguish between DCIS grades and predicting the risk of invasive cancer development. ${ }^{72,73}$ More research is needed to validate this promising technique and to evaluate the ability to identify high-risk DCIS lesions.

\section{Patients perceptive}

The PRISMA trial is currently investigating the added value of 'personalized screening'. The success of the implementation of 'personalized screening' depends not only on healthcare professionals, but also on the women's perception. Women's interest in knowing their breast cancer risk is high, therefore more intensive screening for women with above average risk is generally welcomed..$^{74-76}$ However, lowering the intensity of surveillance for low-risk lesions could lead to anxiety in women as well as healthcare professionals. ${ }^{75}$ Since healthcare professionals will 
play a key role in informing women the PRISMA trial investigates the acceptability of 'personalized screening' in women as well as medical specialists. Although implementation of 'personalized screening' will be challenging it might be a promising strategy to optimize the harm-benefit ratio of mammographic screening in the future. Women who may benefit from 'personalized screening' are those with extremely dense breast tissue. Those women have an increased risk of breast cancer and their cancers are also less likely to be detected on mammography. ${ }^{77,78}$ In 2019 the DENSE trial concluded that the use of supplemental MRI screening in women with extremely dense breast tissue and normal results on screening mammography resulted in the diagnosis of significantly fewer interval cancers. ${ }^{79}$ However, the downside is an increased false positive rate, which leads to overdiagnosis, therefore MRI is not routinely used in mammography screening yet. $^{79}$

Even if the integration of various clinical, radiological, histological, and molecular markers will improve our ability to distinguish between progressive and nonprogressive premalignant lesions, women's acceptability of watchful waiting remains an issue. For many patients it is very difficult to distinguish between premalignant and invasive disease, which may drive patients to invasive treatment from a 'better be safe than sorry' point of view. ${ }^{80}$ Therefore, breast cancer specialists need a thorough understanding of this delicate issue to explain this in an understandable manner to their patients. A possible improvement might be excluding the word 'cancer' or 'premalignant lesion', since the terminology used to describe DCIS has significant impact on patients' perception. ${ }^{81}$

In conclusion, tailoring recalls, biopsies and invasive treatments to the likelihood that the lesion will progress and become invasive is a desirable step in preventing overtreatment. 


\section{References}

1. Plevritis SK, Munoz D, Kurian AW, Stout NK, Alagoz O, Near AM, et al. Association of Screening and Treatment With Breast Cancer Mortality by Molecular Subtype in US Women, 2000-2012. JAMA. 2018;319(2):154-164.

2. van Luijt PA, Fracheboud J, Heijnsdijk EA, den Heeten GJ, de Koning HJ, National Evaluation Team for Breast Cancer Screening in Netherlands Study G. Nation-wide data on screening performance during the transition to digital mammography: observations in 6 million screens. Eur J Cancer. 2013;49(16):3517-3525.

3. Bluekens AM, Holland R, Karssemeijer N, Broeders MJ, den Heeten GJ. Comparison of digital screening mammography and screen-film mammography in the early detection of clinically relevant cancers: a multicenter study. Radiology. 2012;265(3):707-714.

4. Baker SG, Prorok PC, Kramer BS. Lead time and overdiagnosis. J Natl Cancer Inst. 2014;106(12).

5. Marcus PM, Prorok PC, Miller AB, DeVoto EJ, Kramer BS. Conceptualizing overdiagnosis in cancer screening. J Natl Cancer Inst. 2015;107(4).

6. Ellis IO. Intraductal proliferative lesions of the breast: morphology, associated risk and molecular biology. Mod Pathol. 2010;23 Suppl 2:S1-7.

7. Weigel S, Hense HW, Heidrich J, Berkemeyer S, Heindel W, Heidinger O. Digital Mammography Screening: Does Age Influence the Detection Rates of Low-, Intermediate-, and High-Grade Ductal Carcinoma in Situ? Radiology. 2016;278(3):707-713.

8. Paci E, Group EW. Summary of the evidence of breast cancer service screening outcomes in Europe and first estimate of the benefit and harm balance sheet. J Med Screen. 2012;19 Suppl 1:5-13.

9. Independent UKPoBCS. The benefits and harms of breast cancer screening: an independent review. Lancet. 2012;380(9855):1778-1786.

10. Nederend J, Duijm LE, Louwman MW, Groenewoud JH, Donkers-van Rossum AB, Voogd AC. Impact of transition from analog screening mammography to digital screening mammography on screening outcome in The Netherlands: a population-based study. Ann Oncol. 2012;23(12):30983103.

11. Calhoun BC. Core Needle Biopsy of the Breast: An Evaluation of Contemporary Data. Surg Pathol Clin. 2018;11(1):1-16.

12. Sen LQ, Berg WA, Hooley RJ, Carter GJ, Desouki MM, Sumkin JH. Core Breast Biopsies Showing Lobular Carcinoma In Situ Should Be Excised and Surveillance Is Reasonable for Atypical Lobular Hyperplasia. AJR Am J Roentgenol. 2016;207(5):1132-1145.

13. Mooney KL, Bassett LW, Apple SK. Upgrade rates of high-risk breast lesions diagnosed on core needle biopsy: a single-institution experience and literature review. Mod Pathol. 2016;29(12):1471-1484.

14. Donaldson AR, Sieck L, Booth CN, Calhoun BC. Radial scars diagnosed on breast core biopsy: Frequency of atypia and carcinoma on excision and implications for management. Breast (Edinburgh, Scotland). 2016;30:201-207.

15. Rudin AV, Hoskin TL, Fahy A, Farrell AM, Nassar A, Ghosh K, et al. Flat Epithelial Atypia on Core Biopsy and Upgrade to Cancer: a Systematic Review and Meta-Analysis. Ann Surg Oncol. 2017;24(12):3549-3558.

16. Ouldamer L, Poisson E, Arbion F, Bonneau C, Vilde A, Body G, et al. All pure flat atypical atypia lesions of the breast diagnosed using percutaneous vacuum-assisted breast biopsy do not need surgical excision. Breast (Edinburgh, Scotland). 2018;40:4-9.

17. Speer ME, Huang ML, Dogan BE, Adrada BE, Candelaria RP, Hess KR, et al. High risk breast lesions identified on MRI-guided vacuum-assisted needle biopsy: outcome of surgical excision and imaging follow-up. Br J Radiol. 2018:20180300.

18. Chou WYY, Veis DJ, Aft R. Radial scar on image-guided breast biopsy: is surgical excision necessary? Breast Cancer Res Treat. 2018;170(2):313-320.

19. Falomo E, Adejumo C, Carson KA, Harvey S, Mullen L, Myers K. Variability in the Management Recommendations Given for High-risk Breast Lesions Detected on Image-guided Core Needle Biopsy at U.S. Academic Institutions. Curr Probl Diagn Radiol. 2018. 
20. Taplin SH, Abraham L, Geller BM, Yankaskas BC, Buist DS, Smith-Bindman R, et al. Effect of previous benign breast biopsy on the interpretive performance of subsequent screening mammography. J Natl Cancer Inst. 2010;102(14):1040-1051.

21. van Breest Smallenburg V, Duijm LE, Voogd AC, Groenewoud JH, Jansen FH, van Beek M, et al. Lower sensitivity of screening mammography after previous benign breast surgery. Int J Cancer. 2012;130(1):122-128.

22. Elshof LE, Tryfonidis K, Slaets L, van Leeuwen-Stok AE, Skinner VP, Dif N, et al. Feasibility of a prospective, randomised, open-label, international multicentre, phase III, non-inferiority trial to assess the safety of active surveillance for low risk ductal carcinoma in situ - The LORD study. Eur J Cancer. 2015;51(12):1497-1510.

23. Francis A, Thomas J, Fallowfield L, Wallis M, Bartlett JM, Brookes C, et al. Addressing overtreatment of screen-detected DCIS; the LORIS trial. Eur J Cancer. 2015;51(16):2296-2303.

24. Kuhl CK, Schrading S, Bieling HB, Wardelmann E, Leutner CC, Koenig R, et al. MRI for diagnosis of pure ductal carcinoma in situ: a prospective observational study. Lancet. 2007;370(9586):485-492.

25. Benveniste AP, Ortiz-Perez T, Ebuoma LO, Sepulveda KA, Severs FJ, Roark A, et al. Is breast magnetic resonance imaging (MRI) useful for diagnosis of additional sites of disease in patients recently diagnosed with pure ductal carcinoma in situ (DCIS)? Eur J Radiol. 2017; 96:74-79.

26. Furman-Haran E, Schechtman E, Kelcz F, Kirshenbaum K, Degani H. Magnetic resonance imaging reveals functional diversity of the vasculature in benign and malignant breast lesions. Cancer. 2005;104(4):708-718.

27. Ottinetti A, Sapino A. Morphometric evaluation of microvessels surrounding hyperplastic and neoplastic mammary lesions. Breast Cancer Res Treat. 1988;11(3):241-248.

28. Hieken TJ, Farolan M, D'Alessandro S, Velasco JM. Predicting the biologic behavior of ductal carcinoma in situ: an analysis of molecular markers. Surgery. 2001;130(4):593-600; discussion 600-591.

29. Fancellu A, Turner RM, Dixon JM, Pinna A, Cottu P, Houssami N. Meta-analysis of the effect of preoperative breast MRI on the surgical management of ductal carcinoma in situ. Br J Surg. 2015;102(8):883-893.

30. Yoon GY, Choi WJ, Kim HH, Cha JH, Shin HJ, Chae EY. Surgical Outcomes for Ductal Carcinoma in Situ: Impact of Preoperative MRI. Radiology. 2020;295(2):296-303.

31. Szynglarewicz B, Kasprzak P, Biecek P, Halon A, Matkowski R. Screen-detected ductal carcinoma in situ found on stereotactic vacuum-assisted biopsy of suspicious microcalcifications without mass: radiological-histological correlation. Radiology and oncology. 2016;50(2):145-152.

32. Ahmed M, Rubio IT, Klaase JM, Douek M. Surgical treatment of nonpalpable primary invasive and in situ breast cancer. Nat Rev Clin Oncol. 2015;12(11):645-663.

33. Tardioli S, Ballesio L, Gigli S, F DIP, D'Orazi V, Giraldi G, et al. Wire-guided Localization in Nonpalpable Breast Cancer: Results from Monocentric Experience. Anticancer Res. 2016;36(5):24232427.

34. Sajid MS, Parampalli U, Haider Z, Bonomi R. Comparison of radioguided occult lesion localization (ROLL) and wire localization for non-palpable breast cancers: a meta-analysis. J Surg Oncol. 2012;105(8):852-858.

35. Luini A, Zurrida S, Paganelli G, Galimberti V, Sacchini V, Monti S, et al. Comparison of radioguided excision with wire localization of occult breast lesions. Br J Surg. 1999;86(4):522-525.

36. Gray RJ, Salud C, Nguyen K, Dauway E, Friedland J, Berman C, et al. Randomized prospective evaluation of a novel technique for biopsy or lumpectomy of nonpalpable breast lesions: radioactive seed versus wire localization. Ann Surg Oncol. 2001;8(9):711-715.

37. Gobardhan PD, de Wall LL, van der Laan L, ten Tije AJ, van der Meer DC, Tetteroo E, et al. The role of radioactive iodine-125 seed localization in breast-conserving therapy following neoadjuvant chemotherapy. Ann Oncol. 2013;24(3):668-673.

38. Postma EL, Verkooijen HM, van Esser S, Hobbelink MG, van der Schelling GP, Koelemij R, et al. Efficacy of 'radioguided occult lesion localisation' (ROLL) versus 'wire-guided localisation' (WGL) in breast conserving surgery for non-palpable breast cancer: a randomised controlled multicentre trial. Breast Cancer Res Treat. 2012;136(2):469-478. 
39. Langhans L, Tvedskov TF, Klausen TL, Jensen MB, Talman ML, Vejborg I, et al. Radioactive Seed Localization or Wire-guided Localization of Nonpalpable Invasive and In Situ Breast Cancer: A Randomized, Multicenter, Open-label Trial. Ann Surg. 2017;266(1):29-35.

40. Wang GL, Tsikouras P, Zuo HQ, Huang MQ, Peng L, Bothou A, et al. Radioactive seed localization and wire guided localization in breast cancer: A systematic review and meta-analysis. J BUON. 2019;24(1):48-60.

41. Langhans L, Klausen TL, Tvedskov TF, Talman ML, Oturai PS, Vejborg I, et al. Preparation and Administration of I-125 Labeled Seeds for Localization of Nonpalpable Breast Lesions. Curr Radiopharm. 2016;9(2):143-149.

42. Harvey JR, Lim Y, Murphy J, Howe M, Morris J, Goyal A, et al. Safety and feasibility of breast lesion localization using magnetic seeds (Magseed): a multi-centre, open-label cohort study. Breast Cancer Res Treat. 2018;169(3):531-536.

43. Donker M, Litiere S, Werutsky G, Julien JP, Fentiman IS, Agresti R, et al. Breast-conserving treatment with or without radiotherapy in ductal carcinoma In Situ: 15-year recurrence rates and outcome after a recurrence, from the EORTC 10853 randomized phase III trial. J Clin Oncol. 2013;31(32):4054-4059.

44. Cuzick J, Sestak I, Pinder SE, Ellis IO, Forsyth S, Bundred NJ, et al. Effect of tamoxifen and radiotherapy in women with locally excised ductal carcinoma in situ: long-term results from the UK/ANZ DCIS trial. Lancet Oncol. 2011;12(1):21-29.

45. Wapnir IL, Dignam JJ, Fisher B, Mamounas EP, Anderson SJ, Julian TB, et al. Long-term outcomes of invasive ipsilateral breast tumor recurrences after lumpectomy in NSABP B-17 and B-24 randomized clinical trials for DCIS. J Natl Cancer Inst. 2011;103(6):478-488.

46. Warnberg F, Garmo H, Emdin S, Hedberg V, Adwall L, Sandelin K, et al. Effect of radiotherapy after breast-conserving surgery for ductal carcinoma in situ: 20 years follow-up in the randomized SweDCIS Trial. J Clin Oncol. 2014;32(32):3613-3618.

47. Correa C, McGale P, Taylor C, Wang Y, Clarke M, Davies C, et al. Overview of the randomized trials of radiotherapy in ductal carcinoma in situ of the breast. J Natl Cancer Inst Monogr. 2010;2010(41):162-177.

48. Silverstein MJ. An argument against routine use of radiotherapy for ductal carcinoma in situ. Oncology (Williston Park). 2003;17(11):1511-1533; discussion 1533-1514, 1539, 1542 passim.

49. Sagara Y, Freedman RA, Vaz-Luis I, Mallory MA, Wong SM, Aydogan F, et al. Patient Prognostic Score and Associations With Survival Improvement Offered by Radiotherapy After BreastConserving Surgery for Ductal Carcinoma In Situ: A Population-Based Longitudinal Cohort Study. J Clin Oncol. 2016;34(11):1190-1196.

50. van Maaren MC, Lagendijk M, Tilanus-Linthorst MMA, de Munck L, Pijnappel RM, Schmidt MK, et al. Breast cancer-related deaths according to grade in ductal carcinoma in situ: A Dutch populationbased study on patients diagnosed between 1999 and 2012. Eur J Cancer. 2018;101:134-142.

51. Francis AM, Haugen CE, Grimes LM, Crow JR, Yi M, Mittendorf EA, et al. Is Sentinel Lymph Node Dissection Warranted for Patients with a Diagnosis of Ductal Carcinoma In Situ? Ann Surg Oncol. 2015;22(13):4270-4279.

52. Holm-Rasmussen EV, Jensen MB, Balslev E, Kroman N, Tvedskov TF. Risk factors of sentinel and non-sentinel lymph node metastases in patients with ductal carcinoma in situ of the breast: A nationwide study. Breast (Edinburgh, Scotland). 2018;42:128-132.

53. van Roozendaal LM, Goorts B, Klinkert M, Keymeulen K, De Vries B, Strobbe LJA, et al. Sentinel lymph node biopsy can be omitted in DCIS patients treated with breast conserving therapy. Breast Cancer Res Treat. 2016;156(3):517-525.

54. Zetterlund L, Stemme S, Arnrup H, de Boniface J. Incidence of and risk factors for sentinel lymph node metastasis in patients with a postoperative diagnosis of ductal carcinoma in situ. Br J Surg. 2014;101(5):488-494.

55. Magnoni F, Massari G, Santomauro G, Bagnardi V, Pagan E, Peruzzotti G, et al. Sentinel lymph node biopsy in microinvasive ductal carcinoma in situ. Br J Surg. 2019;106(4):375-383.

56. Erbas B, Provenzano E, Armes J, Gertig D. The natural history of ductal carcinoma in situ of the breast: a review. Breast Cancer Res Treat. 2006;97(2):135-144. 
57. Rauch GM, Hobbs BP, Kuerer HM, Scoggins ME, Benveniste AP, Park YM, et al. Microcalcifications in 1657 Patients with Pure Ductal Carcinoma in Situ of the Breast: Correlation with Clinical, Histopathologic, Biologic Features, and Local Recurrence. Ann Surg Oncol. 2016;23(2):482-489.

58. Evans A, Clements K, Maxwell A, Bishop H, Hanby A, Lawrence G, et al. Lesion size is a major determinant of the mammographic features of ductal carcinoma in situ: findings from the Sloane project. Clin Radiol. 2010;65(3):181-184.

59. Tang X, Yamashita T, Hara M, Kumaki N, Tokuda Y, Masuda S. Histopathological characteristics of breast ductal carcinoma in situ and association with imaging findings. Breast Cancer. 2016;23(3):491-498.

60. Neal L, Sandhu NP, Hieken TJ, Glazebrook KN, Mac Bride MB, Dilaveri CA, et al. Diagnosis and management of benign, atypical, and indeterminate breast lesions detected on core needle biopsy. Mayo Clin Proc. 2014;89(4):536-547.

61. Gao Y, Albert M, Young Lin LL, Lewin AA, Babb JS, Heller SL, et al. What Happens after a Diagnosis of High-Risk Breast Lesion at Stereotactic Vacuum-assisted Biopsy? An Observational Study of Postdiagnosis Management and Imaging Adherence. Radiology. 2018;287(2):423-431.

62. Rageth CJ, O'Flynn EA, Comstock C, Kurtz C, Kubik R, Madjar H, et al. First International Consensus Conference on lesions of uncertain malignant potential in the breast (B3 lesions). Breast Cancer Res Treat. 2016;159(2):203-213.

63. Rageth CJ, O'Flynn EAM, Pinker K, Kubik-Huch RA, Mundinger A, Decker T, et al. Second International Consensus Conference on lesions of uncertain malignant potential in the breast (B3 lesions). Breast Cancer Res Treat. 2019;174(2):279-296.

64. Pieri A, Hemming D, Westgarth J, Lunt L. Vacuum-assisted biopsy is a viable alternative to surgical biopsy in the investigation of breast lesions of uncertain malignant potential. Surgeon. 2017;15(2):59-64.

65. Hwang ES, Hyslop T, Lynch T, Frank E, Pinto D, Basila D, et al. The COMET (Comparison of Operative versus Monitoring and Endocrine Therapy) trial: a phase III randomised controlled clinical trial for low-risk ductal carcinoma in situ (DCIS). BMJ Open. 2019;9(3):e026797.

66. Van de Vijver MJ, Peterse H. The diagnosis and management of pre-invasive breast disease: pathological diagnosis--problems with existing classifications. Breast Cancer Res. 2003;5(5):269.

67. Pinder SE, Ellis IO. The diagnosis and management of pre-invasive breast disease: ductal carcinoma in situ (DCIS) and atypical ductal hyperplasia (ADH)--current definitions and classification. Breast Cancer Res. 2003;5(5):254-257.

68. van Dooijeweert C, van Diest PJ, Willems SM, Kuijpers C, Overbeek LIH, Deckers IAG. Significant inter- and intra-laboratory variation in grading of ductal carcinoma in situ of the breast: a nationwide study of 4901 patients in the Netherlands. Breast Cancer Res Treat. 2019;174(2):479488.

69. Farabegoli F, Champeme MH, Bieche I, Santini D, Ceccarelli C, Derenzini M, et al. Genetic pathways in the evolution of breast ductal carcinoma in situ. J Pathol. 2002;196(3):280-286.

70. Lopez-Garcia MA, Geyer FC, Lacroix-Triki M, Marchio C, Reis-Filho JS. Breast cancer precursors revisited: molecular features and progression pathways. Histopathology. 2010;57(2):171-192.

71. Rainey L, van der Waal D, Jervaeus A, Wengstrom Y, Evans DG, Donnelly LS, et al. Are we ready for the challenge of implementing risk-based breast cancer screening and primary prevention? Breast (Edinburgh, Scotland). 2018;39:24-32.

72. Coates AS, Winer EP, Goldhirsch A, Gelber RD, Gnant M, Piccart-Gebhart M, et al. Tailoring therapies--improving the management of early breast cancer: St Gallen International Expert Consensus on the Primary Therapy of Early Breast Cancer 2015. Ann Oncol. 2015;26(8):15331546.

73. Li H, Whitney J, Bera K, Gilmore H, Thorat MA, Badve S, et al. Quantitative nuclear histomorphometric features are predictive of Oncotype DX risk categories in ductal carcinoma in situ: preliminary findings. Breast Cancer Res. 2019;21(1):114.

74. Rainey L, van der Waal D, Wengstrom Y, Jervaeus A, Broeders MJM. Women's perceptions of the adoption of personalised risk-based breast cancer screening and primary prevention: a systematic review. Acta Oncol. 2018;57(10):1275-1283. 
75. Rainey L, van der Waal D, Donnelly LS, Evans DG, Wengstrom Y, Broeders M. Women's decisionmaking regarding risk-stratified breast cancer screening and prevention from the perspective of international healthcare professionals. PLoS One. 2018;13(6):e0197772.

76. Evans DG, Donnelly LS, Harkness EF, Astley SM, Stavrinos P, Dawe S, et al. Breast cancer risk feedback to women in the UK NHS breast screening population. Br J Cancer. 2016;114(9):10451052.

77. Wanders JO, Holland K, Veldhuis WB, Mann RM, Pijnappel RM, Peeters PH, et al. Volumetric breast density affects performance of digital screening mammography. Breast Cancer Res Treat. 2017;162(1):95-103.

78. Boyd NF, Guo H, Martin LJ, Sun L, Stone J, Fishell E, et al. Mammographic density and the risk and detection of breast cancer. N Engl J Med. 2007;356(3):227-236.

79. Bakker MF, de Lange SV, Pijnappel RM, Mann RM, Peeters PHM, Monninkhof EM, et al. Supplemental MRI Screening for Women with Extremely Dense Breast Tissue. N Engl J Med. 2019;381(22):2091-2102.

80. Partridge A, Adloff K, Blood E, Dees EC, Kaelin C, Golshan M, et al. Risk perceptions and psychosocial outcomes of women with ductal carcinoma in situ: longitudinal results from a cohort study. J Natl Cancer Inst. 2008;100(4):243-251.

81. Omer ZB, Hwang ES, Esserman LJ, Howe R, Ozanne EM. Impact of ductal carcinoma in situ terminology on patient treatment preferences. JAMA Intern Med. 2013;173(19):1830-1831. 


$$
\text { yo }
$$




\section{Valorization}




\section{Valorization}

The national breast cancer screening program is a free of charge biennial screening mammography for women aged 50-75 years. ${ }^{1,2}$ Yearly, approximately 1.3 million women are invited to the nationwide breast cancer screening program in the Netherlands, of whom almost 1 million women participate. Ever since the introduction of the screening program there has been a broad support among Dutch women, which is expressed by an attendance rate of approximately $80 \%{ }^{3}$

After its introduction many scientific papers have reported about the favorable results of the screening program. Detection of the disease in a less advanced stage will improve the prognosis and allows a less extensive and aggressive treatment with less side-effects. ${ }^{4-6}$ In an effort to detect breast cancer in its earliest phase any breast abnormality found at screening mammography is examined in close detail, which has resulted in a sharp increase in the detection rates of DCIS and other premalignant diseases. A substantial part of these pre-malignant abnormalities may not proceed into invasive breast cancer during a woman's lifetime, ${ }^{7,8}$ and part of them may even regress spontaneously. ${ }^{9}$ From the aforementioned we can conclude that the diagnosis and subsequent treatment of pre-malignant lesions may not be necessary in some women and could be seen as overtreatment, thereby creating avoidable morbidity. ${ }^{10-12}$ Another downside of screening mammography which must not be overlooked are the false positives recalls, which not only cause extra medical costs and psychological stress, but also a potential burden of subsequent unnecessary invasive biopsies. ${ }^{13}$ A careful consideration of the harm-benefit balance associated with breast cancer screening continues to be a matter of debate. This thesis provides a substantiated contribution to the discussion about overtreatment, because it creates more awareness of the magnitude of the problem. Moreover, this thesis helps clinicians to safely refrain from interventions and form the basis for further research in order to combat overdiagnosis and subsequent overtreatment.

\section{Social and economic relevance}

This thesis provides additional evidence for the beneficial effect of screening mammography programs. Our study shows that screen-detected DCIS was mainly high grade in contrast to invasive carcinomas which were mainly found to be low or intermediate grade. This observation suggests that treatment of poorly differentiated DCIS detected through mammographic screening could play a role in the relative reduction of the incidence of poorly differentiated invasive carcinoma, assuming that high-grade DCIS was removed before it could develop into high- 
grade invasive cancer. ${ }^{14,15}$. Furthermore, our study justifies repeated screening, as in every subsequent screening round new and clinically relevant abnormalities are detected.

This thesis also addresses the risk of overdiagnosis and subsequent overtreatment associated with screening, by creating awareness of the trends in invasive diagnostics procedures and their outcome in women with a breast abnormality found at screening mammography. Our data suggest that it is safe omit invasive diagnostic interventions, such as secondary excision biopsies, which should only be considered if radiologic surveillance and repeated percutaneous biopsy continue to yield indeterminate results. Furthermore, there are growing concerns about the increasing trend of recall for suspicious microcalcifications, which is accompanied with a growing number of recalled women with benign pathology. Therefore, invasive diagnostic intervention for microcalcifications should be considered carefully and preference should be given to radiologic surveillance if possible.

In the treatment of DCIS, this thesis shows that the trend of additional radiotherapy following breast conserving surgery (BCS) is decreasing. A more restrictive use of invasive diagnostic procedures and therapeutic interventions such as radiotherapy will not only reduce the physical and psychological burden for the patients, but it will also reduce healthcare costs.

\section{Target audience}

This thesis targets a broad audience as it contains valuable information for all members of the multidisciplinary tumor board, namely surgeons, radiologists, medical oncologists, pathologists, radiotherapists and other specialists such as general practitioners (who will eventually perform follow-up of these patients). This thesis attempts to contribute to the discussion in the multidisciplinary tumor board to more often refrain from invasive interventions instead of following the motto 'better be safe than sorry'. Omitting invasive unnecessary diagnostic or therapeutic interventions prevents avoidable morbidity. Furthermore, patients undergoing BCS for non-palpable disease will benefit from new localization methods, such as iodine-125 guided localization, which proved to be as accurate as wire-guided localization, but is reported as more patient friendly, less painful and has logistic advantages ${ }^{16-19}$.

\section{The future}

As for this moment, predicting which pre-malignant lesions will regress and which will proceed to invasive breast cancer is almost impossible. For that reason, most 
patients will undergo surgical treatment. This thesis contributes to the shift of 'one size fits all'-treatment to a more personalized treatment of pre-malignant lesions detected at mammographic screening. Less invasive treatment options for these pre-malignant lesions are currently subject of ongoing studies consisting of close follow up versus surgical excision. ${ }^{20,21}$ Tailoring treatment of these lesions to the likelihood of progression to invasive disease is the next step in preventing overtreatment. The main goal for future research should be improving our ability to refrain from invasive diagnostics and treatment whenever possible. 


\section{References}

1. Fracheboud J, de Koning HJ, Boer R, Groenewoud JH, Verbeek AL, Broeders MJ, et al. Nationwide breast cancer screening programme fully implemented in The Netherlands. Breast (Edinburgh, Scotland). 2001;10(1):6-11.

2. den Heeten GJ, Broeders MJ. Nationwide breast cancer screening in the Netherlands. Medica Mudi. 2009;53(1):4.

3. IKNL. Monitor bevolkingsonderzoek [cited 2020 Jan]. Available from: https://www.iknl.nl/ getmedia/15bd0ea1-eb30-4647-82b8-12e11c3dbe9c/Monitor-bevolkingsonderzoek-borstkanker2017-2018_IKNL.pdf.

4. Jacklyn G, McGeechan K, Irwig L, Houssami N, Morrell S, Bell K, et al. Trends in stage-specific breast cancer incidence in New South Wales, Australia: insights into the effects of 25 years of screening mammography. Breast Cancer Res Treat. 2017;166(3):843-854.

5. Katalinic A, Eisemann N, Kraywinkel K, Noftz MR, Hubner J. Breast cancer incidence and mortality before and after implementation of the German mammography screening program2019 Nov 1; Int J Cancer. Epub ahead of print.

6. de Munck L, Fracheboud J, de Bock GH, den Heeten GJ, Siesling S, Broeders MJM. Is the incidence of advanced-stage breast cancer affected by whether women attend a steady-state screening program? Int J Cancer. 2018;143(4):842-850.

7. Thomas ET, Del Mar C, Glasziou P, Wright G, Barratt A, Bell KJL. Prevalence of incidental breast cancer and precursor lesions in autopsy studies: a systematic review and meta-analysis. BMC Cancer. 2017;17(1):808.

8. Jorgensen KJ, Gotzsche PC, Kalager M, Zahl PH. Breast Cancer Screening in Denmark: A Cohort Study of Tumor Size and Overdiagnosis. Ann Intern Med. 2017;166(5):313-323.

9. de Gelder R. Predicting the Benefits and Harms of Breast Cancer Screening: Current debates and future directions [Ph.D. thesis]: Erasmus MC: University Medical Center Rotterdam; 2012.

10. Seigneurin A, Labarere J, Francois O, Exbrayat C, Dupouy M, Filippi M, et al. Overdiagnosis and overtreatment associated with breast cancer mammography screening: A simulation study with calibration to population-based data. Breast (Edinburgh, Scotland). 2016;28:60-66.

11. Duffy SW, Agbaje O, Tabar L, Vitak B, Bjurstam N, Bjorneld L, et al. Overdiagnosis and overtreatment of breast cancer: estimates of overdiagnosis from two trials of mammographic screening for breast cancer. Breast Cancer Res. 2005;7(6):258-265.

12. de Gelder R, Heijnsdijk EA, van Ravesteyn NT, Fracheboud J, Draisma G, de Koning HJ. Interpreting overdiagnosis estimates in population-based mammography screening. Epidemiol Rev. 2011;33:111-121.

13. Honig EL, Mullen LA, Amir T, Alvin MD, Jones MK, Ambinder EB, et al. Factors Impacting False Positive Recall in Screening Mammography. Acad Radiol. 2019;26(11):1505-1512.

14. Cuzick J, Sestak I, Pinder SE, Ellis IO, Forsyth S, Bundred NJ, et al. Effect of tamoxifen and radiotherapy in women with locally excised ductal carcinoma in situ: long-term results from the UK/ANZ DCIS trial. Lancet Oncol. 2011;12(1):21-29.

15. Ellis IO. Intraductal proliferative lesions of the breast: morphology, associated risk and molecular biology. Mod Pathol. 2010;23 Suppl 2:S1-7.

16. Sajid MS, Parampalli U, Haider Z, Bonomi R. Comparison of radioguided occult lesion localization (ROLL) and wire localization for non-palpable breast cancers: a meta-analysis. J Surg Oncol. 2012;105(8):852-858.

17. Lovrics PJ, Goldsmith CH, Hodgson N, McCready D, Gohla G, Boylan C, et al. A multicentered, randomized, controlled trial comparing radioguided seed localization to standard wire localization for nonpalpable, invasive and in situ breast carcinomas. Ann Surg Oncol. 2011;18(12):3407-3414.

18. Bloomquist EV, Ajkay N, Patil S, Collett AE, Frazier TG, Barrio AV. A Randomized Prospective Comparison of Patient-Assessed Satisfaction and Clinical Outcomes with Radioactive Seed Localization versus Wire Localization. Breast J. 2016;22(2):151-157. 
19. Murphy JO, Moo TA, King TA, Van Zee KJ, Villegas KA, Stempel M, et al. Radioactive seed localization compared to wire localization in breast-conserving surgery: initial 6-month experience. Ann Surg Oncol. 2013;20(13):4121-4127.

20. Elshof LE, Tryfonidis K, Slaets L, van Leeuwen-Stok AE, Skinner VP, Dif N, et al. Feasibility of a prospective, randomised, open-label, international multicentre, phase III, non-inferiority trial to assess the safety of active surveillance for low risk ductal carcinoma in situ - The LORD study. Eur J Cancer. 2015;51(12):1497-1510.

21. Francis A, Thomas J, Fallowfield L, Wallis M, Bartlett JM, Brookes C, et al. Addressing overtreatment of screen-detected DCIS; the LORIS trial. Eur J Cancer. 2015;51(16):2296-2303. 


$$
\text { yo }
$$




\section{List of publications}




\section{List of publications}

2020

Luiten JD, Voogd AC, Tjan-Heijnen VCG, Luiten EJT, Duijm LEM. Trends in recall and outcome of screen detected microcalcifications during two decade of screening mammography in the Netherlands. Radiology 2020 Mar; 294; 528 - 537. PMID: 31990268

\section{9}

Luiten JD, Gadjradj PS. Author's Reply: Honorary authorship in the Surgical Literature. World J Surg 2019 Nov. PMID: 31712847

Luiten JD, Korte B, Voogd AC, Vreuls W, Luiten EJT, Strobbe LJ, Rutten MJCM, Plasier ML, Lohle PN, Hooijen MJH, Tjan-Heijnen VCG, Duijm LEM. Trends in frequency and outcome of high risk breast lesions at percutaneous biopsy in women recalled at biennial screening mammography, a multiinstitutional study. Int J Cancer 2019 May; 15; 145 - 155. PMID: 31001821

Luiten JD, Voogd AC, Tjan-Heijnen VCG, Wesseling J, Luiten EJT, Duijm LEM. Utility of diagnostic breast excision biopsy during two decades of screening mammography. Breast 2019 Aug; 46; 157 - 162. PMID: 31195315

\section{8}

Luiten JD, Verhemel A, Dahi Y, Luiten EJT, Gadjradj PS. Honorary authorship in the Surgical Literature. World J Surg 2018 Oct. PMID: 30361745

\section{7}

Luiten JD, Voogd AC, Luiten EJT, Duijm LEM. Trends in incidence and tumour grade in screen-detected ductal carcinoma in situ and invasive breast cancer. Breast Cancer Res Treat 2017 Nov, 166: 307 - 3014. PMID: 28748346 
Rinkel WD, Luiten JD, van Dongen J, Kuppens B, van Neck JW, Polinder S, Castro Cabezas M, Coert JH. In-hospital costs of diabetic foot disease treated by a multidisciplinary foot team. Diabetes Res Clin Pract 2017 Oct; 132: 68 - 78. PMID: 28802698

\section{5}

Luiten JD, Beek MA, Voogd AC, Gobardhan PD, Luiten EJT. Iodine seeds versus wire guided localisation in breast-conserving surgery for non-palpable ductal carcinoma in situ. Br J Surg 2015 Dec; 102: 1665 - 1669. PMID: 26492349 


$$
\text { yo }
$$


Curriculum Vitae 


\section{Curriculum Vitae}

Jacky Denise Luiten was born on the $20^{\text {th }}$ of October 1993, in Capelle aan den IJssel, The Netherlands. She grew up in Eindhoven in a family of two children. In 2011 she graduated high school at the Lorentz Casimir Lyceum in Eindhoven. The same year she started medical school at the Erasmus University Rotterdam. As a medical student, she gained her first research experience at the department of surgery of the Amphia Hospital in Breda, which she continued during her internships at the Elisabeth Tweesteden Hospital in Tilburg. In September 2017 she graduated from

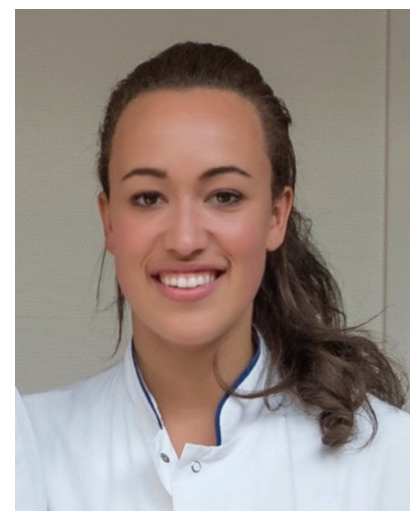
medical school, after which she spent three months preparing for the United States Medical Licensing Examination (USMLE). In January 2018 she started her first job as a surgical resident at the surgery department of the Elisabeth Tweesteden Hospital in Tilburg. Besides her daily work, she worked as a PhD student in her spare time under the supervision of Prof. dr. V. Tjan-Heijnen, Dr. L. Duijm, Dr. A. Voogd and her father, Dr. E. Luiten. As a PhD student she attended numerous conferences and gave multiple presentations.

In 2019 she was admitted to the general surgeon training which she started in July at the Elisabeth Tweesteden Hospital in Tilburg (dr. P. Vriens and dr. M. Ibelings). In 2022 her training will continue at the Radboud University Medical Center (dr. B. Verhoeven). 


$$
\text { yo }
$$


Acknowledgment - Dankwoord 


\section{Acknowledgment - Dankwoord}

To all who contributed to this thesis I want to express my sincere gratitude. This thesis would not have been possible without the support and encouragement from a lot of people This thesis has been a team effort. In this most read, for some maybe even the only, chapter of this thesis: the Acknowledgements (Dankwoord) I would like to thank some persons in specific for their help, support and efforts in Dutch.

Professor Tjan-Heijnen, geachte promotor, beste Vivianne. Dank voor het vertrouwen en de waardevolle input. Onze overleggen vonden altijd plaats in de hal van het MMC Eindhoven na het MDO. Tijdens deze overleggen had u altijd nieuwe ideeën en gaf u mij de ruimte om mijn eigen plannen uit te werken. Maar af en toe trok u ook aan de handrem. Ik herinner me nog goed dat u een overleg afsloot met 'Jacky, het mag ook allemaal iets rustiger aan. Ik zou niet willen dat je geen tijd hebt om een goede keuze voor je nieuwe huis te maken, omdat je al je tijd in je promotie gestoken hebt'. Maar ik deed het met veel plezier. Ik wil u hartelijk danken voor de mogelijkheid om bij u te promoveren.

Dr. Duijm, geachte copromotor, beste Lucien. Jij was de motor achter dit proefschrift. Wat een enorme database het jij door de jaren heen opgebouwd. Dank voor de ontelbare uren die je hierin hebt gestoken. Ik prijs mezelf dan ook erg gelukkig dat ik gebruik heb mogen maken van deze goudmijn aan data. Als ik een nieuwe versie van een manuscript stuurde kwam er vaak dezelfde dag nog een reactie, welke dan eindigde met 'groeten uit *** (vul hier een willekeurig land in)'. Waar ter wereld je je ook bevond toch vond je altijd tijd om direct op al mijn vragen te reageren. Door jou liep dit promotietraject als een Märklin HO trein.

Dr. Voogd, geachte copromotor, beste Adri. Vanaf de allereerste keer dat ik kennis maakte met onderzoek doen was jij erbij. Statistische testen had ik op dat moment nog niet echt onder de knie. Gelukkig kon jij me uitleg geven om mij hierin op weg te helpen. Later in het traject, toen ik zelfstandig de testen uit voerde controleerde ik toch vaak bij jou of het wel klopte. We hadden altijd korte lijntjes, een manuscript ging vaak een aantal keer tussen ons heen en weer voordat ik het naar heel de groep stuurde. Jij weet de nuance te brengen in mijn soms ietwat stellig geformuleerde conclusies. In het bijzonder wil ik je nog bedanken dat jij mij in contact hebt gebracht met de rest van het promotieteam en er zodoende voor gezorgd hebt dat dit onderzoek uitgroeide tot een promotietraject. Kortom, zonder jou was dit boekje er niet geweest. 
Dr. Luiten, beste Ernest, lieve papa. Hoe bijzonder is het om je proefschrift samen met je vader te kunnen schrijven. De poster van het eerste onderzoek dat wij als twee dokters Luiten publiceerden heeft dan ook lange tijd als pronkstuk in jouw spreekkamer gehangen. Als de regels anders waren geweest was jij zeker mijn derde copromotor, want wat heb jij een belangrijke bijdrage aan mijn promotie geleverd. Jouw passie voor de wetenschap is bewonderenswaardig. Wanneer ik vastliep in het schrijven of door alle getallen het even niet meer zag zitten kwam jij met een nieuwe invalshoek, waar ik nog niet aan had gedacht. Het ontroerd me als ik zie hoe trots jij op me bent. Lieve papa, heel erg bedankt voor alle hulp de afgelopen en komende jaren.

De leden van mijn beoordelings- en oppositiecommissie wil ik hartelijk danken voor hun kritische beoordeling en nuttige commentaar. In het bijzonder professor de Bruïne om als voorzitter plaats te nemen in de beoordelingscommissie. Uiteraard dank ik ook de overige leden te weten professor Pijnappel, professor Verkooijen, professor Dinant, professor Smidt en professor Roukema. Zonder uw kritische blik zou ik deze promotie niet kunnen volbrengen. Dank voor alle tijd en moeite die u hebt opgebracht.

Dank aan alle co-auteurs. Promoveren is teamwork en publiceren doe je zeker niet alleen. Hartelijk dank voor ieders bijdrage aan de artikelen.

Daarnaast mijn dank aan Tiny Wouters, voor het maken van de lay-out.

Fotograaf/kunstenaar Henri Senders wil ik speciaal bedanken voor het ter beschikking stellen van zijn werk om te dienen als kaft voor dit proefschrift. (www.henrisenders.nl)

And special thanks to artist David Cantu for letting me use his artwork on the title pages in the thesis. (www.infinitenoon.com)

Drs. Pieters, lieve Angelina. Vanaf het allereerste moment dat we begonnen aan onze geneeskunde studie ben jij nooit meer van mijn zijde geweken. Samen verhuisd naar 'het Klooster' in Tilburg om daar al onze coschappen samen te doen en later ook beide met onze eerste baan daar te starten. Jij was mogelijk nog trotser dan ik zelf, toen ik m'n eerste artikel publiceerde. Jij als lieve vriendin, maar ook zeker als AIOS Radiologie bent dan ook de uitgelezen paranimf. Lieve Ang, ik wil je bedanken voor alle steun en support.

Lieve Marleen. Beste vriendinnen sinds de middelbare school. Ik ben dan ook ontzettend blij dat jij deze dag aan mijn zijde staat als mijn paranimf. Jij was erbij 
om elk klein succesje uitgebreid te vieren. In 2008 is aan de Universiteit van Utrecht onderzoek gedaan naar vriendschappen. Hierbij werd geconcludeerd dat mocht je de magische grens van 7 jaar bereiken het echte vriendschap is. Lieve Marly, die 7 jaar hebben wij al ruim overschreden. Ik wil je bedanken voor al die jaren en de vele die nog gaan komen, je ben fantastisch.

Lieve VVV'tjes. Maud, Marleen, Anne, Noor, Toemen, Schel en Anouk dank voor al jullie support om bij elk etentje toch altijd weer de vraag te stellen; hoe ver ben je met je promotie en dan ook nog geïnteresseerd naar het antwoord te luisteren. Vanaf vandaag is het antwoord; Het is af!

In het bijzonder mijn dank aan Anne die met haar creativiteit en design achtergrond mij kon sturen bij de vele keuzes die gemaakt moeten worden bij het drukken van een proefschrift.

Lieve clubgenootjes, Garnalenvissers. Dank voor jullie support, stimulerende woorden en opbouwende kritiek. Laura kon ik altijd gebruiken als 'lekenpubliek' om te controleren of ik niet te veel medische termen gebruikte.

En wat ben ik blij dat jij, Marieke in je beginjaren nog niet precies wist wat je wilde studeren en zodoende meerdere studies hebt geprobeerd. Dit heeft ertoe geleid dat jij momenteel nog steeds een EUR-account hebt, wat mij instaat stelde om alle artikelen die ik als referenties wilde gebruiken met jouw inlogcodes van de universiteit te downloaden. Lieve Rik zonder jou had ik dit proefschrift nooit kunnen maken. Heel erg bedankt.

Ook mijn dank voor de Garnalenfietsers, die mij hebben gestimuleerd in het wielrennen, iets waarbij je toch even je hoofd kan leeg maken. Wanneer doen we weer een sprintwedstrijd?

Lieve oma, ik wil u bedanken voor de lieve appjes die vaak begonnen met; 'Hoi hoi lieverd, net je artikel gelezen'. Ik ben dan ook ongelooflijk trots dat ik u mijn proefschrift mag overhandigen.

Lieve Emile en Charlotte, wat mag ik me gelukkig prijzen dat ik me in jullie warme nest heb mogen voegen. Dank voor jullie interesse en support. En wat mooi dat deze feestelijkheid in het voor jullie wel bekende Maastricht gevierd mag worden.

Lieve Bart en Romee dank voor jullie kritische blik om zelfs tijdens de vakantie in Cadzand je te buigen over de lay-out van mijn proefschrift. Ik ben het helemaal met jullie eens, abstract is mooier. En oh ja, een tulp is echt mijn favoriete bloem... 
Lieve mama, zonder jouw steun had ik dit nooit kunnen doen. Na elke meeting met mijn promotieteam kon ik deze nog even dunnetjes overdoen, omdat jij van alle ins en outs op de hoogte wilde blijven. Maar waar ik je echt voor wil bedanken is de invloed die jij op papa hebt. Als hij lekker voor de tv wilde gaan zitten, maar nog niet gereageerd had op een nieuwe versie die ik rondgestuurd had was jij degene die zei; 'Nee Ernest, eerst ga je Jacky's stuk lezen!' en dan werd dat ook direct gedaan. Jij staat altijd voor me klaar hoeveel ik ook van je vraag. En misschien zeg ik het niet vaak genoeg, maar mama ik ben je ongelooflijk dankbaar voor alles wat je voor me doet.

Kevin, liefste broertje. Op momenten dat ik moet presteren heb ik jou nodig. Samen hebben wij een ritueel, voor elk belangrijk moment; een tentamen, een sollicitatie, of de verdediging van dit proefschrift ben jij degene die me altijd even suc7 moet wensen. Zonder jou waren al deze momenten nooit gelukt. Je studie heb jij doorlopen in London, New York en San Francisco. In no time ging jij van het steenkolen Nederlands-Engels naar een bijna native speaker. Wat heb ik toch mogen profiteren van mijn persoonlijke 'spellingchecker'. Lieve Kev wat ben ik blij dat jij mijn broertje bent, ik had me geen betere kunnen wensen.

En tot slot, allerliefste Jeroen, het is eindelijk af! Wat zal jij blij zijn. Jij hebt van dichtbij meegemaakt hoe saai het is als ik de hele avond in het hoekje van de bank zat met mijn laptop op schoot. Ik wil je bedanken voor je eindeloze geduld. Jij had zo als stand-in kunnen fungeren want jij kent na duizenden keren oefenen al mijn presentaties uit je hoofd. Vanaf nu zal mijn aandacht weer naar jou en ons nieuwe huis gaan, in plaats van naar mijn computerscherm. Ik hoop dat wij voor altijd samen zullen blijven, want met jou is alles leuker. 


$$
\text { yo }
$$


I gratefully acknowledge that the creation of this thesis was supported by Maastricht University, Elisabeth Tweesteden Ziekenhuis Tilburg, Bevolkingsonderzoek regio Zuid, Integraal Kankercentrum Nederland, ABN AMRO, Agendia Inc., ChipSoft BV, Novartis Pharma BV, Pfizer and Surgipoort BV, owner of www.chirurgenoperatie.nl.

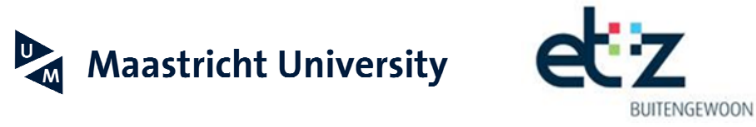

KNL

ChipSoft

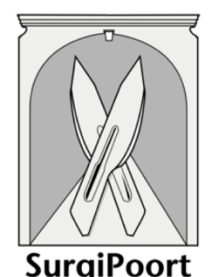

CHIRURGenOPERATIE.nI bevolkingsonderzoek

zuid
ABN·AMRO D AGENDIA

(1) NOVARTIS

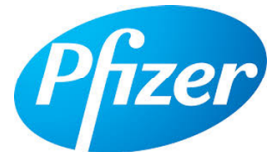


